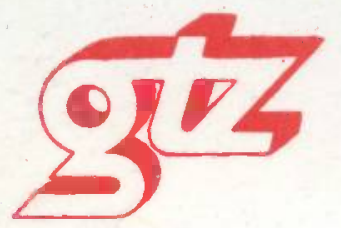

Deutsche Gesellschaft für Technische Zusammenarbeit (GTZ) GmbH Education Department North West Frontier Province PAK - GERMAN BAS - ED

- Bas ic Education

in Areas Affected by the Influx of Refugees, NWFP".

\title{
What did you learn in school today?
}

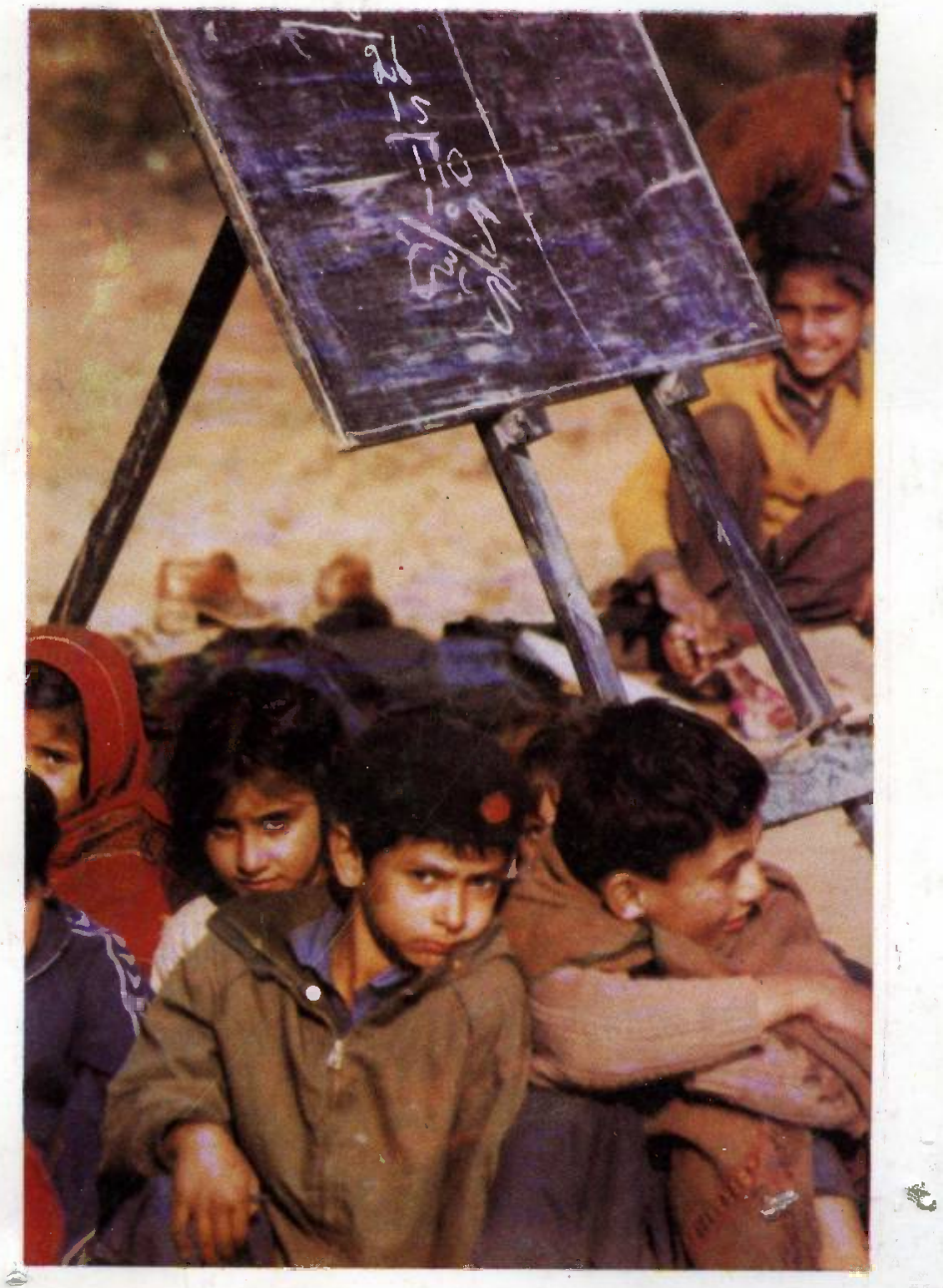

Monitoring Classroom Interactions in Pakistani Government and Afghan Refugee Primary Schools in the North-West Frontier Province 


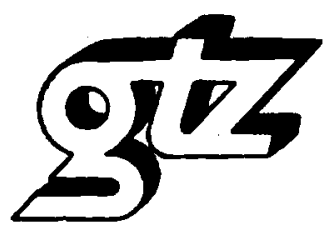

Deutsche Gesellschaft für Technische Zusammenarbeit (GTZ) GmbH Education Department North West Frontier Province

\section{PAK - GERMAN BAS - ED}

"Basic Education

in Areas Affected by the Influx of Refugees, NWFP"

What did you learn in school today?

Monitoring Classroom Interactions in Pakistani Government and Afghan Refugee Primary. Schools in the North-West Frontier Province 


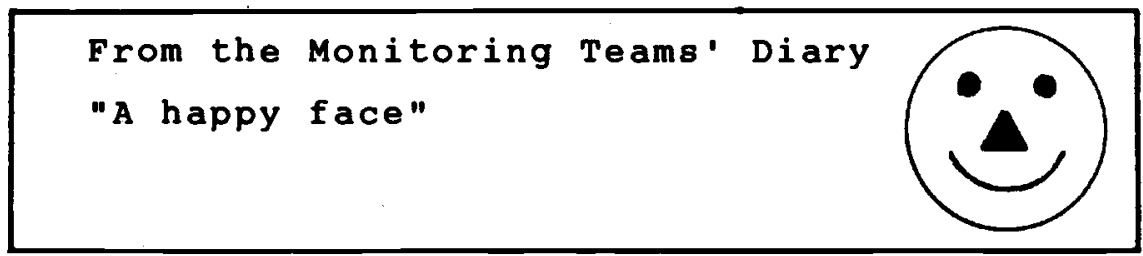

1. INTRODUCTION

1.1 Background

1.2 The Problem Identified

1.3 The strategy Designed

From the Monitoring Teams' Diary

"A neutral face"

2. THE MONITORING EXERCISE

2.1 Preparing the Teachers

2.2 objectives

2.3 Approach and Criteria

2.4 Instruments

2.5 Logistical Aspects

From the Monitoring Teams' Diary "A sad face" 
FOREWORD

The main purpose of this report has been to share experiences that we and our colleagues have had as a result of the school visits. Such visits afforded the rare opportunity of observing some live lessons. The teachers who delivered these lessons had previously. been trained by the project. They had been provided with lesson plans and learning materials and required to carry out various activities with the pupils and thus help to generate meaningful learning amongst children.

The school visits served the twin purposes of providing professional support, if needed by teachers, and of monitoring the actual change. Such an exercise, it was hoped, would reveal to what extent objectives were achieved and which factors were acting as constraints or bottlenecks.

We do hope that those who are engaged in similar programmes aiming at improvements in primary education would find this report instructive and useful. It is this belief that has made us come out with a detailed report. 
NOTE :

Photos on pages 57 (upper one) and 63 (upper one) by Manfred Wehrmann. Remaining photos by Dr. Udo Bude. 

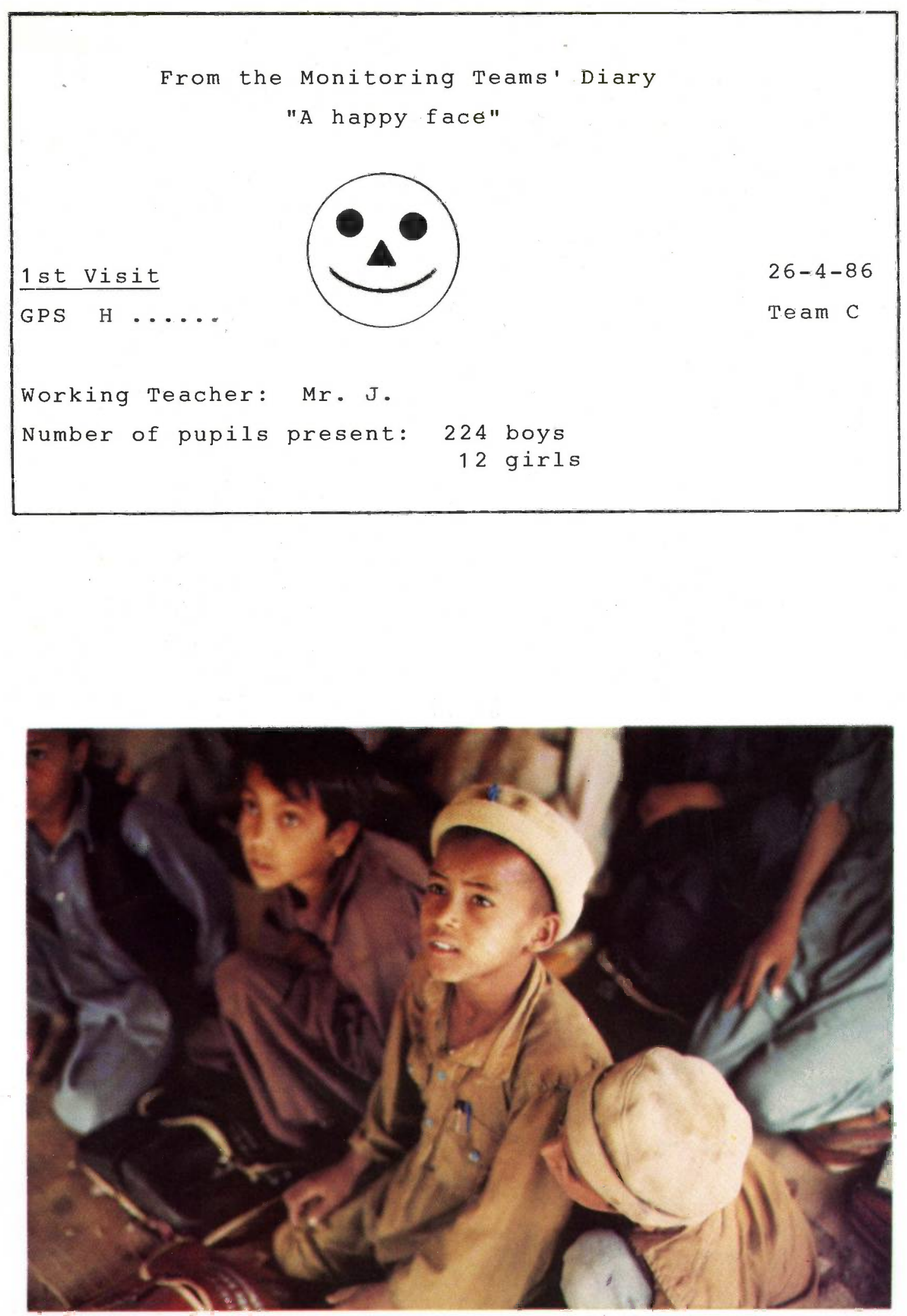
"We - the members of the Monitoring Team C - reach the place at 9.25. As we enter the gate we find that $a$ class is going on right in the compound of the school under the shade of trees. At once one is reminded of Shanti Nakaitan - an institution developed by Rabindra Nath Tagore, the only noble laureate of India honoured for his contribution to the world of literature. This institution was established with a view to providing an atmosphere of permissiveness to the sons and daughters of India to help promote creativity on their part. This school was an intuitive reaction to the extra rigid milieu of authoritarianism rampant in the academic institutions of India then. Shanti Nakaitan had, per design, no classrooms. The class we see in the compound is very big even by our standards. The children are sitting around a table which is laden with a lot of coloured objects mostly made out of plastic. The teacher is standing near this table holding some balloons in his two hands. Some lesson is going on. Instinctively the both of us come to a halt. We begin to survey the scene.

There is some stir in the class and the teacher now looks in our direction. The lesson is stopped. Placing the balloons on the table he moves forward to greet us. We are now standing near the table and two chairs are brought for us to take our seats. We learn that the teacher was, at the moment, busy in giving a Maths lesson and that he completed the lesson plans No.1 and 2 in Mathematics during the last week. He informs us that the lessons went very well. We, now, ask if he has maintained some record of activities undertaken by him during the last week. In response he picks up a file from his table and shows us the records. We feel very happy.

Now we request if he could repeat his Maths lesson ac- 
cording to lesson plan No.1. We take our chairs and place them in two corners of this mass of children, take out our observation schedules and get ready for making the necessary entries.

The actual lesson starts at 9.33 and is about "Matching equal quantities". Mr. J. picks up articles such as bangles, brooms, match-boxes, thread reels one after another from his table, shows them to the class and asks simple questions such as: What is its name? What is it used for? What is its colour? etc. etc. The questions are put to the whole class and the answer comes in chorus. Now he takes four red bangles and four yellow ones and places them on the two outstretched palms of a student who now faces the class and asks another student to match them. The second boy picks a red bangle and then a yellow bangle and puts the pair on the table. Thus he completes his assignment. Others watch these students. The teacher now takes five red and five black bangles and places these on the two outstretched palms of another student and asks a very small child to come forward and pair them. This boy takes two red bangles and places them on the table. The teacher instructs him to stop and asks the class if he was doing it correctly. Again a loud chorus saying no. The teacher asks another child to come forward and do it. He picks one red bangle and one black one, makes a pair and places it on the table. The small boy is now asked to pair these bangles. Now he has no difficulties. The exercise is then repeated by two more kids but the teacher either changes the number or the colour of the bangles.

Mr. J. now takes four green and four yellow combs. He holds them in his two hands in such a way that green combs are almost parallel while the yellow ones are spread out 
and asks Nazeer which are more. Nazeer says yellow ones are more. He now asks Nazeer to come forward and form pairs. He obliges and makes four pairs. Which do you think are more? Nazeer is somewhat shy and says something not heard by me. Mr. J. says loudly that Nazeer says they are the same. The same exercise is repeated by varying their numbers, colours and by changing the position of the closed-ones and relatively spread-outs in the two hands. However, children have grown wiser and now they say that they are the same. subsequently they confirm their statement by forming pairs.

Practically the same exercise is repeated but by using match boxes and thread reels. This time a pair means a match-box and a reel - very dissimilar objects. Mr. J. now forms pairs between the fingers of his two hands. He asks Rashid to do the same. Now, the whole class is doing it. The hands are held high over their heads with fingers as outstretched as possible and their tips touching each other. There is no doubt left that the class is enjoying the game. Now we find four children standing in one corner and four kids in another, one boy asking a child from one corner to step out and another student from the other corner and joining the hand of one with that of the other and telling them to stay together and completing the exercise thus.

The last exercise requires the drawing of dolls in their exercise-books and tie formation of pairs between them by drawing a line between one figure and the other. The time is now 10.00 and we are both busy in filling the observation schedule and writing other details which are to go in our diaries. At this point we discover that two colleagues from Monitoring team $A$ have joined us to see 
what is going on here. It appears that there was not much in their school to keep them occupied.

About teaching Pashto Mr. J. says that he has not yet started with any lesson plan. He prefers to ask them some simple questions about themselves or about their environment and to tell stories to them witha:view to building a close rapport with them.

The Pashto lesson starts at 10.15. Mr. J. says that he is going to narrate another story. He asks his pupils a few questions about a story that he had told them the day before yesterday. This time the answers are given by individual pupils. It is evident that the pupils remember the details of that story. The beginning of to-day's story is more or less the same. However, the difference is that when Umran went up the tree to pick the little birds he was bitten by a snake with the result that he had to be rushed to the hospital. This story is told at an appropriate pace with addition of this and that at proper places. The story is told once and then Mr. J. asks a few questions to solicit the answers from the kids. He then invites children to narrate any stories they know. As many.as five kids volunteer to come out with their stories. Two of these stories are in inverse form. What a surprise! certainly every child, while narrating a story, is not bold but then certainly a few voices are audible. In cases where children are not loud enough to be heard by the whole group the teacher is repeating his/her statement sentence by sentence. This lesson ends at 10.45 .

What a pleasure to witness these two good lessons. Mr.J. is young and not much experienced. There is no doubt that he has been able to imbibe the spirit of the proposed change. We imagine it is the beginning of a pedagogical revolution." 


\section{INTRODUCTION}

1.1 Background

PAK-GERMAN BAS-ED has been concentrating its attention in the formal sector of primary education to the areas of development, production and dissemination of teaching- and learning materials combined with the introduction of adequate teaching methods. It has been all along very clear that utilization of learning materials as a means for change from teacher-centred teaching to pupilcentred approach would basically depend upon the informed acceptance of the teachers after having been thoroughly convinced of the need as well as the desirability of effecting this change. Thus the need to enhance the level of awareness of the teachers and get them involved in this kind of curriculum development has all along been recognised and given a prominent place in the work of PAKGERMAN BAS-ED. However, raising the level of consciousness of teachers and getting them interested in new teaching methods and materials is no simple task. The process involves learning as well as "unlearning", overcoming mental structures preventing the introduction and acceptance of new ideas. Furthermore, there is always the danger that any half-hearted attempt or some simplistic approach may prove counter-productive and just result in confusion.

The main guide-lines concerning the change in classroom interaction as intended by the Project are as follows : 
1. Within the frame-work of the existing curricula there is an urgent need to transform the present methodology which is teacher-centred and inculcates rote-learning to one which is pupil-centred and promotes meaningful learning. Such a change would remove the existing anomaly of modern curricula being taught by old methodology.

2. This transformation of methodology can be best concretised through specific lesson plans clearly telling teachers how to go about their task step by step for a particular grade and a specific topic.

3. A lesson plan is an attempt to design the exact transactions that shall take place for a specific topic. These transactions shall embody the following integration:

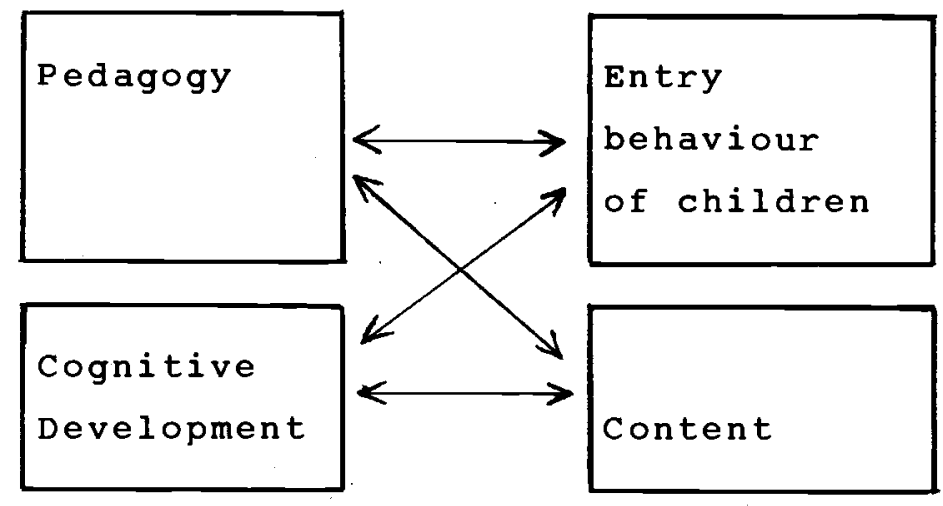

Lesson planning

4. Lesson plans can help to involve pupils actively if such plans are accompanied by relevant learning materials, specially developed, tested and modified to go along with those lesson plans.

5. Teachers will be specially trained in the application of lesson plans through intensive inservice courses. Such courses not only pass on childcentred teaching/learning methods, but cater also for deficiencies on behalf of the teachers in the main subjects Pashto and Mathematics. The courses have to be of a practical nature with less emphasis on theory and more on practice. The training ought to be close to classroom situations that these teachers face in their schools. 
PAK-GERMAN BAS-ED has tried to follow these guide-lines to the extent possible within the existing conditions in the Northwest Frontier Province. The Project gained valuable experience by running a number of workshops/courses for educational experts and for primary school teachers. In 1985 and 1986 eight of such training courses for teachers were conducted involving 260 participants (including 100 lady teachers). Such inservice courses were held in cooperation with the Education cell (for Afghan Refugee Schools) and the Bureau of Curriculum Development and Education Extension Services, N.W.F.P., Abbottabad (for Pakistani Government Schools). Special attention was paid to the training of headteachers and teachers from the 24 pilot schools of the Project who had the opportunity. to attend two information seminars in september 1985 and April 1986 .

Parallel to the activities in the field of teacher training, efforts have been made to design appropriate approaches in the disciplines of Mathematics and Pashto. which are consistent with the kind of pedagogy as promoted by PAK-GERMAN BAS-ED in keeping with the established recent views of child-psychology, and also go along with the objective conditions as exist in the project's pilot schools. The approach adopted in the subject of Mathematics is the well-known activity approach, while for Pashto a new approach called DAAPL (Development Approach to the Acquisition of Pashto Language) is consistent with all the considerations as indicated above and is in line with the nature of the language itself. To help evolve the classroom practices as conceived in these approaches the following teaching-/learning materials have been developed: 
- number chart;

- number cards;

- picture/number cards;

- alphabetic chart;

- letter combination charts;

- key-word picture cards;

- single letter cards;

- pictorial alphabetic chart;

- word cards;

- situation pictures/picture stories;

- single action pictures.

In addition, the 24 pilot schools working with the project are renovated and/or provided with new classrooms.

1.2 The Problem Identified

Large strata of society in Pakistan as well as in Afghanistan have kept their traditional ways of life. The formal school systems in both societies reflect somehow the discrepancy between traditional modes of learning and the challenges of learning needs for a more modernized society only superficially accepted by the majority of people. The problems of the school systems are rather similar particularly the following:

1. At the level of policy decisions of national importance education is yet considered as the vehicle for the transmission of culture from one generation to another. This culture is considered to be something sacrosanct and not as an entity to be subjected to any critical appraisal. Rather than being considered as a liberating force charged to enable human beings to function as self-directed autonomous persons, it emphasises indoctrination of traditions, norms, conduct and values. The fact of change is conveniently forgotten and the individual. is prepared for a society which is conceived as totally static and for a role in life which is believed to be all pre-determined. 
2. At the public level, which is the level of recipients of the benefits acruing from the education system, education is taken as the endproduct and not as a process. The exact specifications of this end-product nobody knows. However, its value is determined by the title of the certificate which the individual is authorised to present on demand.

3. At all levels of management - top, middle and bottom - education is conceived as an operation to be patterned after the image of a primitive cultivator who thinks that after having thrown the seed in the field his duty is over. Because of the educational system's very extensive size some macro-planning is unavoidable.

However, no micro-planning is resorted to whatsoever. There is little wonder if in these circumstances the management finds itself faced with one crisis after another.

4. The kind of interchange that takes place inside a school for Afghan refugees is in no way different from what happens in a Pakistani school. At both places the pedagogy is archaic and traditional. Very excessive use is made of the text-books and the only methodology resorted to is that of drill. Very few of the classroom inter-actions provide any worthwhile challenge for the learner. The whole process is solely geared to over-repetition - a thing highly. frustrating for young children. The system is very inefficient as well as ineffective, besides being irrelevant too.

5. Schools are in very bad shape. Physical facilities are scarce and in dire need of renovation and improvements. Learning materials other than the textbooks are non-existent and the teachers receive very little professional support.

6. Pre-service teacher training is very meagre and short. It is extremely theoretical and is far removed from the considerations of practice. In terms of equipping the teachers with the needed competencies, it has a limited role. In-service teacher training is equally wanting either in enlarging the knowledge base of the teachers or in teaching them the urgently needed skills.

7. Teachers remuneration is very low. In fact the whole system of reward and punishment is thoroughly 
distorted. The pay structure of primary school teachers with its very few chances of upward mobility has sapped any motivation that some of these teachers might have at the time of joining the cadre. There are reasons to believe that most of the pakistani teachers do engage in odd jobs with a view to supplementing their incomes. The urge to gain money, whatever be the means, is endemic. The vast majority of the primary school teachers are living at subsistence level.

\subsection{Strategy Designed}

Trying to introduce some real change in a small segment of a vast educational system is in many respects more difficult than changing the whole system. One cannot touch the curriculum, the text-books in circulation or even the examination sub-system in vogue, for fear of giving the impression of a strange transplant. Similarly one cannot go in for better qualified teachers or opt for modern technology lest something is attempted which cannot be replicated in a large scale or even continued after a project has ended. These are the in-built constraints of the situation, which one has to recognise and which make an effort for improvement such a colossal challenge.

As the education system is always country specific and differs in important respects from that of another, no prescription found suitable in one case can be mechanically adopted for the other. Any such prescription has to be specific to the situation under change. Thus designing of an appropriate broad strategy is a fairly creative exercise and demands taking a comprehensive approach. A close observation of the situation in the pilot schools of PAK-GERMAN BAS-ED convinces one that the weakest link of the chain is the actual planning and execution of teaching. The 

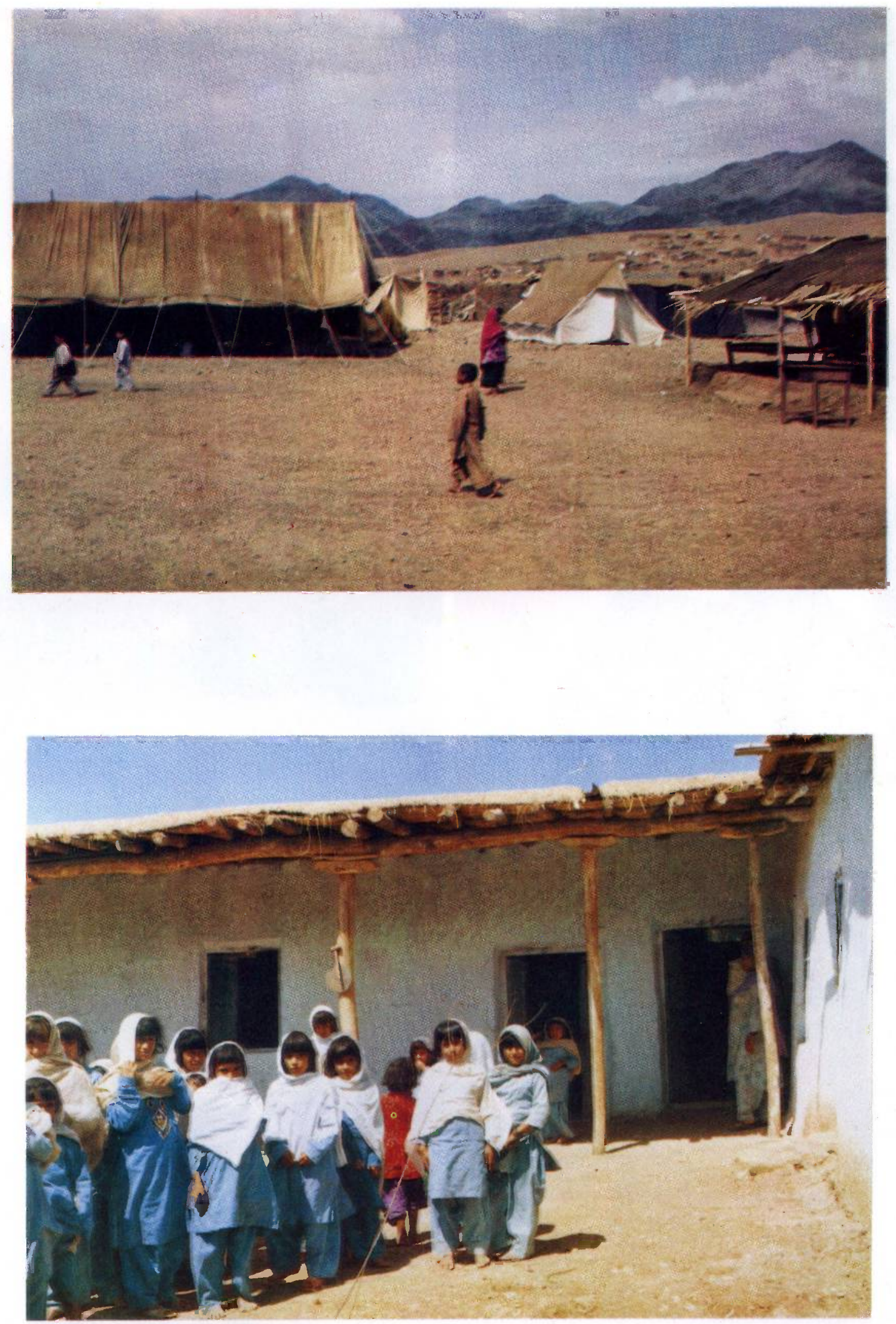

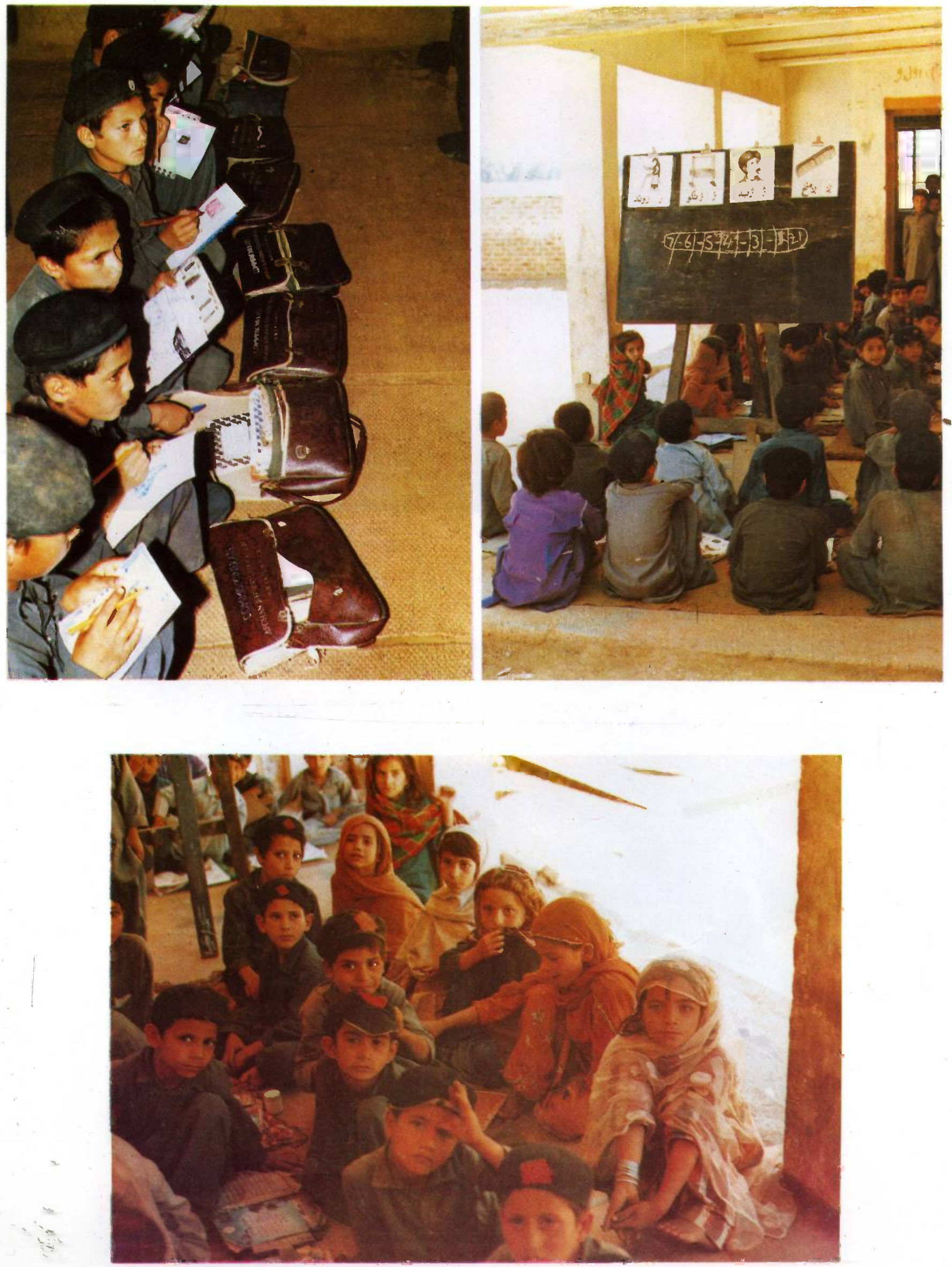
whole task is not being given the importance that it deserves and has been entirely left to the discretion of the uninformed class teacher. Appropriate lesson planning. is no easy job and leaving it to the teacher not competent enough to undertake it means leaving the system in jeopardy.

A teacher who is not capable of planning his/her lesson or left without any advice is like a worker without a job specification. He does not know what is expected of him. The management ought to realise his predicament and should assist him to the maximum. Perhaps, the teacher is apathetic and the management is indifferent to what is going on inside the schools. In such circumstances even if a teacher is doing a bad job, he is, in all fairness, hardly to be blamed for it. A static milieu is hardly a situation for the teacher to show his/her abilities.

Based on the analysis as given above PAK-GERMAN BASED has designed the following broad strategy:

- maximum support and assistance to be provided to the teachers and supervisors in delineating and microplanning the classroom interchange in such detail as may leave no doubt as to what is to be done;

- while undertaking microplanning care has to be exercised to integrate it with the national curriculum and the textbooks in circulation;

- sharing of experiences and thinking with the midlevel management likely to assist the project with a view to evolving shared perceptions or consensus;

- designing short term teachers' courses through linking them to the proposed changes in classroom activities;

- producing teaching materials which fit into the existing educational system (e.g. curricula, text- 
books, student-teacher ratiol without overloading the teacher with new responsibilities but to assist $\mathrm{him} / \mathrm{her}$ in daily work and to facilitate a broad variety of learning situations based on well-specified and professional sound subject approaches; and

- taking critical assessment of similar activities as being undertaken currently by other agencies with a view to benefitting from their efforts to the extent that is possible. 
From the Monitoring Teams' Diary

"A neutral face"

2nd visit
ARPS K ....(girls $)$

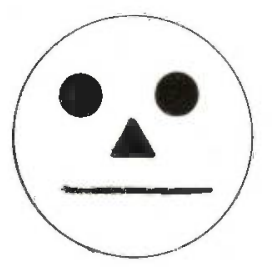

Working Teacher: Ms. F .

Number of pupils present: 19 girls

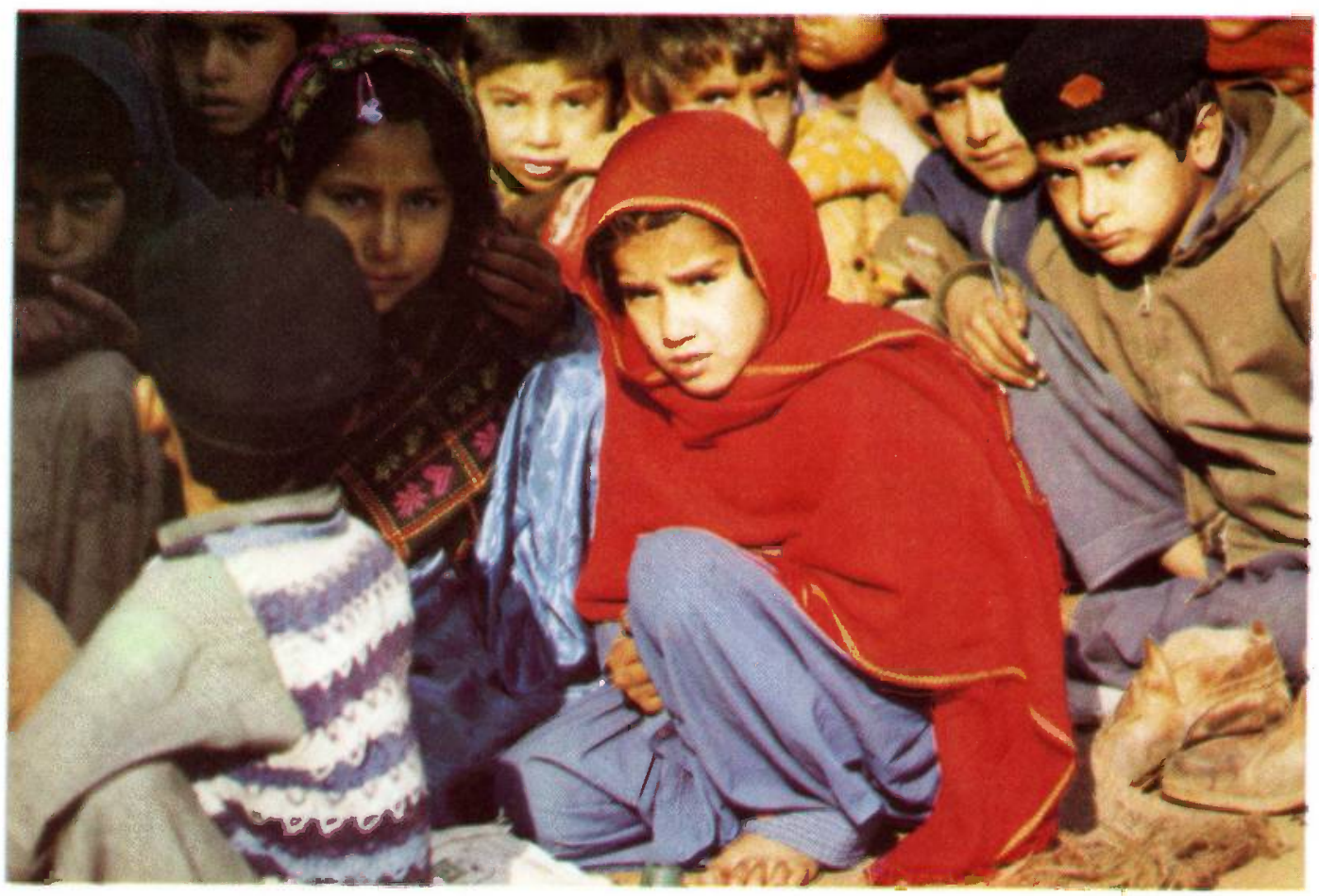


"After two and a half hours" drive our Monitoring Team arrives at the school at 9.30. It is a small kacha building, housing $115 \mathrm{girls}$ in 5 classrooms. There are only two teachers for the four grades, one female teacher, Ms. F. the headteacher, and another male teacher. Ms. F. is in charge of grade $I$. We find 19 girls present in grade $I$. Their ages appear to vary from $4 *$ to $6+$. The oldest girl seems to be extremely shy, avoiding any eye-contact. We are later told that she is dumb - what a tragedy! What is she doing here? She had her books with her. Maybe she finds the company of these little girls more accommodating and refreshing. Maybe she gets better communication and understanding in this group. The girls are lovely, very neat with eyes which are literally shining. They are all Afghan girls and come from this refugees' camp. It is a typical camp school. Ms. F. informs us that she has completed lesson plan No. 6 in Pashto and she intends to teach lesson plan No. 6 in Mathematics today. While giving her reactions about the way these lesson plans have worked so far she distinctly exhibits her animation. There is no doubt left that she finds the new approach more meaningful and productive. She readily agrees to give two full lessons in our presence. We dig out our relevant observation schedules and get ready to watch the coming interaction with meticulous care.

The first lesson starts at 9.50. It pertains to lesson plan No. 6 (Pashto) and involves answering questions about a story. The teacher starts telling the story of a boy who climbed up a tree to fetch the young ones of a sparrow, fell down in the attempt and hurt his leg. The teacher's voice is loud and clear. She is slow and has adopted a pace most suited to telling a story. In between her narration she says a sentence or two about things occuring in the story so as to promote the assimilation of the ideas involved. The story comes to an end and now the questionanswer session starts. The questions are almost all about 
the facts and events of the story and the stress is on their veracity with a view to ascertaining their-comprehension. The answers are mostly telegraphic and far too economical in words. The lesson is over in about 20 minutes.

At this stage Mrs. B. steps in and takes over teaching. She asks open-ended questions about objects mentioned in the story. Her purpose is to solicit some extended talk. She accepts an answer, repeats it aloud, and starts to extend it. To a one sentence answer two more sentences are added to enlarge it to a three sentence answer. Soon there is visible improvement and the pupils begin to open up. In particular one small intelligent girl named $P$. enters a dialogue and talks intensively.

The lesson in Mathematics is about the concepts of light and heavy. A number of objects are now placed on the table. The lesson begins at 10.30. A girl is called to the table. She is to lift a brick and a stone and to tell which of the two is lighter. This exercise is repeated many times involving different girls and different combinations of objects. A girl places abig cardboard carton on the palm of her left hand and picks a stone in the right. She judges their pulls and says that the stone is heavier. This lesson, too, is completed in 20 minutes.

Again one of our team members tries to demonstrate how such a lesson could be taught according to the lesson plan. He draws the diagram of a balance and ask what it is. Unfortunately we do not have a real balance at our disposal. Another diagram showing a tilted balance with objects in the two pans is drawn and the girls are asked which object is heavier. The class is silent for a while and then P. stands up and touches the object in the downward pan. The teaching colleague asks another girl if 
she is right: she is not sure. Another girl, however, supports her answer and thereafter the class is unanimous.

W.e have mixed reactions to the lessons. They are good in the sense that activities are there and the participation of pupils is obvious. The pupils are enjoying the lesson and some learning is taking place, yet the teacher is missing cues from the pupils: she is following the lesson plan more in a mechanical style rather than in a creative manner." 
2. THE MONITORING EXERCISE

2.1 Preparing the Teachers

The proposed changes in teaching practices from being totally teacher-centred, as they are at present, to being more child-centred, were to be tried out in two key subjects of the primary school curriculum: Mathematics and Pashto, starting from grade $I$. We presumed that the acquisition of skills on the part of teachers would facilitate later on their transfer to other subjects. It was further assumed that if the teachers learn to make proper use of lesson plans and teaching aids, children's curiosity and interest could be stimulated and their learning capacities developed.

Overcoming the natural resistance on the part of teachers to accept such new ideas on classroom instruction and to modify their teaching practices, mere theoretical lecturing or distributing of handouts will not bring out changes in the classroom. What is needed is a kind of training/coaching of teachers including a demonstration of the underlying pedagogical principles while teaching and learning takes place inside the school. Once teachers have accepted the usefulness of lesson planning and learnt how to apply certain teaching aids, classroom teaching is hoped to become more child-centred. To expect teachers to conduct their teaching employing new procedures and techniques is only possible if they themselves have a chance to learn how to handle these new teaching methods and the new teaching materials in situations very much like their classrooms. 
Teachers of the 24 pilot schools cooperating with PAK-GERMAN BAS-ED had over the last year been introduced to the teaching methods and teaching aids developed by the project. Before the start of the new academic year $86 / 87$, however, it was planned to specially monitor the very first six weeks for the new pupils in grade $I$. to get further experiences on the practicability of the materials and methods developed so far. A "second Information seminar For Teachers of Pilot Schools" was held in the Project's office from 5th April to 16th April, 1986. Participants were teachers who were due to work with the new grade I in their respective school in the course of the academic year 1986-87 starting with effect from 15th April, 1986. As many as 23 teachers out of a total strength of 24 attended the seminar. The seminar focused on the following:

- to familiarize as well as sensitize the teachers about the ACTIVITY-approach in Mathematics and about DAAPL (Development Approach for the Acquisition of Pashto Language) in Pashto;

- to present and discuss with the teachers the proposed schemes of work for grade I in the two subjects mentioned above;

- to make the teachers actually develop Lesson Plans according to the schemes of work proposed for the first 6 weeks as per format designed in the project;

- to present to the teachers some mock-teaching by resource persons according to specific Lesson Plans; 
- to make the teachers present mock-teaching with a view to discussing the strong as well as the weak points of such presentations;

- to utilize all such activities to demonstrate to, or discuss with, the teachers the ways in which learning aids/materials could be effectively used in the classrooms;

- to make the teachers understand the details of the subsequent operation regarding trials in schools; and

- to distribute, explain, and demonstrate learning aids/materials to be used in the project's pilot schools.

The programme of the seminar may be seen as annexure I. The lesson plans as developed by the various groups of participants were discussed in the plenary sessions and were finalized by the resource persons. They were then duplicated and passed on to each teacher for his own record. Hand-outs in pashto tried to give further explanations for the application of the new teaching methods/materials. On the last day of the seminar each teacher was given a complete learning package consisting of the required learning aids, learning materials, lesson plans and the manual. The teachers promised to try out the new approaches with their fresh grade I classes on return to their schools. They were told that some follow-up of their activities would definitely be undertaken. 
Teachers of the 24 pilot schools cooperating with PAK-GERMAN BAS-ED had over the last year been introduced to the teaching methods and teaching aids developed by the project. Before the start of the new academic year $86 / 87$, however, it was planned to specially monitor the very first six weeks for the new pupils in grade $I$, to get further experiences on the practicability of the materials and methods developed so far. A "Second Information Seminar For Teachers of Pilot Schools" was held in the Project's office from 5th April to 16th April, 1986. Participants were teachers who were due to work with the new grade I in their respective school in the course of the academic year 1986-87 starting with effect from 15th April, 1986. As many as 23 teachers out of a total strength of 24 attended the seminar. The seminar focused on the following:

- to familiarize as well as sensitize the teachers about the ACTIVITY-approach in Mathematics and about DAAPL (Development Approach for the Acquisition of Pashto Language) in Pashto;

- to present and discuss with the teachers the proposed schemes of work for grade I in the two subjects mentioned above;

- to make the teachers actually develop Lesson Plans according to the schemes of work proposed for the first 6 weeks as per format designed in the project;

- to present to the teachers some mock-teaching by resource persons according to specific Lesson Plans; 

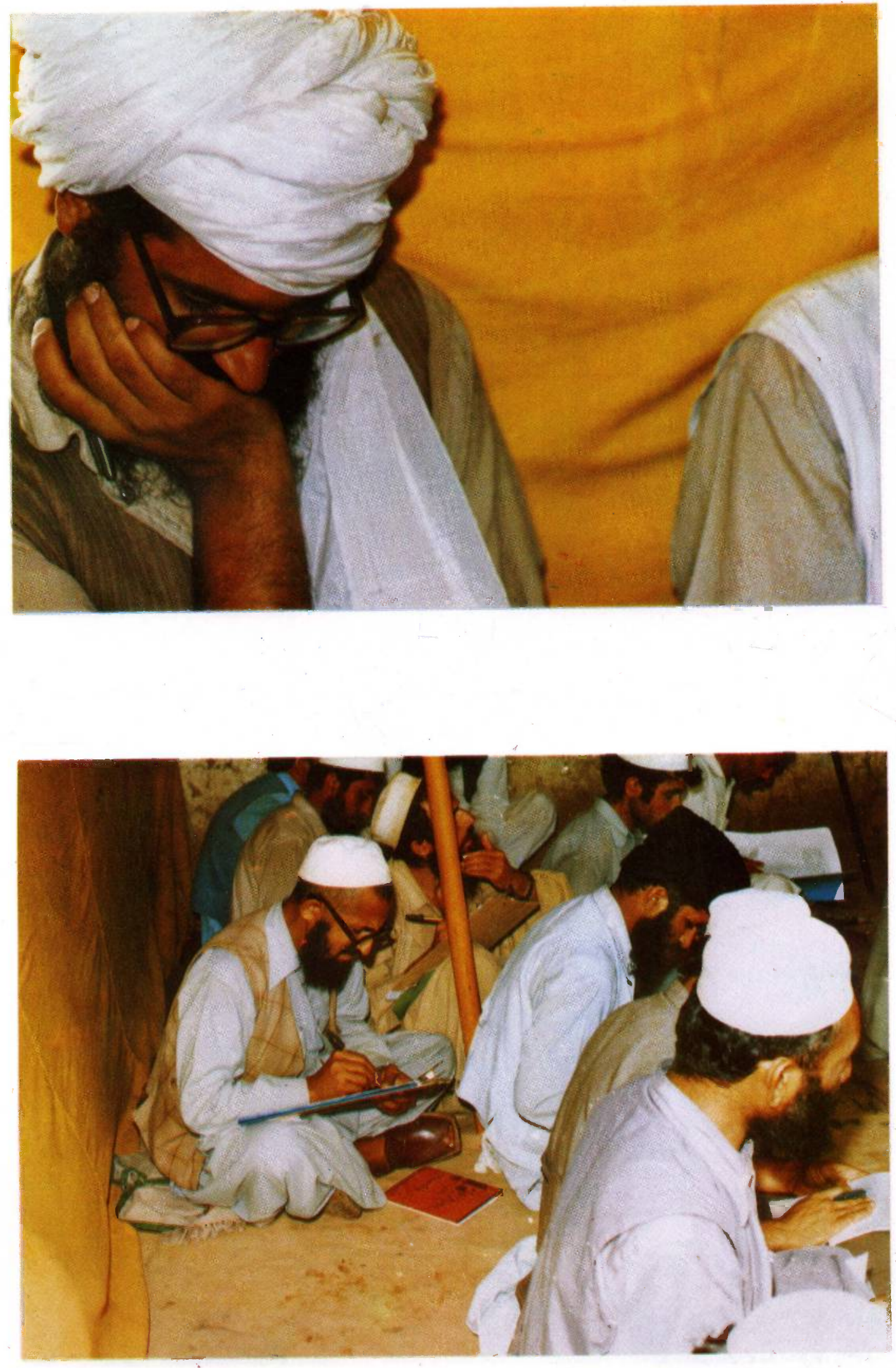

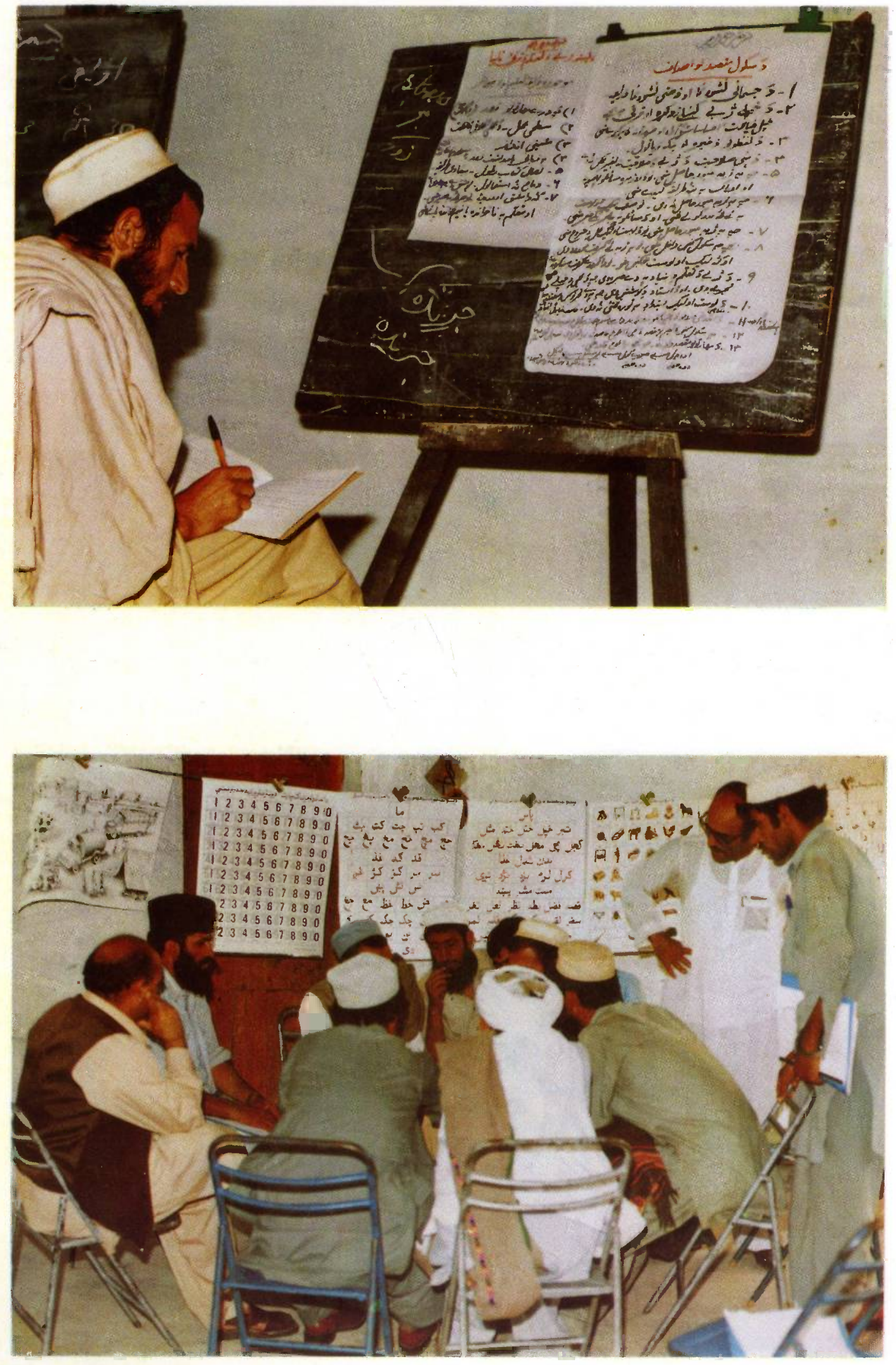


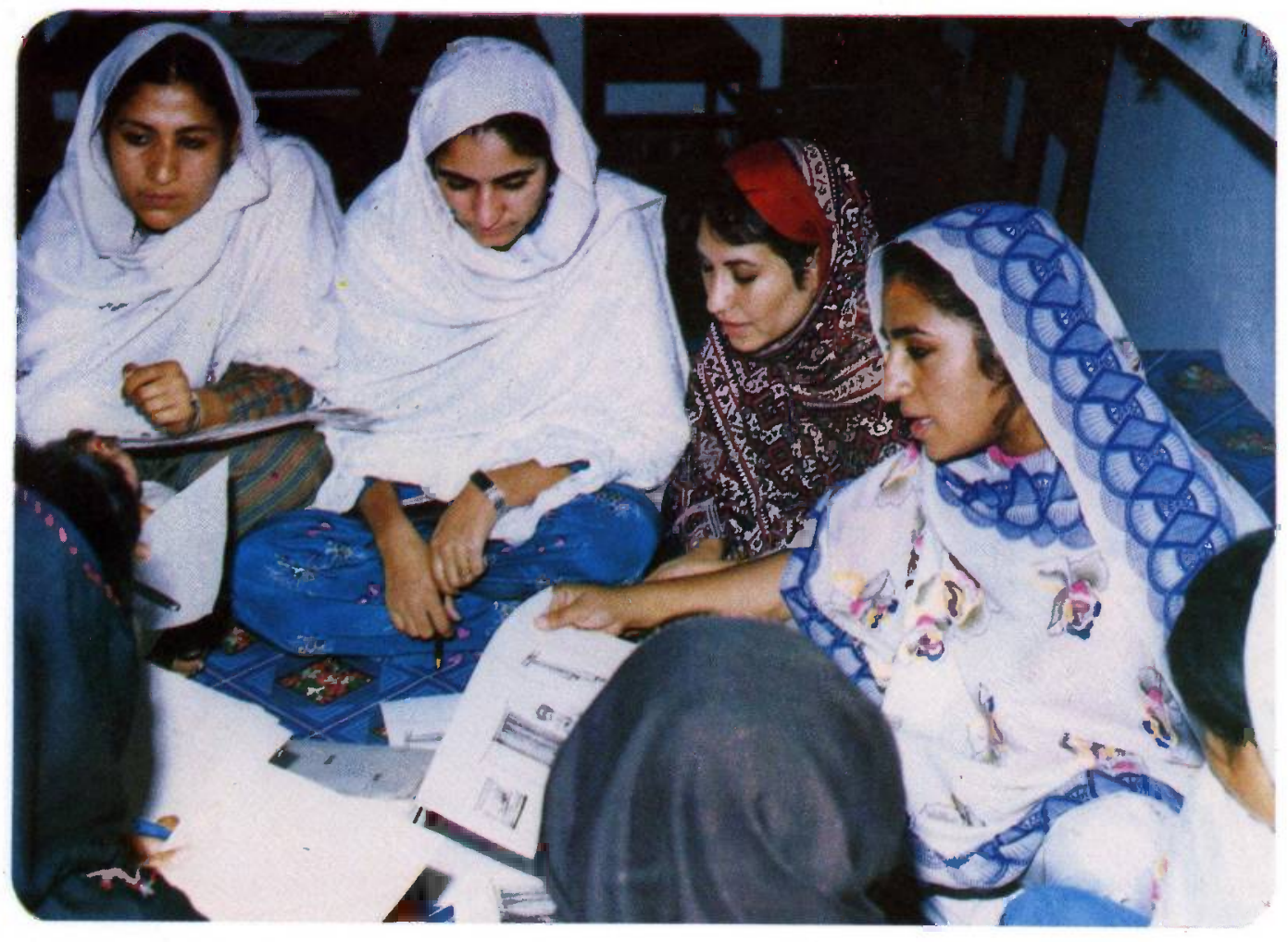

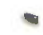

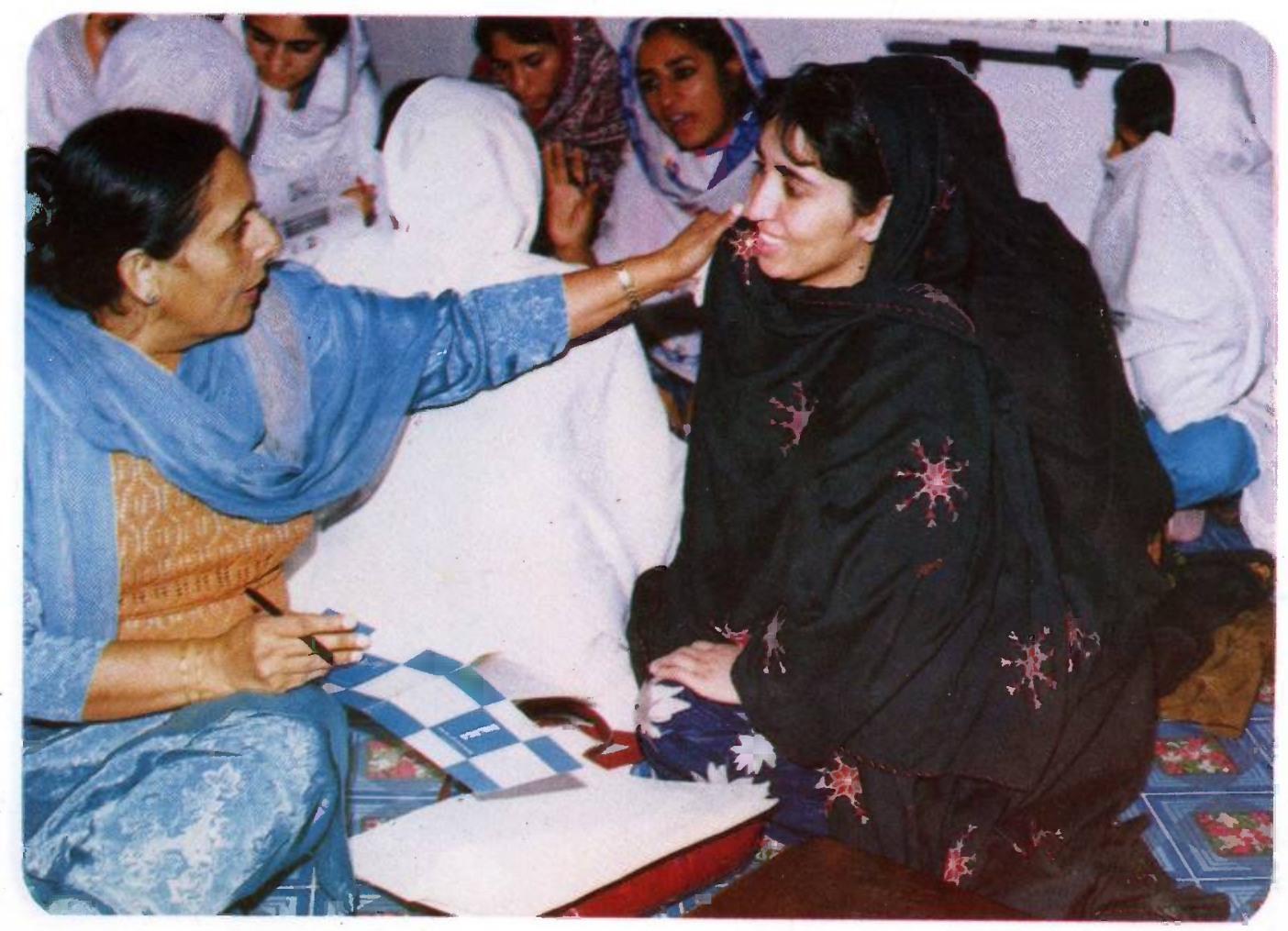



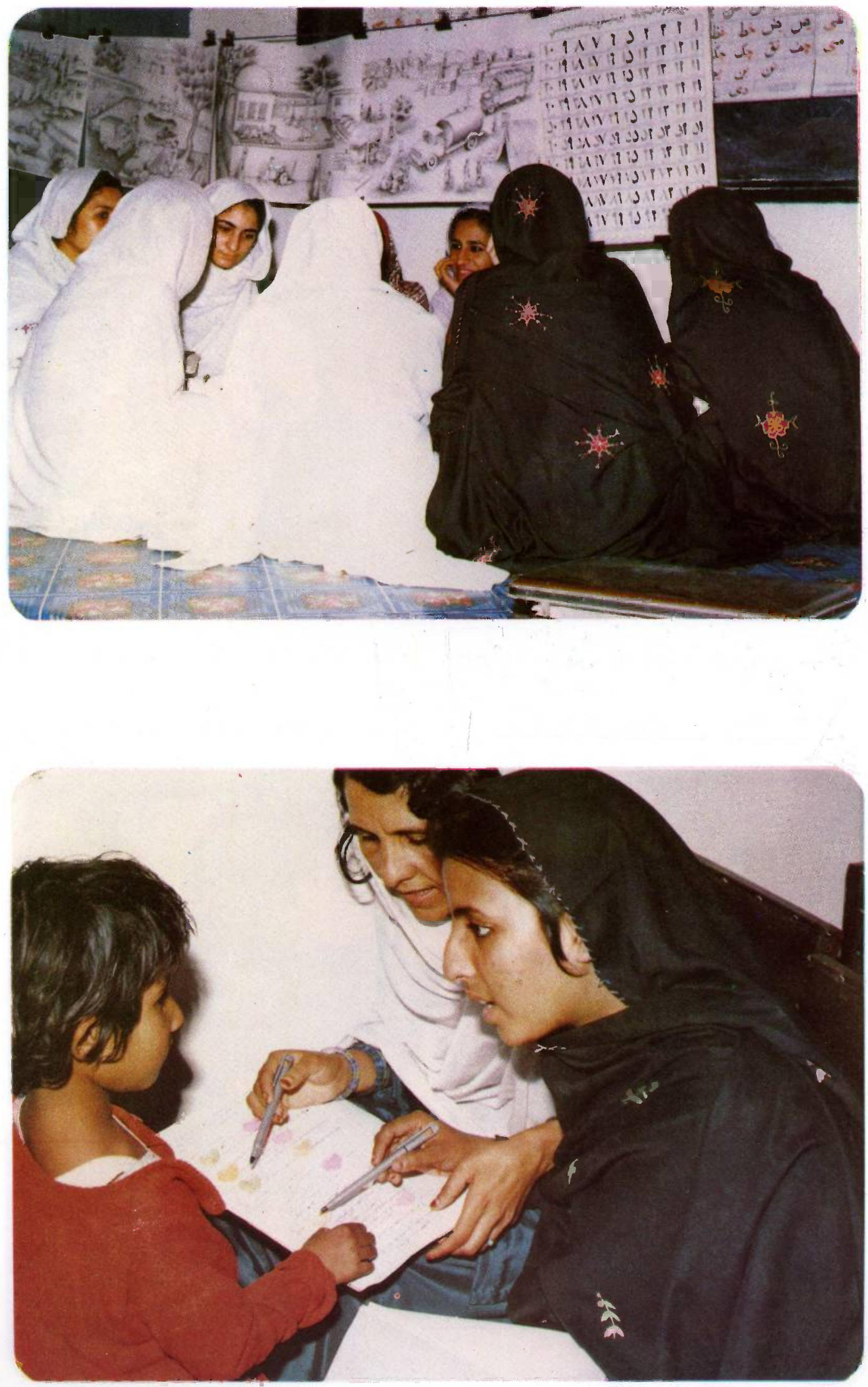
2.2 objectives

One week after the briefing seminar for teachers the first round of school visits started (23rd of April, 1986). The Monitoring Exercise lasted till the 27 th of May, 1986, and was the first attempt of a systematic observation of innovations in primary schools in the Northwest Frontier Province. During this period each of the pilot schools was visited three times by one of the Monitoring Teams.

The main purpose for the school visits was to observe in more depth how the teachers were applying lesson plans and teaching aids developed so far by PAK-GERMAN BAS-ED, and what kind of classroom interactions were really taking place. The questions we hoped to find answers for were e.g.:

1. Did the teachers prepare their model lessons according to the Lesson Plans?

2. Did the teachers read the scheme of works and instrugtions?

3. Did the teachers follow the steps recommended in the Lesson Plans?

4. Were the pupils actively involved in the learning process?

5. Were the Teaching Aids used at all and how were they applied?

6. Did the teachers deliver such Model Lessons regularly according to the agreed scheme? 
A sensitive area where only scanty knowledge is available for the situation in NWFP is the entry behaviour of pupils admitted newly into the school system. Since no systematic comprehensive research study has so far been undertaken to assess the cognitive development of Pakistani children, PAK-GERMAN BAS-ED when developing its devices for classroom interactions had to rely on the experiences and results derived from other and/or similar cultural environments. The monitoring visits to the pilot schools were therefore also seen as a chance to test some of the assumptions that were made when the new approaches for Pashto and Mathematics were developed. For example it was assumed

(1) that in the case of starting with Pashto children of $5+$ possess deficient oral competency in the sense that they do not or cannot verbalise their experiences. Since expectation. plays a fundamental role in the mechanism associated with reading, oral competency of a certain level is the sine qua non for the process of reading; and

(2) that in the case of Mathematics children do possess certain ideas of pre-number concepts but lack the knowledge and skills in the case of number concepts.

Besides observing the classroom interactions and testing some of the underlying assumptions concerning children's entry behaviour further results were expected to answer questions deriving from the following:

- The extent to which those teachers being trained by PAK-GERMAN BAS-ED have been able to absorb, 
interpret and apply the changes in teaching methodology proposed by the project;

- the grade of acceptance of the micro-planning aids by the teachers, and whether they were able to contribute to the refinement of lesson plans or teaching materials, or whether they had applied similar techniques of planning lessons for other subjects; and

- whether the new teaching approach shows any spread effects in a particular pilot school beyond grade I.

2.3 Approach and Criteria

After joint planning meetings with all members of the monitoring teams it was decided that the intended monitoring study should not follow a strictly quantitative-statistical approach only, but should include as far as possible qualitative elements deriving from others than hard fact sources. A suitable mix of collecting and analyzing hard-data enriched by utilizing soft-data information was seen to be more appropriate in view of the specific situation. The data were to be gathered through the application of a structured formal observation schedule. However the soft-data were to be collected with the help of a personal diary kept by each monitoring team.

For the observation scheme it was decided to select six of the most basic activities (at least four) to be performed in every lesson indicating the classroom interactions as the measuring criterion. A Discrepancy 
Status was to be measured in respect of each activity by observing the degree of agreement between the intended and the actual. Four categories were applied:

A. = Almost no discrepancy (when the agreement between the intended and the actual is $80 \%$ or more).

B. = Limited discrepancy (when the agreement between the intended and the actual is of the order of $50-80 \%$ ).

$C_{.}=$Substantial discrepancy (when the agreement between the intended and the actual is of the order of $10-50 \%$ ).

D.= Total discrepancy (when the agreement between the intended and the actual is of the order of $0-10 \%$ ).

These four Discrepancy statuses can then help determine the category of the lesson according to the norm:

- any three As, provided there is not more than one D, would be judged a good lesson (" a happy face") ;

- any three Ds, provided there is not more than one $A$, would entitle the lesson to be considered as a bad lesson ("a sad face"); and

- a lesson neither good nor bad would be called a neutral lesson (a face neither happy nor sad but a "neutral" one). 
A similar operation tried to check the degree of achievement of the instructional objectives of each lesson. Again discrepancy status in respect of each of these objectives can be assessed. This operation can serve the purpose of a check or confirmation of the assessment of its instructional activities. The hunch is that in the case of a lesson categorised as a "happy face" more than 50\% of the instructional objectives would be observed as almost achieved. On the other hand, in the case of a lesson assessed as a "sad face" at least $50 \%$ of these objectives would belong to the discrepancy status $D$, objectives which have not been achieved at all.

Only two instruments were used during this monitoring exercise

1. the classroom monitoring schedule - a 4-page formal instrument designed in the planning session for the collection of hard-data; and

2. the observer's diary - an informal, open-ended device suitable for keeping record of all such observations likely to illuminate one or the other aspect of the classroom teaching/learning situation.

The classroom Monitoring schedule comprises the following eight sections: 


\begin{tabular}{|c|c|c|}
\hline $\begin{array}{l}\text { Section } \\
\text { No. }\end{array}$ & $\begin{array}{l}\text { No. of } \\
\text { Questions }\end{array}$ & Topic of question \\
\hline I & 8 & school related information \\
\hline I I & 6 & $\begin{array}{l}\text { Guiding questions for the } \\
\text { Working Teacher to answer }\end{array}$ \\
\hline I I I & 4 & $\begin{array}{l}\text { Particulars of the Monitoring } \\
\text { Team Member }\end{array}$ \\
\hline I V & 6 & observation scheme \\
\hline v & 4 & $\begin{array}{l}\text { Information Concerning Learning } \\
\text { Material }\end{array}$ \\
\hline VI & 3 & Pupils' Behaviour \\
\hline VII & 8 & Teacher's Behaviour \\
\hline VIII & 3 & General \\
\hline
\end{tabular}

Most of the questions are of the restricted response type, while the rest are open-ended. The schedule varied somewhat from lesson to lesson while retaining a substantial common core. Seven out of the above eight sections constituted the common core. Only section no. IV (Observation scheme) varied from lesson to lesson. Examples of Monitoring schedules for some lessons in Mathematics and pashto may be seen in the Annexure.

2.5 Logistical Aspects

The following three teams were constituted to visit the 24 pilot schools:

Team A: Mrs. Farkhanda Akhtar Bhatti and Dr. Bude (PAK-GERMAN BAS-ED) 
Team B: Said Ahmad Mohmand (PAK-GERMAN BAS-ED) and syed Manzar Jan Sajid (Consultant)

Team C: Habib-ur Rahman (Consultant) and Arif Nasim (Principal, Superior Science College).

The team undertook three rounds of visits to schools on the following dates:

Ist round -- from 23rd April to 29th April, 1986. 2nd round - from 5th May to 10 th May, 1986. 3 rd round -- from 18 th May to 27 th May, 1986.

The three rounds of visits consumed 20 working days ( 6 days in the month of April and 14 days during May, 1986). On the first two rounds each team used to visit usually two schools on any working day according to a set programme. For the schools each visit used to be a surprise visit as they were never informed in advance about the schedule of visits. of course the schools knew that the project intended to conduct a follow-up programme. Therefore these schools had no other option but to wait for the visit which could possibly take place on any day. On the third round which fell in the month of fasting (Ramazan), when normal working hours are curtailed, each team visited just one school each day. The usual pattern was for the full team to go together and assess the lessons separately to reach a consensus regarding the quality of the lesson after it was over. Such a procedure was thought expedient to make up, for at least to a certain extent, the inter-observer reliability.

Matters related to the availability of conveyance needed thorough pre-planning. None of the three teams 
had to experience any inconvenience on that score. The programmes (see Annex) on all the three rounds were followed to the letter. The motivation of the monitoring teams can be judged from the fact that not a single member absented himself/herself on any of these 20 working days, which in the circumstances of Pakistan is somewhat unusual. Observation schedules were plentiful and always available. These used to be completed on each visit and passed on to Habib-urRahman at the first opportunity.

Planning sessions were held to discuss many issues connected with monitoring immediately before the start of each round. These were also the occasions to summarize some of the reactions from the last round of visits as well and to deepen the understanding for the procedures of organizing the feed-back. 


\section{From the Monitoring Teams' Diary}

\section{"A Sad Face"}

3 rd round

GPS $s \ldots . .($ boys $)$

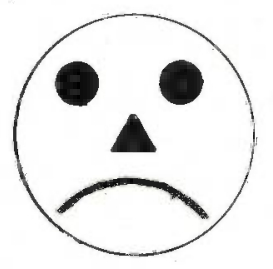

$21-5-86$

Team C

Working Teacher: Mr. M.

Number of pupils present: 72 boys

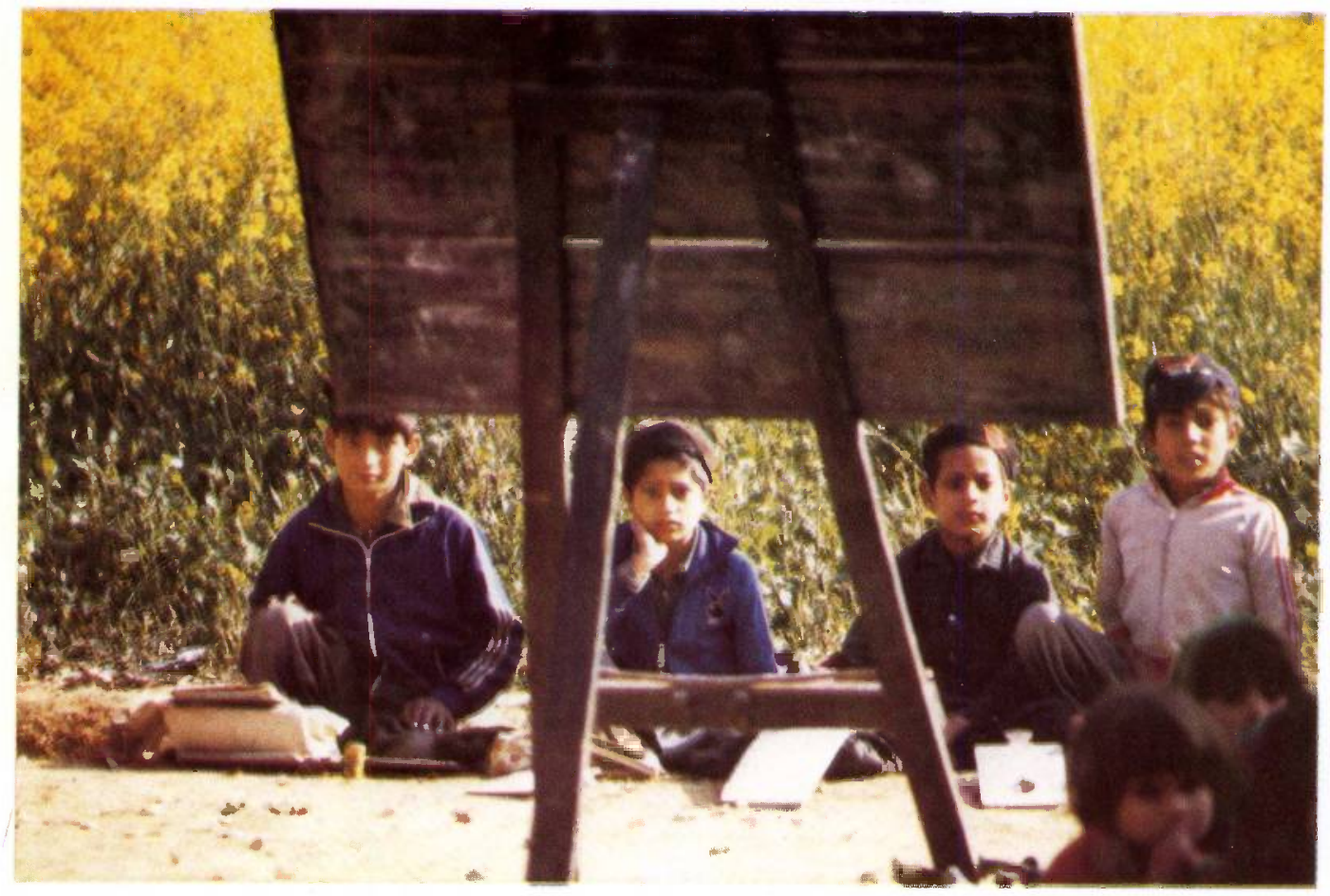


"It is the month of fasting (Ramazan) and the monitoring teams make an early start so as to be able to finish the daily assignment before the day gets really hot. The vehicle carrying the Monitoring Teams $B$ and $C$ stops at the front of the school gate at the village of $\mathrm{s}$. at $7.30 \mathrm{a} \cdot \mathrm{m}$. Before we got out team $B$, who is to proceed to a nearby school at the refugee camp M., suggests we make sure that the working teacher is in and is not on leave. From earlier experience they have little hope of finding him on seat.

We from team $C$, too, remember the day when we visited this school on our first round of visits. The working teacher was absent. He had left an undated application with the teacher to show to any official of the department who may happen to drop in per chance. We, however, on that occasion did not take his absence as a misfortune and began to probe as to what had been happening in the grade I from those teachers who were present in the school. We wanted to have some feel of the Hawthorn Effect. We soon discovered that the learning materials, as provided to the school by PAKGERMAN BAS-ED, had aroused curiosity of these teachers and some interaction has been going on between this working teacher (who is incidentally also the Head Teacher) and the rest of the staff. One particular teacher (Mr. T.) had watched the working teacher trying to make use of the lesson plans and teaching materials. He was all praise for the shift in methodology that had been designed and he claimed that he had also been using the materials in an effective way. That was a big temptation for us to observe what he - who had not attended our course, had been doing exactly. Mr. T. was requested to give two lessons to the children in grade I. To our surprise we did find that he was doing well. Apparently for him the suggested change in the teaching approach was not very radical. Thus 
we stayed in the school for about two hours. As we were coming out of it, some residents of the village approached us with the request that the working teacher be transferred to another place. They complained that he was usually absent. obviously they mistook us for some high-ups of the Education Department. The monitoring team which went to this school during the course of the second round also failed to find him present in the school. He was again on leave.

However, today we are lucky. He is very much there. What a surprise! Mr. M. is happy to receive us. He says that he has been able to complete six lesson plans, each both in Pashto and Mathematics. He thinks that he is some what behind the schedule but it is because he believes in complete mastery of the content or concepts on the part of children rather than their formal coverage as such. To our enquiry he replies that he has not kept any record of his activities with him. He is, however, all praise for the lesson plans. Mr. M. is an old man and has been in this profession for the last 25 years. He is on the verge of his retirement and he thinks that now he cannot be put to any harm.

In order to give his first lesson on Mathematics regarding the concepts of heavy and light he goes out and brings with him a brick, some stones and a flat balloon. He then takes the brick in one hand and the stone in the other and asks which of the two is heavier. The class replies in a loud chorus. Placing the stone back on the table he now picks up the balloon and repeats the same question. Once again there is a loud answer. Keeping these objects in his hand he now asks why the brick is heavier and before an answer is attempted he himself explains. The brick is heavier because it is bigger. This step is repeated by taking 
the stone and the balloon in the two hands. Once again it is repeated by taking two stones - one bigger and the other smaller. Now a boy is called to the table and is asked to lift the brick and the stone and to tell which is heavier and which is lighter. The boy gives the correct answer. "But why is the brick heavier than the stone"? "Because the brick is bigger." "Yes, but why so"? The boy looks puzzled. Another boy is called and is instructed to lift the brick with one hand and the balloon with the other. The boy is apprehensive lest the brick may slip through his hand. He, therefore, picks the brick with his two hands and then places it back on the table. He has now the balloon in one hand only and he says that the brick is heavy. To the whyquestion of the teacher he says, "Because it is bigger". The teacher is not satisfied. The boy is silent. He is obviously racking his brain. He is busy searching for an answer. The teacher is impatient. "Because you had to apply more power to lift the brick" is the answer that is doled out to the class. The same activity is then repeated by involving two more children. Now Mr. M. refers to the brick and a chair. on being told that the chair is heavier than the brick he repeats his question, "But how do you know"? "Because I have to apply more power", comes the patanswer. The teacher now informs the class that we find out which object is heavier and which is lighter by using a balance. He further says that he is going to draw a diagram of a balance. He draws a figure marked Ist. He then draws the figure marked 2nd and says that the longer pan shows that the object in it is heavier. The lesson lasts for about 20 minutes. 


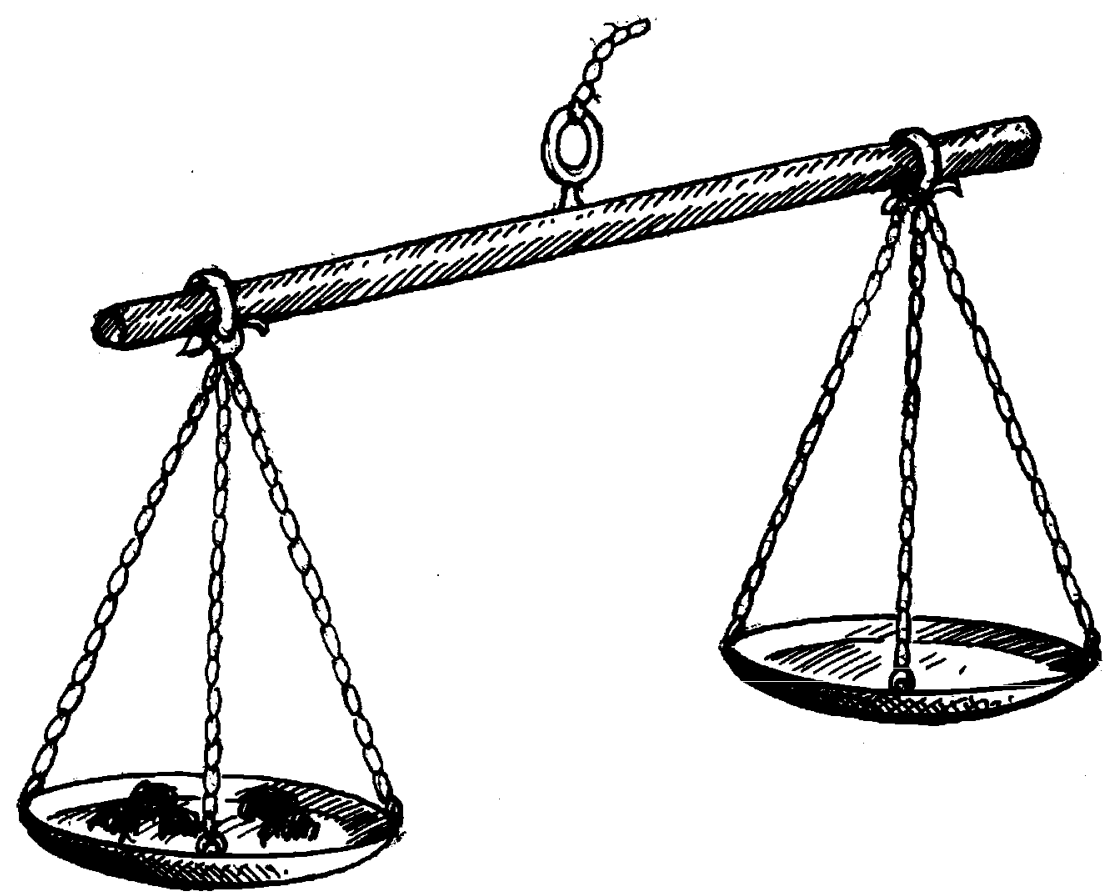

For his second lesson on Pashto the working teacher opens the almirah (cupboard) and takes out 4 picture sheets and the iron hooks. He fixes these sheets on the blackboard. They are about a cat which spoils a meal when a person who is busy eating has to go out for a while. pointing towards the first picture he asks the student to observe carefully. We are a bit surprised, because Mr. M. is confusing the charts of the picture story and one of the single action pictures that is not part of the set of the cat story. However Mr. M. does not bother. He points towards objects shown in the picture one by one and asks his students to name them. Passing to the second picture he tells the class what is happening there, despite the fact that it should have been up to the students to find proper descriptions of the actions.shown. He, now, passes on to the third picture and describes again what is happening there. After giving the fourth picture a similar treatment, he draws the conclusion. 
During his narration he was at times acting also. In view of his advanced age it looks a bit strange. Now begins the question-answer session. All questions are regarding facts or events. Answers are all telegraphic. The lesson lasts for 18 minutes.

Seeing the lessons we feel very depressed. It comes to our minds what was said in one of our planning sessions by Dr. B. "The real question is not why learning does not take place. In this situation, the pertinent question is why some learning does take place at all". If inspite of such a teacher ohildren are really learning then it is definitely somethiñg not short of a miracle. We may safely assume that this teacher has never taken the trouble to plan and organise any of his lessons in advance. He has probably never reflected during his teaching career what he is about to do with his class or what he has done to his pupils. He may think his instinctsare sufficient to guide him or he does not think about his teaching at all.

Back in the office we tell our colleagues of the experience of these two specimen lessons as an example how not to teach a lesson. To our further surprise we. discover that this teacher had delivered exactly these two same lessons two weeks ago when they went to his school during the second round, after ensuring his presence in the school through an intermediary." 


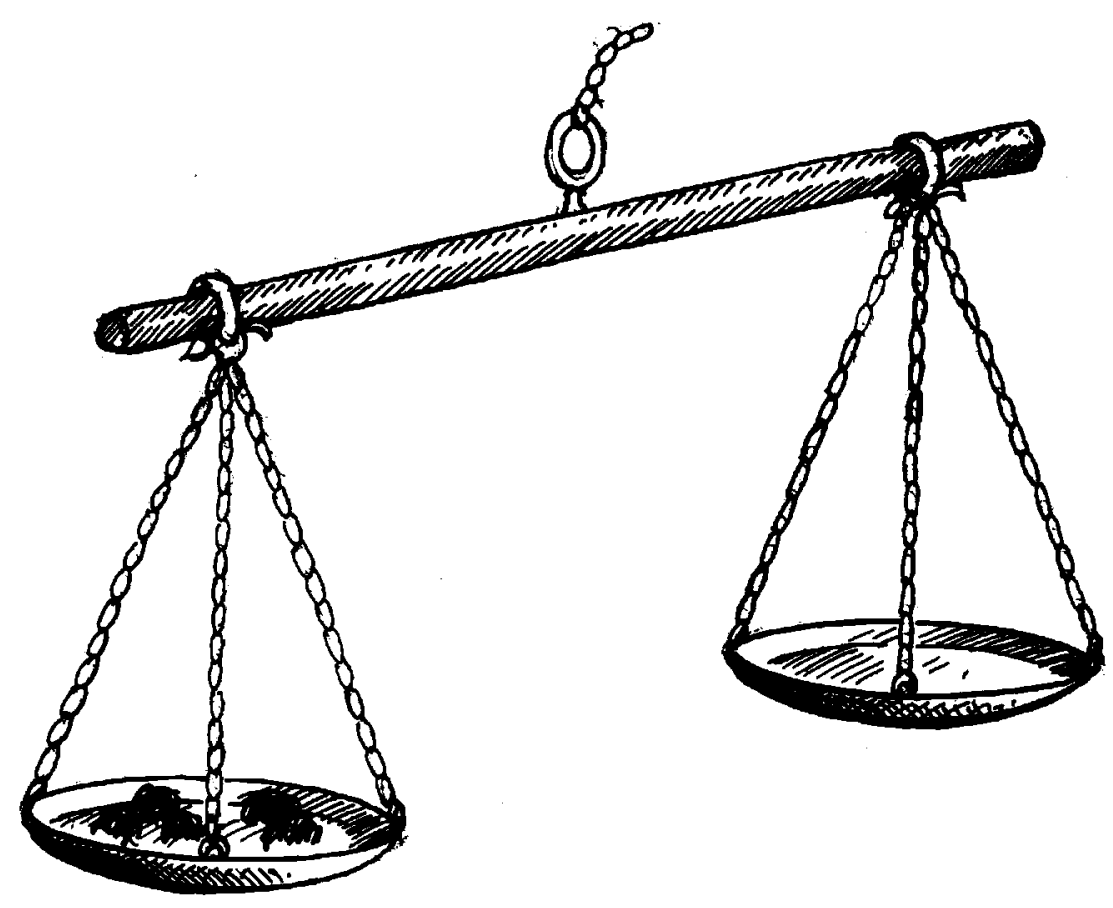

For his second lesson on pashto the working teacher opens the almirah (cupboard) and takes out 4 picture sheets and the iron hooks. He fixes these sheets on the blackboard. They are about a cat which spoils a meal when a person who is busy eating has to go out for a while. Pointing towards the first picture he asks the student to observe carefully. We are a bit surprised, because Mr. M. is confusing the charts of the picture story and one of the single action pictures that is not part of the set of the cat story. However Mr. M. does not bother. He points towards objects shown in the picture one by one and asks his students to name them. Passing to the second picture he tells the class what is happening there, despite the fact that it should have been up to the students to find proper descriptions of the actions.shown. He, now, passes on to the third picture and describes again what is happening there. After giving the fourth picture a similar treatment, he draws the conclusion. 
3. F INDINGS

3.1 The socio-cultural situation

When reporting the findings of the monitoring visits one has to keep in mind that we had to deal with two different target groups, Afghan Refugee Primary Schools (ARPS) and Pakistani Government Primary Schools (GPS). The most unifying factor of both school systems is the use of Pashto as a medium of instruction in the primary schools. Other cultural and social values are also shared, especially with reference to Islam and as to the norms of Pashto-society.

However at the same time there are obvious differences between the two school systems ${ }^{1}$ ). For example all pakistani male teachers in the Government Primary schools participating in the exercise were trained teachers, whereas none of the Afghan teachers had undergone a proper teacher training. This deficit of the Afghan teachers seemed to be compensated for by their longer general schooling (up to 12 th class) compared to their Pakistani colleagues (up to 10 th class) and some short in-service training courses they had attended.

The training situation of the lady teachers is even worse. Only one Pakistani teacher was a

1) For further details on the situation in the 24 pilot schools of PAK-GERMAN BAS-ED see Frommer/ Wehrmann/Mumtaz/Tanival (1985) Case Study. The Situation in 24 Pilot schools in NWFP, Pakistan, Peshawar. 
PTC (Primary Teachers Certificate) holder.

All the other seven female teachers were untrained. Out of the four ladies teaching in refugee camp schools, three were of Pakistani and only one of Afghan nationality, all without any teacher training.

Though working very of ten in close proximity Pakistani and Afghani teachers belong to different worlds. Almost all of the Afghan teachers live in refugee camps where living conditions are very harsh. Before coming to Pakistan these teachers lived in extremely stable but highly static patriarchal communities. Many refugees left their homes to uphold their traditions and way of life. Their fervour to retain their old lifestyle and their belief in a pre-ordained scheme of events gives them the strength to endure all the hardship of the conditions in the refugee camps. Thus, the Afghan refugees, though living at a bare survival level, appear to be more contented with life, and this situation lends a lot of stability to their living and working conditions. Moreover, the Afghan teacher because of being part of a more traditional society is used to blindly following orders given to him from higher ranking people. He will follow an order to his best of abilities. To expect that he would act in a creative manner and not in a mechanical style is to expect too much of him: He is less prone to creativity, and the society is less enthusiastic to changes in the style of learning in school, since the traditional methods deriving from the learning of the Quran are regarded as sacrosanct. The existing 

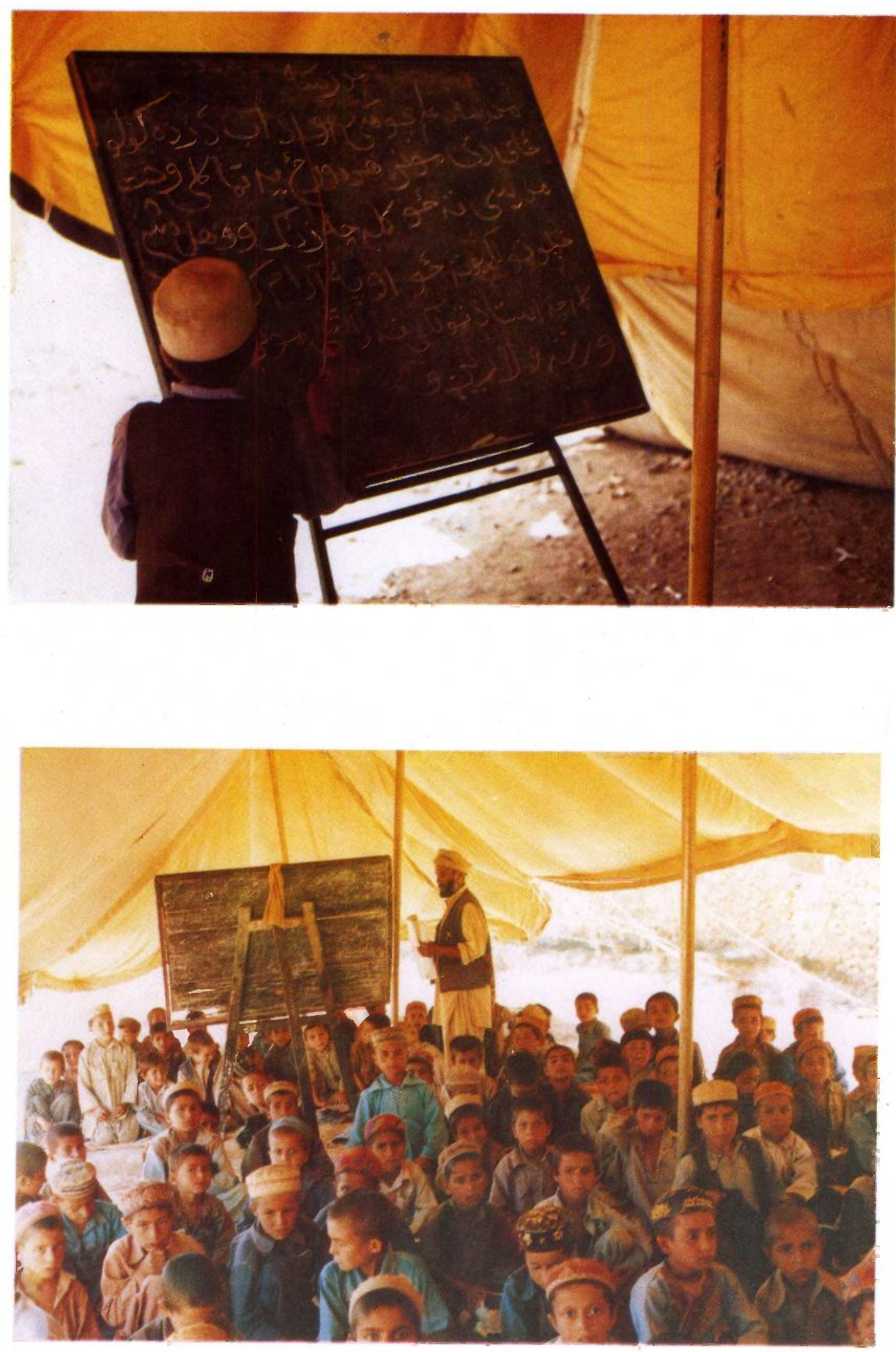
practices current in the schools are more suitable for indoctrination than for meaningful learning. Indoctrination implies meek acceptance of whatever is told by an authority. Asking questions which the new approaches designed by the project promote is always inimical to a traditional milieu. Children brought up through the adoption of these new approaches may be bound to question many things. This the community may find unwholesome. Thus some overt, some covert, resentment and opposition may begin to simmer. In fact, in one Afghan Refugee school a narrow-minded headteacher refused to use pictures for the purpose of teaching. He did not permit the working teacher to proceed with the programme. Only after the Education Cell as the higher authority intervened was the teacher allowed to use the teaching material developed by PAK-GERMAN BAS-ED. The headteacher had argued that the use of pictures for classroom instructions is against Islamic belief and has to be avoided. In another case it was observed that an Afghan teacher seemingly did not feel at ease with handing the new approach and materials, since it was so different from the practice he was used to.

Pakistani teachers on the other hand are more open for changes. Over the years they have been exposed to several attempts towards innovations in the primary education sector. Unfortunately, many of these new ideas failed to take ground due to the reluctance on behalf of the political decision makers to provide a certain stability 
for the underlying educational policy, and to make sure that plans developed at top level were really executed for the benefit of those concerned. The Pakistani teacher. also lives in a society showing more signs of transition than the Afghan refugee community. People are more aware of politics affecting their lives and have started claiming their share of what they produce. "The worker, whether engaged in physical labour or mental work, is no longer willing to exert himself for the food of the elite", comments Habib-ur-Rahman on the situation in Pakistan, "He is not willing to put his heart and soul in the process of production until and unless he is assured of a fair distribution of all that he produces. For the lack of such a promise the whole nation is caught in sloth and is suffering from acute frustration" ${ }^{1}$ ).

If the prevailing mood in a society is more that of inaction, inertia and stagnation because of the lack of perspectives teachers are less willing to exhibit creativity and and dynamism. Many teachers - like other civil servants - therefore have just decided not to work as they could, until and unless they are given a better deal. Teachers do not seem to have mental reservations for the proposed changes. In fact, some intuitively feel the desirability and usefulness for such new ways of teaching. However, can we expect the teachers to be enthusiastic about the additional work these new methods/materials mean for them,

1) Habib-ur-Rahman (1986), Background Material to School Monitoring (Manuscript). 
when they earn a meagre average salary of Rs.800-1000, per month, not enough to maintain their families? The teachers in Pakistani primary schools do not resist the change in methodology per se, but they are only willing to exert themselves if the rewards are more just and equitable.

The potential for innovations in classroom instruction in the primary schools of the Northwest Frontier Province (NWFP) does exist. However, many Pakistani teachers are reluctant to cooperate because of their antipathy for the prevailing socio-economic system and their low level of remuneration. The Afghan teacher is much more cooperative, but his cooperation stems from a set of special circumstances, and not because of the fact that the introduction of such a change is felt as necessary. With some shift in the set of those circumstances it is very probable that the present zeal may completely vanish. A last minor point in this connection is worth mentioning. The Afghan teacher is also better paid for his job than his Pakistani counterpart. On top of his salary he receives his free rations like other refugees. Thus he is paid in money as well as in kind. This further helps to sustain his motivation to work diligent$1 \mathrm{y}$. 
3. 2 Teachers' Acquaintance with the New Method/Materials

It was intended to visit each school three times during the whole monitoring exercise. During these visits the teams were to see two model lessons, one in pashto and one in Mathematics. As a result, 72 observation schedules in Mathematics and 72 in Pashto were expected to be completed after these lessons were delivered in the pilot schools. However, sometimes circumstances prevented lessons from being taught, because teachers were not alvays on seat, schools had declared their own holiday or teachers were just not prepared for the lessons. The monitoring teams finally observed 62 lessons in Mathematics and 59 in Pashto.

The lessons were usually taught in classes with between 50 and 60 pupils. The education authorities normally regard 40-50 pupils per class as the maximum. Nevertheless, we came to face a situation where more than 200 class I pupils surrounded one single teacher. The other extreme was a girls school with only 18 girls in class I.

Although the time for each lesson on average was planned to last for about 30-40 minutes, the teachers finished their work in a shorter time, usually in 20-25 minutes. The shortest "model lesson" even was over in 5 minutes, leaving the monitoring team baffled and the teacher scattered.

Except for three teachers in the first round of 


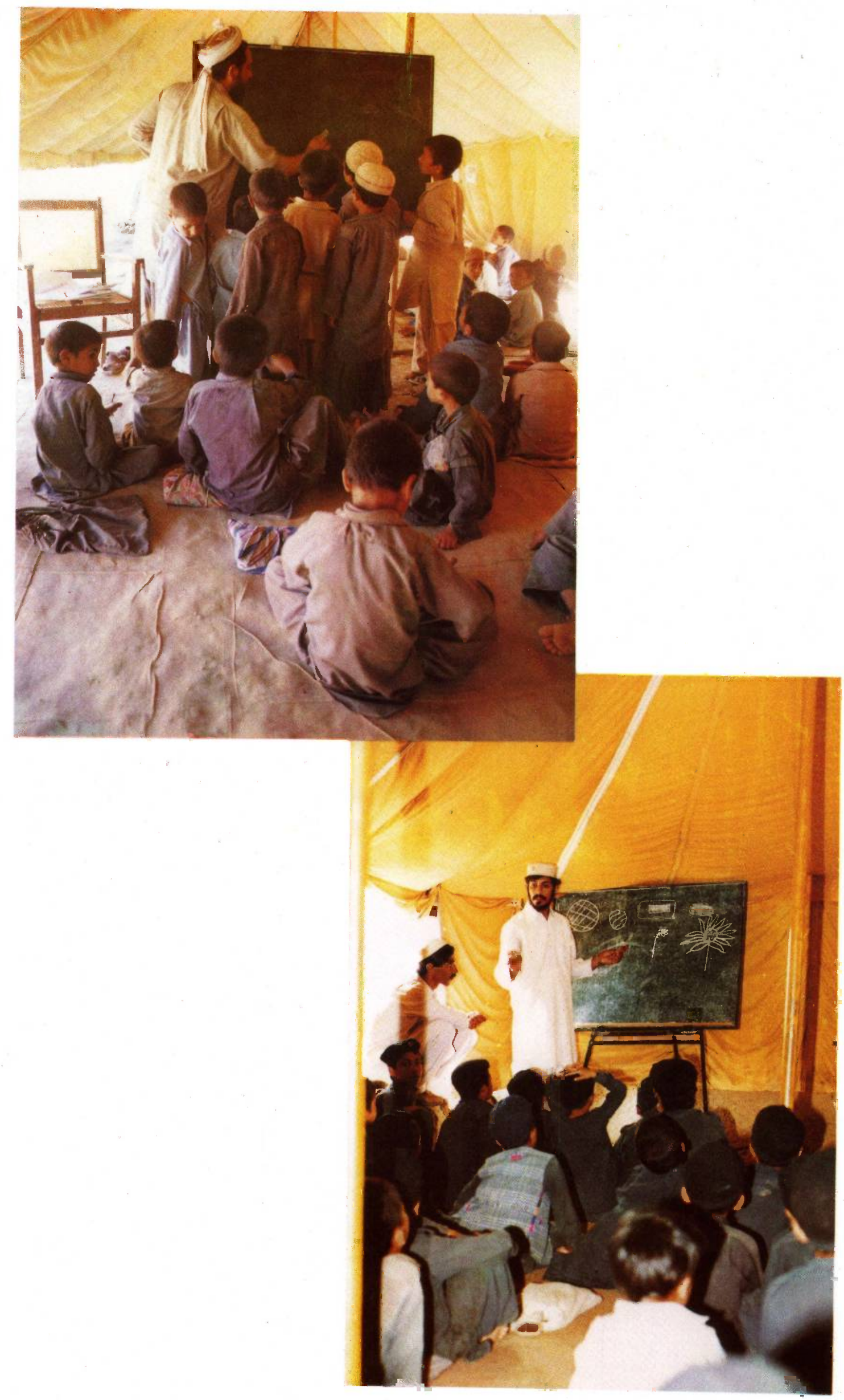


visits, every teacher pretended to have read the schemes of work. It is difficult to verify any such claim. The number of lesson plans taught by these teachers during the six weeks under supervision varied from 6 to 12 . Invariably all those schools who had very strictly observed the planned schedule were those where we saw good teaching. Thus the good schools were not only teaching better, they were also found having covered more model lessons.

During the preparation seminar in April 86 the working teachers were advised to keep records of their teaching (what lesson plan in which subject was taught when and with what results). The project did not suggest any special format for recording. This was left to the teachers. since only three teachers actually kept some $k$ ind of records, and only two in a proper way, it seems to be advisable to prescribe a common format for recording future experiences with the lesson plans and teaching materials.

Almost all the teachers were in agreement that the lesson plans worked very well. However, none of these teachers could suggest any modifications. It appears that the lesson plans were not accorded the critical look which the teachers were requested to do. They just accepted these lesson plans. Only six teachers pointed out certain difficulties which they experienced. These problems were all related to the absence of learning materials referred to in these plans or, as in one case, the reference was to a text prescribed in Pakistani schools, 
but unknown to Afghan schools. In fact, it was observed that the provision of some learning materials has sapped badly the initiative of the teachers. Rather than using the blackboard or designing their own illustrations they were demanding illustrations in the case of such lessons as were not supplied.

The good services of the project seem to have created an expectation on behalf of the teachers that everything is being prepared for them and supplied to them by PAK-GERMAN BAS-ED. Either the teachers do not feel competent enough to alter or change the proposed lesson plans, or they just accept the lesson plans as devices from a higher authority that are to be followed to the letter.

Except for four less enthusiastic teachers (all Pakistanis) the rest seriously tried to follow the new teaching method and to make use of the teaching materials provided. However, most of them did it mechanically rather than in a creative way. The lesson plans were followed rigidly without any signs of flexibility according to particular situations in the classroom. In half of the lessons teachers did not hande the lesson plans properly, however in $20 \%$ of all cases the monitoring teams were satisfied to a large extent. 
Table 1: Teachers' Behaviour During Teaching of Trial Lessons

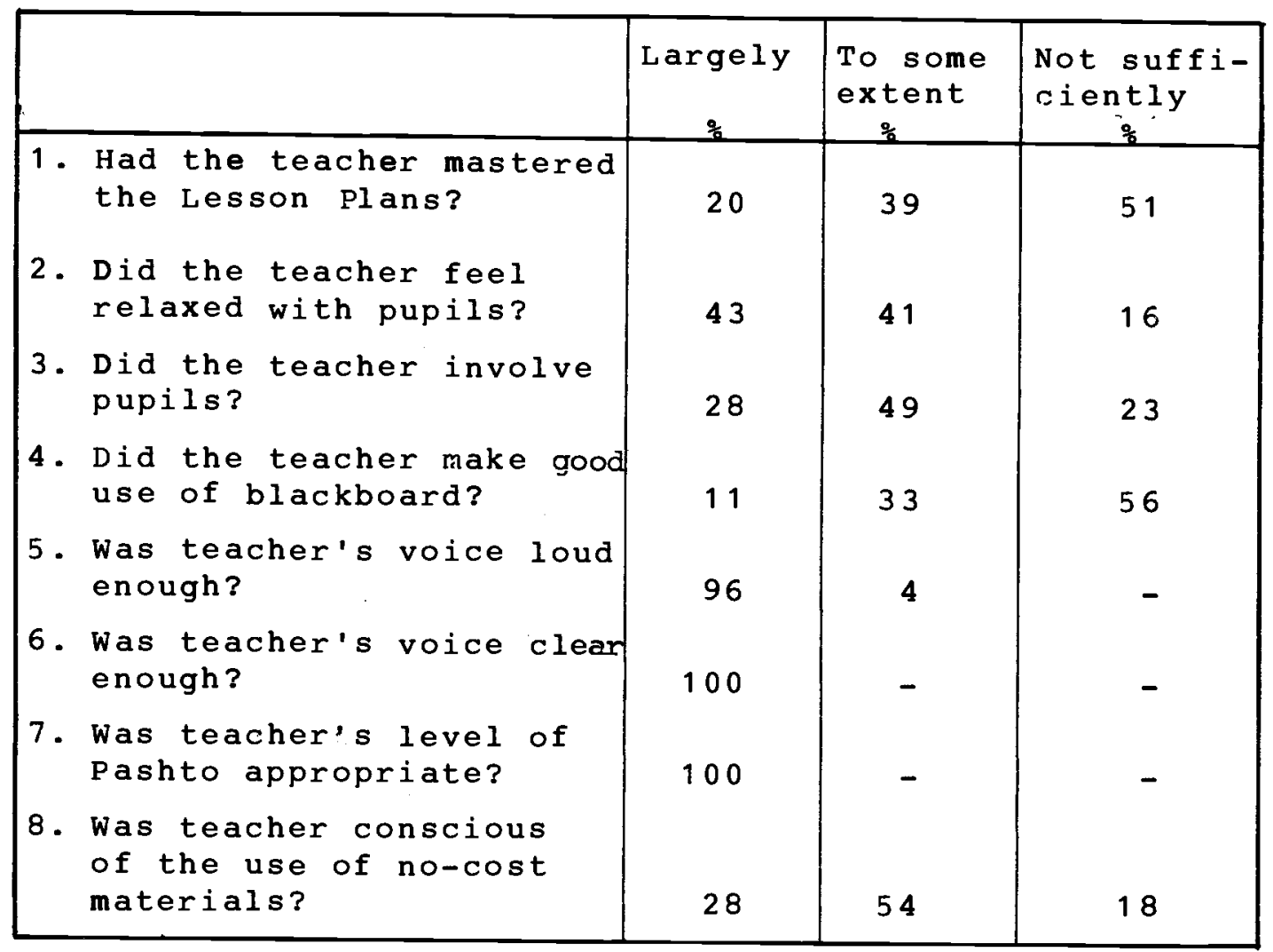

Note: $\quad 100 \%=121$ lessons observed

The involvement of pupils and the use of the blackboard are two further problem areas. Lesson plans and teaching materials aim at actively involving the pupils in the learning process. Such a novelty however needs much more time and effort before it becomes routine practice in the schools. In 28 instances ( $=23 \%$ ) teachers did not involve the pupils sufficiently despite the hints in the lesson plans. Good use of the blackboard was a rare phenomenon and very often the blackboard (even when available in the classroom) was not used at all. perhaps many teachers thought that the teaching materials provided could be seen as substitutes for blackboard work. 
Nearly all teachers used the learning materials going with the lesson plans during the trtal lessons, and the pupils enjoyed being more involved in the process of learning. The use of teaching materials definitely helped to promote interaction in the classroom, and when materials were used as intended, the teachers had no problems in handing them (see table 2).

Table 2: Use of Learning Materials During Trial Lessons

\begin{tabular}{|c|c|c|c|}
\hline & $\begin{array}{c}\text { Largely } \\
\frac{\%}{8}\end{array}$ & $\begin{array}{c}\text { To some } \\
\text { extent } \\
\frac{\%}{6}\end{array}$ & $\begin{array}{l}\text { Not suffi- } \\
\text { ciently } \\
\frac{\circ}{6}\end{array}$ \\
\hline $\begin{array}{l}\text { 1. Were the relevant } \\
\text { learning materials } \\
\text { used during lessons? } \\
\text { 2. Did pupils enjoy the } \\
\text { learning materials? } \\
\text { 3. Were the learning } \\
\text { materials easy to } \\
\text { handle? } \\
\text { 4. Did the learning } \\
\text { materials promote } \\
\text { interactions? }\end{array}$ & $\begin{array}{r}92 \\
100\end{array}$ & - & 5 \\
\hline
\end{tabular}

The introduction of new teaching methods and materials into the pilot schools has certainly had an impact on the quality of classroom instruction. Even in such cases where teachers did not master the new approach completely, but tried their best, changes were visible: pupils actually worked with learning materials, teaching materials were used to stimulate learning, and teachers tried 

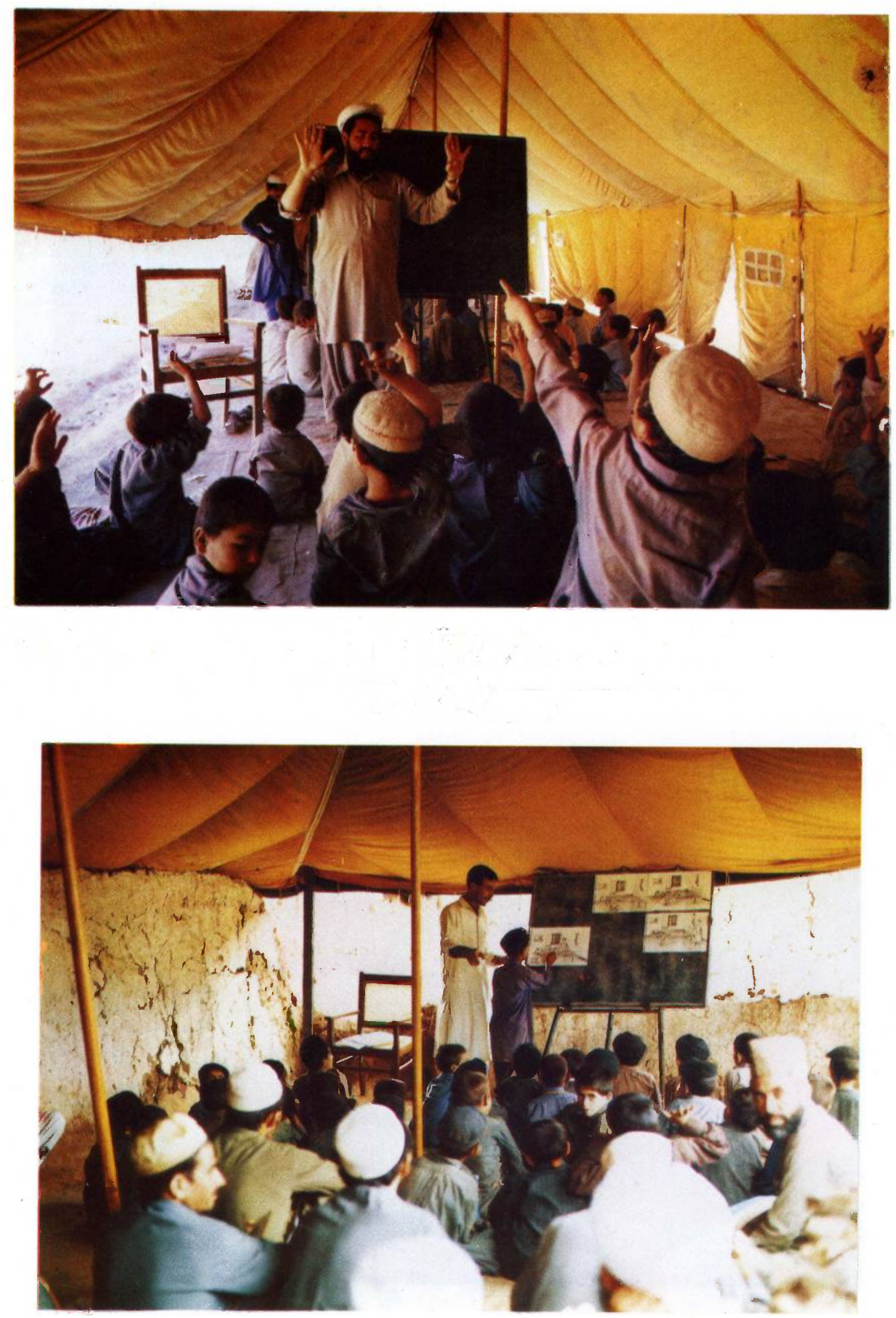

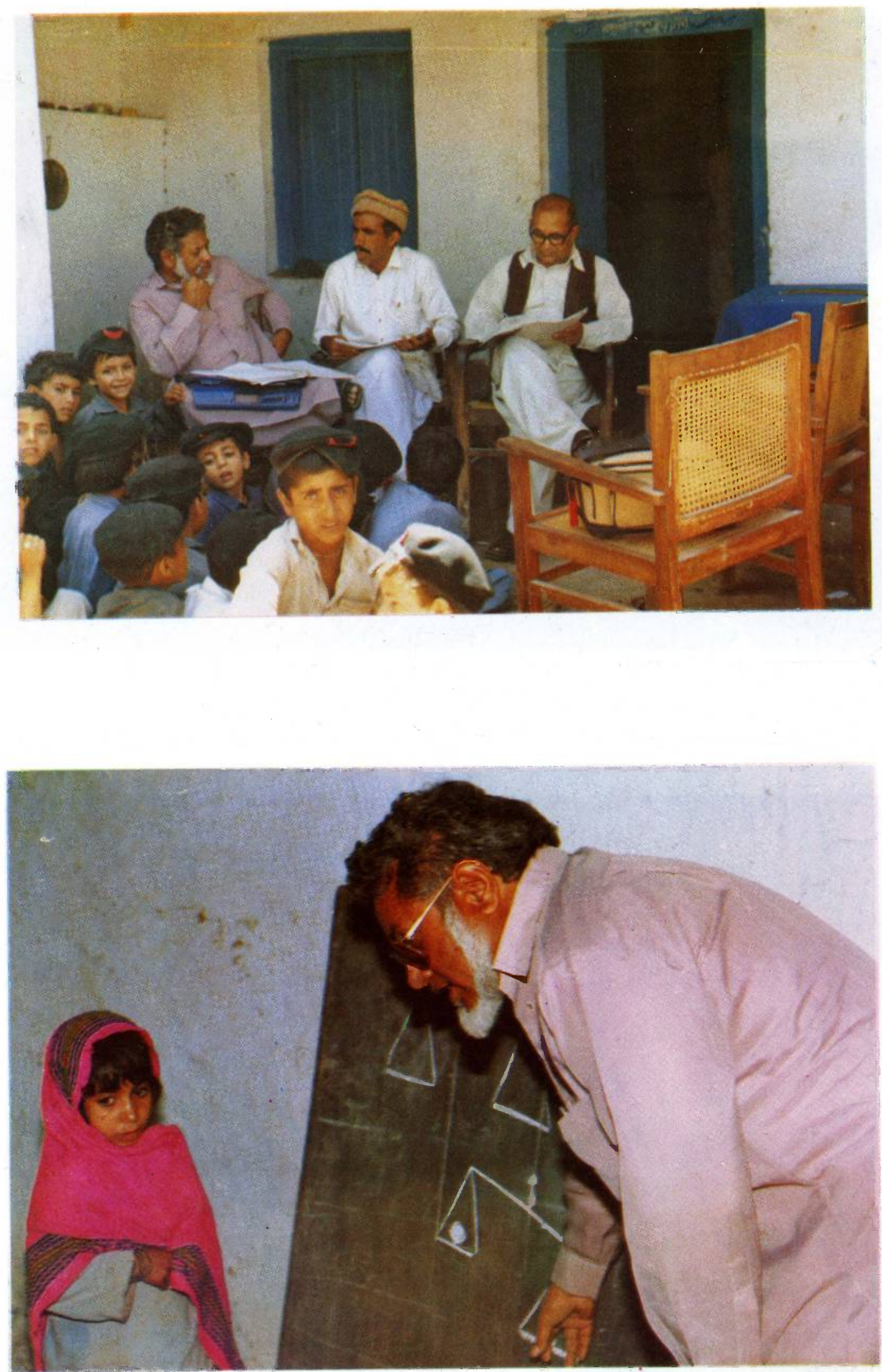
to communicate with their pupils.

As we mentioned before, most teachers followed and used the lesson plans rather mechanically and unimaginatively. One possible explanation for this behaviour may be seen in the fact, that nearly all teachers (trained or untrained) failed to understand the concepts of certain lesson plans. Here the plan designers either overestimated the teachers' professional background or the explanations giving in the lesson plans were not sufficient for the teachers' level of comprehension. The problem may be illustrated by the following examples from Mathematics and Pashto.

Pre-number concepts were to be taught in Mathematics as part of the exercise. The concepts were always to be interlinked with concrete operations to help children of that age to develop an understanding of concepts like equal/unequal, heavy/light, big/small.

Chart: Teaching of Pre-number Concepts in Mathematics

Concepts

I. $\quad$ Equal/unequal

II. Heavy/light

III. Big/small

\section{Concrete operations}

Pairing objects for the decision

Using a simple balance

for the decision

Using a container for the decision 
What was observed by the monitoring teams was that either the concepts were treated through abstract formal logic (not realising that a child of that age is incapable of understanding any formalism) or concrete operations were undertaken as an activity as an end in itself. The essential entity, i.e. the interlinking, was never brought within the focus of the child. Thus the activities were very much there, the involvement of the child was amply visible and yet the pedagogical output was missing.

In the case of Pashto the picture story involving the cat and the story about Rashid were very popular. The children were asked by the teachers about the objects, the persons, the overt, the visible and the explicit. The pupils were not allowed to indulge in fantasy, to talk about the covert, the invisible or the implicit. The questions were framed such that they had just one right answer. These lessons were not being used as situations forming the child to induce language. Enrichment of the language of the child was never aimed at by the teacher. He was not at all conscious of the deficient level of the child's language or of the need for mastery of the language as the essential support for reading with comprehension and writing for a purpose. Furthermore, teachers appeared not to have fully understood the framework of DAAPL (Development Approach for the Acquisition of Pashto Language). Again the teams observed that a lot of activities were going on during the language lessons, children were very much involved, but extention of the child's language or the enrichment of his vocabulary were not being achieved. 
Since the teachers were employing the proposed methodology and the newly developed materials for the first time, we could not expect them to handle their classroom affairs without problems. For future activities of PAK-GERMAN BAS-ED it is necessary to take into consideration some of the most obvious problems teachers were facing mainly due to the lack of professional skills:

1. Teachers do not know how to treat responses from children if they do not fit completely in their line of thinking; children are not encouraged to say how they view things;

2. teachers do not know the art of extending the child's talk. They do accept what he/she says, but they do not let the child know and experience how the same answer can be put in a better elaborate statement. Instead, they just reinforce the child's tendency to be very brief ;

3. teachers do not realise the need and importance of the individual answer. Born out of the habit to resort to chanting, the teachers put the question to the whole class and accept a collective answer in form of chorus. The teachers need to be equipped with the art of setting questions;

4. teachers insist on and demand uniformity from their pupils. They tend to imagine that a question can have only one right answer. They would not permit their pupils to come out with their answers which may be pertinent to their 
specific experiences. They would demand the one answer that they think is right because the same has been dished out by some authority, as if the authority can never be wrong;

5. some teachers have misused the learning materials. In some schools the material were employed as decorative pieces to cover the bare walls of the classrooms. In another situation they were used in higher grades in ways which were rather questionable;

6. learning materials meant to be manipulated by the children were - in many schools - never distributed to the pupils. Children were only allowed to watch the display or demonstration by the teacher from a safe distance. The idea of letting children play/work with learning materials is far from being applied in the schools;

7. teachers do not give special attention to the childrens' level of understanding of their mother tongue and the selection of words understood by the pupils. They tend to use only the terms mentioned in the textbooks, even if the message does not reach the children. For example, when the children worked on prenumber concepts the monitors discovered that the children could not cope with the word "difference" ("what is the difference between an orangea:nd an apple"?), and thus did not understand what the teacher was after. However, when Mrs. B. from the monitoring team phrased the sentence "In what ways is an orange 
unlike an apple"? The children came out with answers.

The pedantic use of terms mentioned in the textbooks or in the lesson plans only shows that the teachers themselves lack understanding of the content and the underlying concepts.

3.3 Teaching Performance During School Visits

over a period of six weeks the three monitoring teams observed how the teachers of the 24 pilot schools were applying lesson plans and teaching aids, and what kind of classroom interactions were really taking place. Many a teacher was taken by surprise - if on seat -, since lessons could not be arranged in advance to please the visitors. These visits by the monitoring teams very often turned into training sessions for the teacher or teachers of a particular school, hence teaching was corrected on the spot and demonstrations were given by members of the teams.

The majority of teachers in the pilot schools were surprised when the teams really appeared in their schools, and took such serious interest in their teaching. They were even more supprised when a second and third visit followed. The monitoring teams judged the performance of each visit according to the application of the socalled "teaching/learning material package" in the classroom situation (see chart: PAK-GERMAN BAS-ED APPROACH TO CLASSROOM INSTRUCTION) : whether the teacher was prepared for his lessons 
(having read the scheme of work and lesson plans), followed the lesson plans while teaching, using the teaching materials meaningfully, involving the pupils actively, etc. The teachers performance in both lessons (Pashto and Mathematics) was summarised in one of three possible categories:

1. "A happy face"

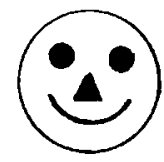

2. "A neutral face"

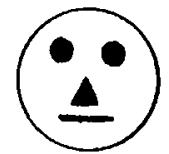

3. "A sad face"

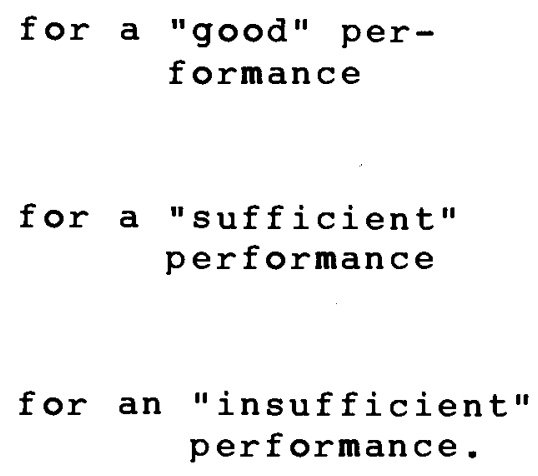

for a "sufficient" performance performance. 

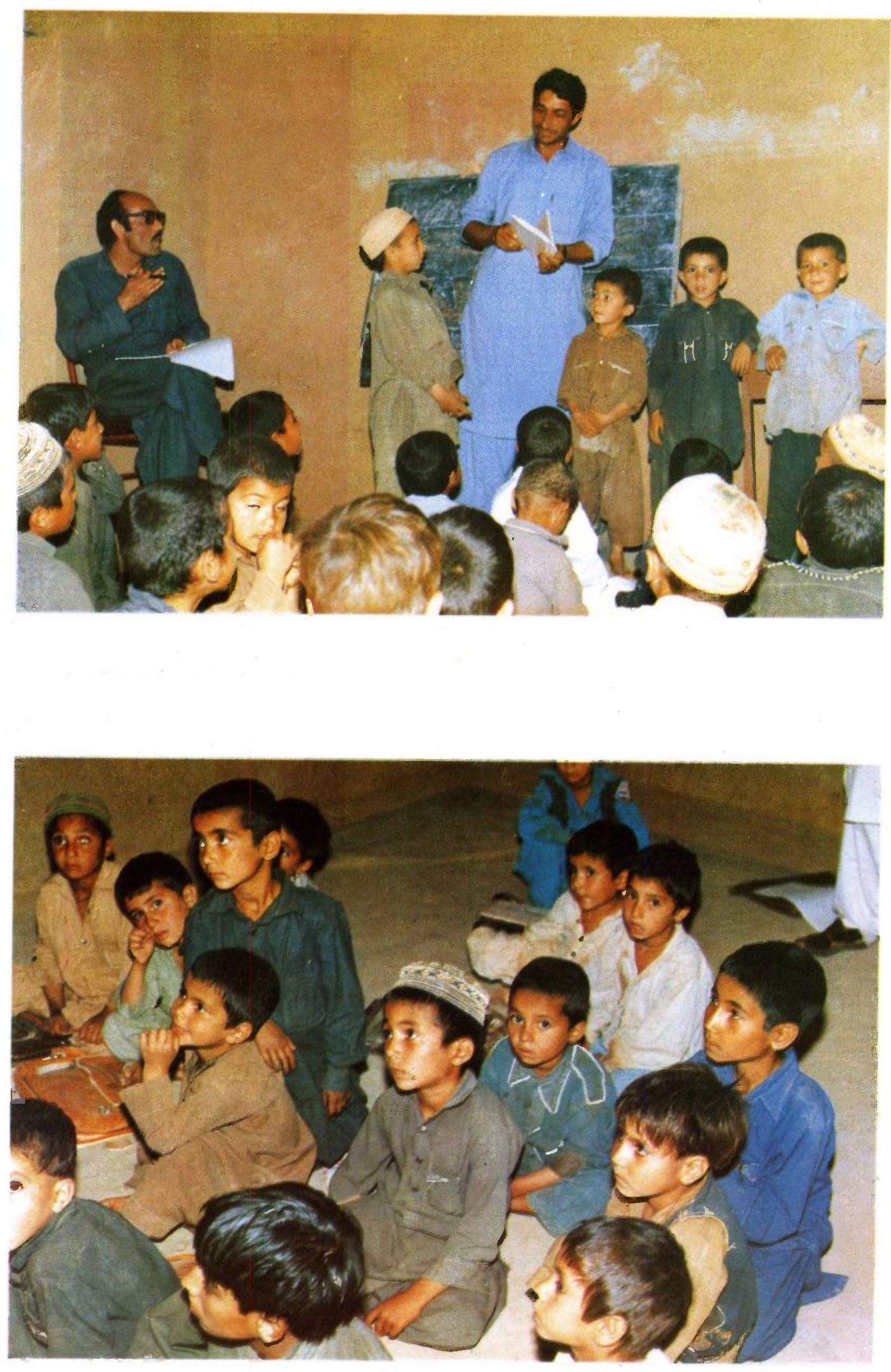
PAK-GERMAN BAS-ED APPROACH TO CLASSROOM INSTRUCTION

(TEACHING/LEARNING MATERIAL PACKAGE)

Ist term

$\underline{2 n d}$ term

$\underline{3 r d \operatorname{term}}$

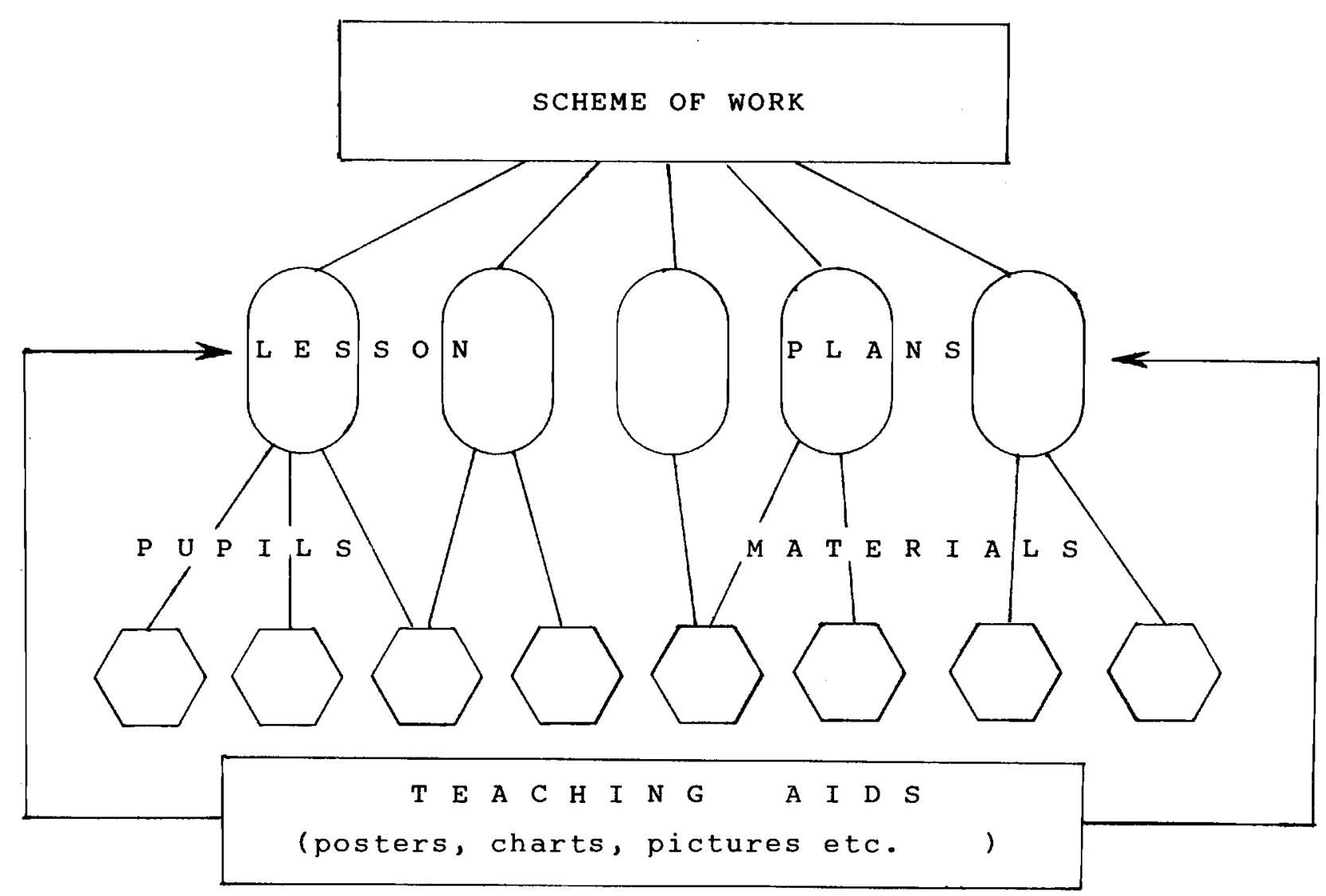

Note: Each academic year is divided into 3 terms per grade. Thus each term starts with a scheme of work explaining the objectives to be achieved and work to be carried out in a particular subject. Every week of a term contains two model lessons according to a planned format per subject. Each lesson plan gives hints for applying teaching aids and/or hints out or provides materials for pupils. 
It was reassuring to observe that at least in some pilot schools teachers showed keen interest in our kind of lesson preparation and teaching aids. In those cases we found evidence that the teachers had understood the instructions given during the training seminar and performed quite well. In other schools we had to record honest attempts to make use of things learnt and materials which the children had been exposed to. However, very often lack of ability and prevailing conditions prevented good classroom instruction. Disappointing teaching was to be registered in nearly every second visit to a school. Either teachers did not show any interest in the project's proposed teaching/ learning approach, often disguised in lame excuses like "I had no time to study the lesson plans", "the SDEO does not allow this kind of teaching", "parents do not like me teaching in this way", "my headmaster told me to stop teaching, because using pictures is un-Islamic", or messed up the project's good intentions for a meaningful lesson by using teaching aids wrongly or mixing up different lesson plans in one lesson, or ending up somewhere not knowing why and what they were expected to teach.

The following chart shows the results of the school monitoring according to Pakistani Government and Afghan Refugee Schools. There is an obvious discrepancy between these two systems. Whereas the Afghan teachers in their majority have not had a fully fledged teacher training compared with their Pakistani colleagues, their performances is far better than the results in the Pakistani primary schools. Nearly three quarters of the school visits to Afghan Refugee Primary Schools were judged as "sufficient" or "good". On the other side $61 \%$ 
RESULTS OF SCHOOL-MONITORING IN PROJECT'S PILOT SCHOOLS

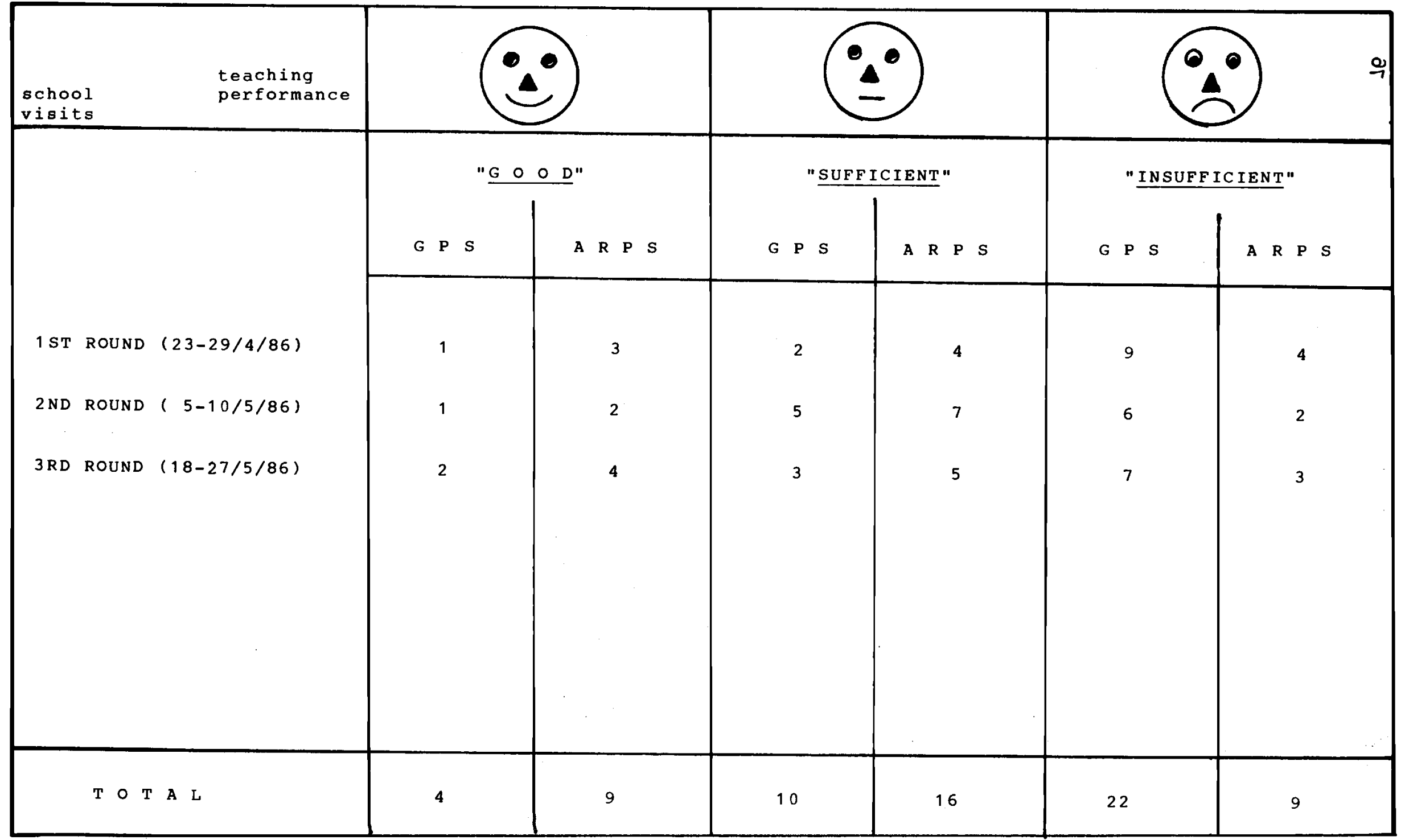


of the visits to Pakistani schools were considered as "insufficient". However, the government schools are not totally hopeless. Some $11 \%$ of visits to these schools brought good results. The weakest performances were to be noted in girls schools. Here the lady teachers in Pakistani and Afghani primary schools are on equal terms as far as teacher training is concerned. Except for one lady teacher in a Pakistani school none of them were trained teachers. Not surprisingly not a single visit to a girls school brought home "a happy face" for good performance. A few "neutral faces" could be recorded, the great majority of visits saw poor performances.

If one compares the teachers' performances in the two subjects, as a group teachers did better in Mathematics than in Pashto. The new approach to the teaching of Pashto probably demanded more radical adjustments from the teachers than the activityapproach in Mathematics. Since the monitoring team anticipated certain problems with the approach to pashto teaching, a manual had been developed by the project and been explained and disseminated to the teachers before the first lessons were observed. The manual was deliberately written in simple Pashto, avoiding all kind of jargon or complicated terminology. During the monitoring visits the teams discovered, that only a tiny minority of the teachers had taken the trouble to go through this manual and even those who did read it seemed to have failed to catch the message. The underlying assumption during the preparation of this manual had been that the working teachers will learn independently from such a booklet. Now we had to realise that teachers do 
not possess this capacity. They are simply incapable of acting as independent learners. They are not equipped with the necessary competencies and they have hardly read for such purposes before.

In order to illustrate further the impressions gained by the monitoring teams during their visits the following remarks highlight the best and worst aspects of the lessons observed.

(1) Positive Remarks Concerning Teachers' Performance

- "opening up" of children;

- the atmosphere of relaxation and enjoyment in the classroom;

- children really engaged in activities such as pairing, testing the weights of different objects etc.;

- pupils offering their own interpretations of pictures or stories (referring io situation pictures);

- pupils were treated as learners in a meaningful way.

(2) Negative Remarks Concerning Teachers' Performance

- teachers falling back on old methods;

- allowing pupils to answer in chorus;

- following lesson plans mechanically rather than creatively;

- consulting the lesson plan too often, even at the cost of interrupting activities;

- not accepting cues from children;

- goading pupils to come out with the only one right answer expected by the teacher;

- sticking to the form of the lesson plan and ignoring its spirit; 
teachers aiming at uniformity rather than promoting diversity;

pupils were not allowed to express their own views and fantasies.

After the 70 monitoring visits in the project's 24 pilot schools we were in a position to identify the following categories of teachers who took part in the teaching exercise:

$(A)=$ These are teachers who proved to be just incompetent. Their prospects for any professional development are dim, since they lack even the basic competencies for communi= cation (reading, writing, arithmetic). There were only 3 teachers in this category, and they should not be allowed to work in primary schools.

$(B)=$ This group comprises teachers, who were found to be indifferent and without any motivation. They reluctantly participated in the exercise and were not keen on being exposed to inservice courses. Six teachers fall into this category.

(C) $=15$ teachers $(=63 \%)$ were identified as basically cooperative and interested. It is this group where further efforts may pay of and changes in classroom-teaching become possible.

The development and dissemination of teaching/learning materials combined with some kind of lesson preparation and in-service training for primary school 
teachers will only in exceptional cases result in improvements in the pupils' learning. It seems to be a right step into the direction of introducing more activity-oriented methods into the schools. However, one has to consider seriously the problems prevailing in pakistani and Afghan Refugee schools, as stated in this report. Furthermore, certain measures for improving the teachers skills do not seem to work. For example, hand-outs, written instructions, teachers' guides, etc. are seldom read and used, since teachers lack the habit of independent learning.

It seems that some kind of permanent coaching in the actual classroom situation with interested and motivated teachers (category $C$ ) may produce better results and could help teachers to understand WHY and HOW to apply new teaching methods and materials.

3.4 Pupils' Reactions

The general impression throughout the school visits was that the pupils enjoyed the new kind of learning tremendously. Dull, absent-minded faces turned bright and became interested when the children were getting actively involved. To quote from the monitoring teams' diary, "children's faces were beaming with joy, and they were beginning to feel about the school as a place which does afford much pleasure and satisfaction. For the kids learning was playing and playing was learning, and they seemed to like such a situation"........children were opening up and were visibly in better command 
of articulation. Seeing the children behave that way is an experience difficult to forget".

Table 3 confirms these observations. Nearly all the lessons were very positively assessed since the children showed great interest in the new teaching approach. The overwhelming majority of the pupils were attracted by the different way of teaching and enjoyed the lessons thoroughly.

Table 3 Reaction of Pupils Towards New Teaching Approach

\begin{tabular}{|c|c|c|c|}
\hline & $\begin{array}{c}\text { Largely } \\
\frac{\circ}{6}\end{array}$ & $\begin{array}{c}\text { To some } \\
\text { extent } \\
\frac{\%}{6}\end{array}$ & $\begin{array}{l}\text { Not } \\
\text { sufficiently } \\
\qquad \frac{\circ}{6}\end{array}$ \\
\hline $\begin{array}{l}\text { 1. Did pupils enjoy } \\
\text { the lesson? } \\
\text { 2. Were pupils involved } \\
\text { in group activities? } \\
\text { 3. Did pupils show } \\
\text { interest in the } \\
\text { lesson? }\end{array}$ & 76 & $\begin{array}{l}24 \\
89\end{array}$ & - \\
\hline
\end{tabular}

Not surprisingly the teachers did not find it easy to arrange group activities during these lessons. Much more has to be done in this field before such educational activities become part and parcel of classroom instruction in the project's pilot schools.

Nevertheless, the activity-oriented teaching methods combined with stimulating materials resulted in a kind of creativity on behalf of the pupils that seemed to be new to teachers and educationists. 

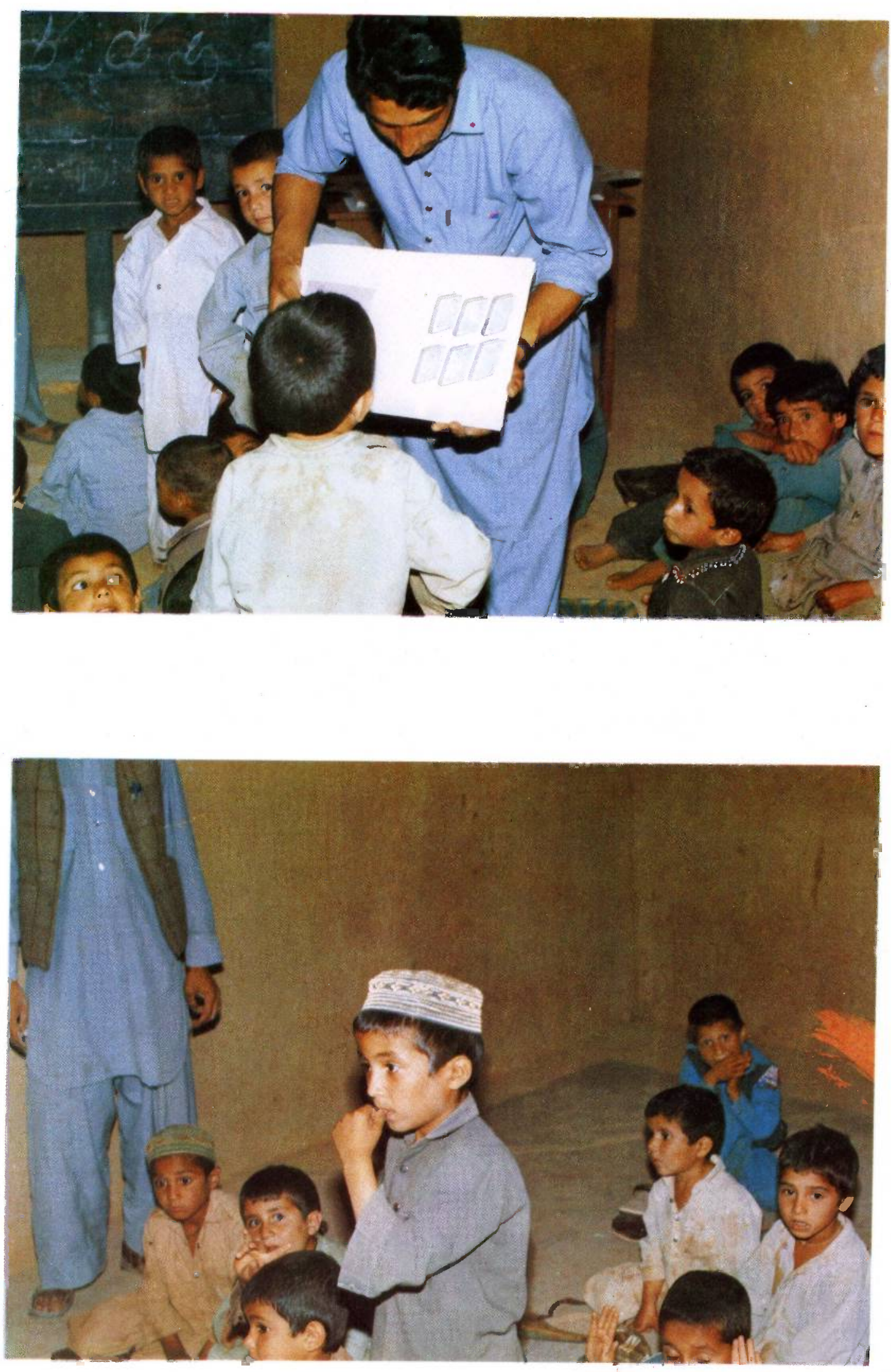
If encouraged, children quickly picked up the clues and applied it in other fields or gave frankly their 으므 interpretation of e.g. the situation pictures.

The pupils enjoyed the lessons very much. However the teachers complained about the time and energy this kind of teaching demanded, and many admitted having problems since they were used to a more passive role. Others, however, remarked that the new way of teaching and learning was also a great source of professional satisfaction. For the success of the "experiment" they demanded less classes to work with and less children in each class.

3.5 Entry Behaviour of Pupils

One thing that can be stated with certainty is that the teachers in primary schools have hardly any idea of the capacities and abilities of the children when they start coming to school. Children are seen by the teachers as "little adults" possessing all the competencies being available with an adult but differing only in degrees. If a child for example answers a question correctly it is thought, that it has also understood the concepts behind. Thus, parroting is easily mistaken for an indication of understanding something.

The assumptions regarding the entry behaviour of children at the age of $5+$ as were made in the Development Approach to the Acquisition of the Pashto Language (DAAPL) were more or less confirmed by 
their behaviour during this monitoring exercise. It was assumed that children would possess only poor oral competency, limited vocabulary, lack of confidence while speaking, and the inability to organise their thinking or to express their feelings and perceptions in a wider range of words. Thus DAAPL was reasonably based on the objective conditions prevailing amongst children when they enter primary school.

In Mathematics the design for a more active involvement of the children in class $I$ was based on the assumptions that children of $5+$ had only an insufficient mastery of pre-number concepts and were not able to deal with numbers properly. Both assumptions proved not to be valid. The children appeared to have near-mastery of pre-number concepts and half-mastery of the number concepts (1-9) when expressed not in abstract symbolism but as characterisation of concrete objects. Thus "5" as such may be confusing for the child, but five books is something of which he has a fair grasp. If one book is taken away then they are reduced to four books and if one is added to the lot then it turns them into six books. Thus, these assumptions need some revision for future material development.

It may be clearly mentioned at this stage that these perceptions of the entry behaviour of the pupils are judgements derived from observations of the pupils' behaviour in a limited number of schools, not being a representative sample. Each lesson plan involved some tasks for children to undertake, and the ease or difficulty that the children faced in carrying out those tasks revealed the status of their entry behaviour. It is 

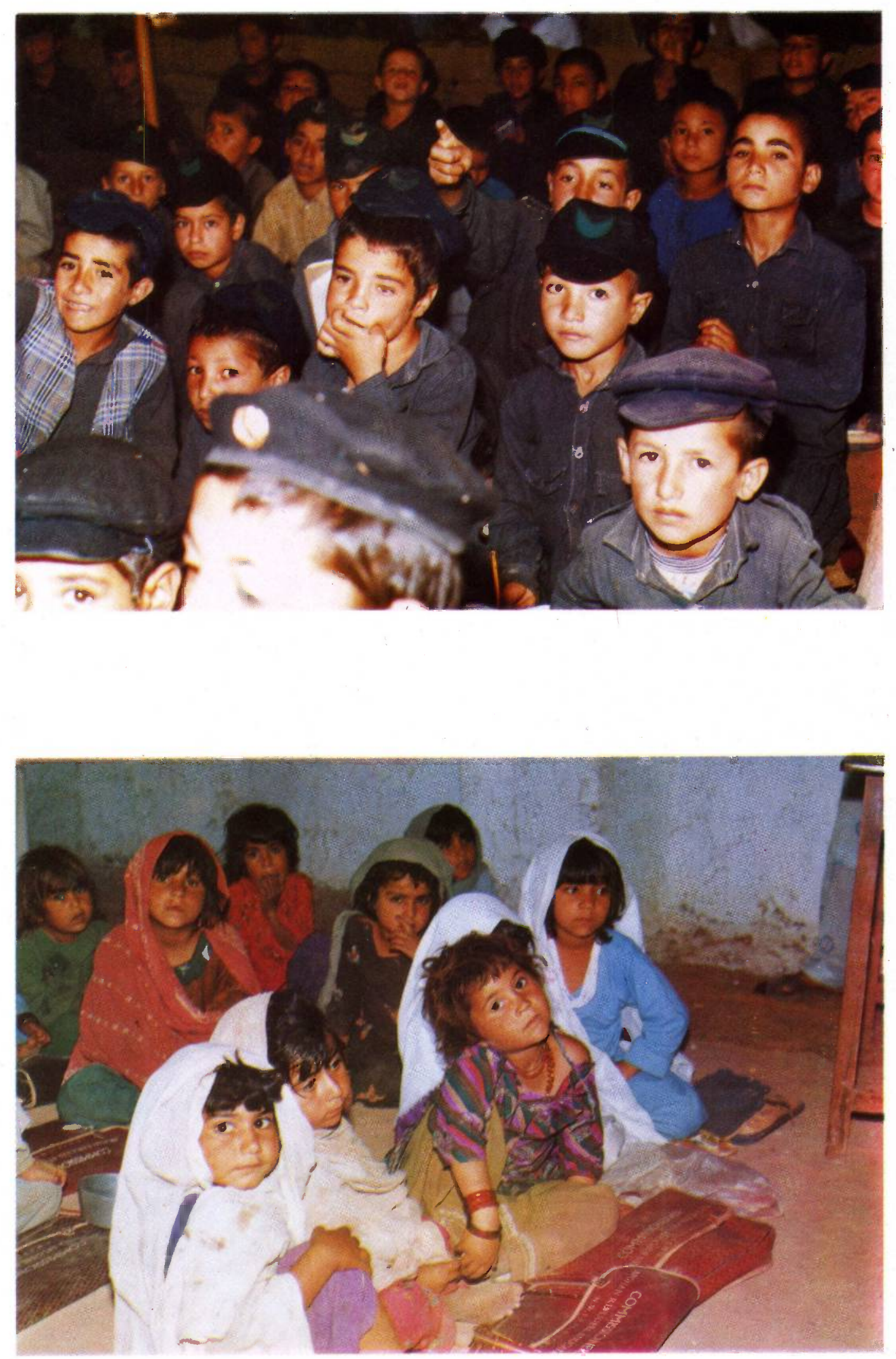
an inference that may be fairly valid. However, it is no substitute for actual research and experimentation in the very necessary area of the cognitive development of Pakistani and Afghan children. Without the results of such research available to those who are called upon to design new teaching/learning strategies, the experiences gained from the pilot schools can only be taken as useful hypotheses. Pragmatism dictates that certain assumptions be made and they be tentatively held valid unless rejected by fieldobservations. PAK-GERMAN BAS-ED has been consistently adopting such a strategy and has been proved fairly productive in prattice.

3.6 Spread Effects in the Pilot Schools

Some kinds of spread effects were evident in nearly all pilot schools, surprisingly enough even in some of those schools where the working teachers did not perform well. In two schools (one Pakistani and one Afghani primary school) other teachers had volunteered also to give lessons to grade I pupils, following the new approach. They themselves had watched the working teacher delivering lessons, had studied the lesson plans and materials, and had had discussions with those teachers who had participated in the seminar preparing them for the model lessons.

In another case two teachers shared the teaching load. One concentrated on Pashto, the other on Mathematics, according to their own interest and preferences. Sometimes the monitoring teams had 
to shift the assignments to other teachers (and thus causing spread effects), because the working teacher, who had first received all the instructions, felt sick or proved to be completely unwilling or incompetent. Such instances, however, were very rare. In one primary school the headmaster seriously desired the project to develop a similar approach for the teaching of Islamiyat. Many pilot schools reported that teachers from neighbouring schools had approached them for having access to the newly developed teaching/learning materials. 

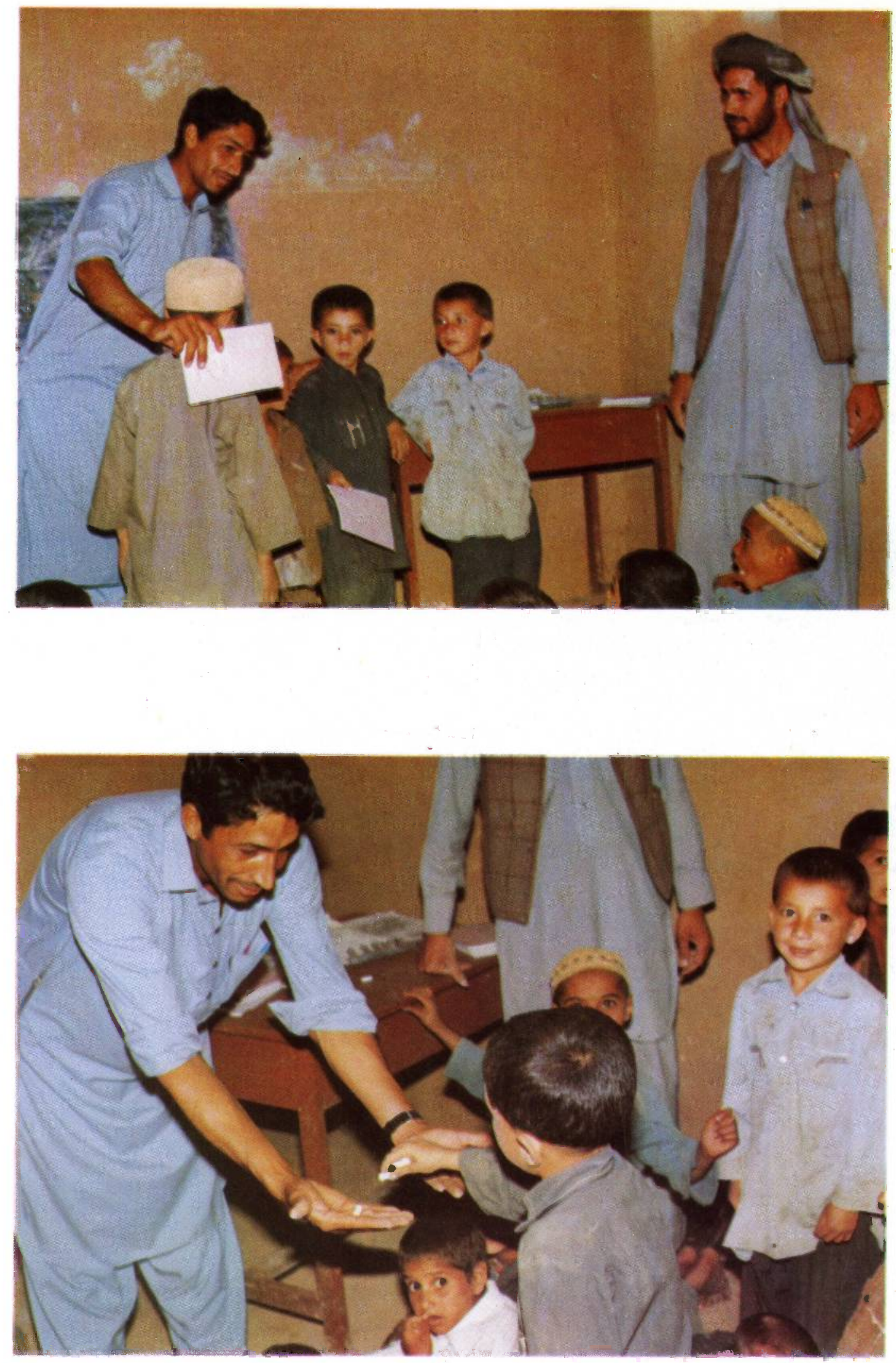
A Chit-Chat on the way Back

2nd Round Visit $7-5-86$

Monitoring teams $A$ and $C$ are on their way back to Peshawar after observing lessons in Kohat district. The following discussion develops in the car:

PH: "Well Mrs. B., how was the teacher of your last school doing?"

MB: "Well, my feelings are mixed. There are definitely some improvements, but it seems still to be a long way before real changes inside the schools will take place."

AR: "How many lesson plans has the teacher completed so far?"

MB: "She has completed six lesson plans, each in Pashto and Mathematics. She is very much on schedule."

PH: "What do you think, has she read those lesson plans carefully?"

MB: "She appears to have read those lesson plans, however, I have my doubts if she has completely understood them."

DB: "Has she kept some records of her activities?" 
MB: "Yes, the records are there. But I am not satisfied how they are kept."

AR: "Does the headteacher support the activities of the working-teacher?"

MB: "In this case the head-teacher is also our working-teacher. But then there are many many other problems."

PH: "What do you think is the biggest problem?"

MB: "I think it's the accommodation.

There are more than $400 \mathrm{girls}$, and there are as many as 9 teachers with only four small classrooms. The compound is very small. The classes are in such close proximity to one another that outside.interference cannot be avoided."

AR: "Can't they build more classrooms?"

MB: "It is a private building on rent with the Eduoation Department, therefore the only solution would be to shift the school."

DB: "The project tries to help the schools and normally renovations are done or additional classrooms constructed. But here space is the limiting factor, and we cannot do anything about it."

PH: "Are there any positive aspects?"

MB: "The teacher is serious and she has been doing her bit to follow the lesson plans. The girls 
have been involved in group activities. They appear to be enjoying the lessons. The relation between the teacher and pupils is excellent."

DB: "So what are the problems besides the matter. of lack of classrooms?"

MB: "Well, they too are many. There are 90 girls in grade I and there are two sections. The working-teacher has been taking just one section. The other section is continuing with the old practices. This appears to me to be very unjust. I have proposed that she should teach both sections. The working-teacher, however, thinks that this would be too much for her, because teaching in the new way demands much more work on the part of the teacher - before the lesson as well as during the lesson."

AR: "Besides the problem of large numbers what other weak points did you discover?"

MB: "The teacher was constantly consulting the lesson plan. She has not yet internalized the various steps given there. Such consultation disrupts the flow of activities and adversely affects the concentration of pupils. Besides, she wasn't teaching well this time as compared to the way she performed last time."

DB: "Perhaps this was to be expected. In the initial stage concepts were easy for the teachers to handle and consequently their performances were better. Now the concepts are getting more and more complex and the teachers find it more and 
more difficult to cope with."

PH: "Well, how would you rate her performance this time Mrs. B.?"

MB: "I think, it is still in the middle. So neither a "happy face" nor a "sad" one. A "neutral face" would be alright this time. But how about your experiences?"

$\mathrm{PH}$ : "Well the girls school in $\mathrm{K}$. is doing fine. Mrs. F. seems to be a serious teacher. She is on schedule. So far she has completed six lesson plans each in Maths and Pashto. She is very confident and enjoys the best of relationship with her pupils."

MB: "Does it mean the school will be given a "happy face"?"

PH: "Not exactly. I still feel that Mrs. F. is following our lesson plans more in a mechanical way rather than in a creative manner."

DB: "What are the specific limitations?"

PH: "Firstly, not accepting cues from the children. Mrs. F. appears to be bent upon going her planned path irrespective of what happens in the class. She is rather rigid in her teaching." 
The monitoring exercise in the 24 pilot schools of PAK-GERMAN BAS-ED provided a unique chance to test and observe the practicability of the project's ideas and materials for the improvement of teaching in primary schools. The close and continued contacts with the teachers of those schools helped to develop a better understanding for their problems on behalf of the members of the monitoring teams and awoided unrealistic solutions. For the first time in their professional career many teachers actually felt that they received honest assistance from an outside institution to improve their teaching and their pupil's learning. Equally important was the fact that they themselves were given the feeling of being treated as partners, not just receivers, in the process of searching for better teaching methods and meaningful teaching-/learning materials.

Seeing the teachers so many times in action and reviewing together their lesson performances brought out another important problem that had not been foreseen in its whole dimension by the project. The majority of teachers, whether trained or untrained, possess far lower competencies contentwise and professionally than was assumed (teaching methods, elements of children's development and behaviour etc.). Furthermore they are not used to acting as independent learners, e.g. reading, understanding, and applying written texts and instructions, in particular handouts, notes, manuals. One-time exposures to new materials and methods will therefore hardly change teachers behaviour in the classroom. Introductory seminars, education days, school visits and the like can only be seen as a first step in a new direction. Only longer contacts of a "coaching type" - approach may bring desired results in the primary schools towards a more active and meaningful learning. 
For the project's future development the following recommendations may be seen as imperative:

(1) The link between concepts and concrete operations needs to be made very clear to the teachers. At tempts in this direction were made during the 2 nd information seminar for teachers, but they did not suffice. Explanations covering these aspects should be incorporated specifically into the LESSON PLANS (under column $V$ "Background Information"). The existing lesson plans ought to be revised accordingly. More details are needed to help the teachers to understand the relationship between concepts and actual steps in teaching a particular topic.

(2) Teachers also need clear and sufficient information about the entry behaviour and capabilities of children starting their primary schooling. Many wrong notions exist among the teachers, resulting in many instances in misunderstandings of children's intellectual and psycho-motor skills. Often children are overburdened in the beginning of their school career, whereas later on they get bored since intellectual challenges are not provided.

To avoid mere memorising of facts on this topic by the teachers without visible results in their teaching, we do not fancy writing up teachers handouts or manuals on children's entry behaviour. There exist already some manuals for teachers developed by different agencies covering some of the aspects discussed. However, whether read or not by teachers, they have no effects on the actual teaching practice in schools. Perhaps it would be a different thing if the entry behaviour of children is repeated more regularly in the lesson plans for grade I (under a 
separate heading or as a part of column 10 ("Previous Knowledge"), because the lesson plans aim more at practical teaching.

(3) Some of the very basic pedagogical skills, like questioning techniques, use of chalk-boards, grouping of children etc. that were found to be lacking in many schools, need also to be given due attention. Demonstration lessons containing these aspects could be recorded by V.C.R. and used for in-service instructions.

(4) Changing the primary school teachers classroom behaviour and convincing them to adopt new practices which are labour intensive and more timeconsuming is not an easy task. It has been stated throughout the findings of this report that such changes can only be achieved through regular and intensive contacts with the teachers. Some kind of Mobile Advisory Teams could be established to look after the pilot schools. Later on the project's pilot schools themselves could be used to spread the new methods and materials to the neighbouring schools.

:5) In addition, teachers are also in dire need of upgrading their knowledge base and competencies in the main subjects of Pashto and Mathematics. Another important field where action is urgently required is to get teachers interested in reading professional papers and adapting the habit of selflearning. It is perhaps the most difficult and ambitious target, but one worth tackling. 
5. A N N E X 
5.1 Teacher Training Programme

(2nd Information-seminar) 


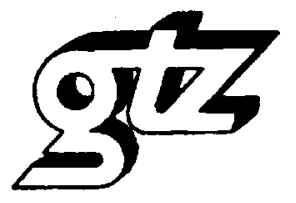

Deutsche Gesel/schaft für Technische Zusammenarbeit (GTZ) GmbH Education Department North West Frontier Province

\section{PAK - GERMAN BAS - ED}

"Basic Education

in Areas Affected by the Influx of Refugees, NWFP"

2nd INFORMATION SEMINAR FOR TEACHERS OF PAK-GERMAN BAS-ED PILOT SCHOOLS

(5th to 16 th of April 1986)

$\underline{5-4-1986}$ (Saturday)

8.00 Recitation of Holy Quran

8.15 Introduction to the Seminar ( $\mathrm{Dr}$. Bude)

8.30 Overview of Teaching Aids developed by

to PAK-GERMAN BAS-ED (Said Ahmad Mohmand)

10.15

10.30 OPENING CEREMONY (Chief Guest Mr. Rangin Shah, Education Cell)

11.00 Break

11.30 DAPL (Development Approach for Teaching of Pashto Language)-

to Suggested Change for Teaching Pashto in Primary Schools(1)

12.15 (Mian Muzafar Shah, PEP)

12.30 Video on Situation Picture used in Pashto Teaching

to (Said Ahmad Mohmand/Dr. Bude)

13.00

$\underline{6-4-1986}$ (Sunday)

8.00 Recitation

8.15 School Renovation Programme in Pilot Schools

to (Dr. Bude/Hakim Taniwal)

9.00

9.05 Primary Schools and Hygiene -

to Film Show and Discussion

10.00 (Gulfam Khan, Exec. Engineer, PHED, NWFP)

10.05 Primary Schools and Hygiene

to

11.00

11.00 Break

11.30 Suggested Change for Teaching Pashto in Primary Schools(II)

to

12.15 (Mian Muzafar Shah)

12.15 Scheme of Work for Pashto, grade 1, week $1-6$

to (Prof. Arif Nasim, Superior Science College) 


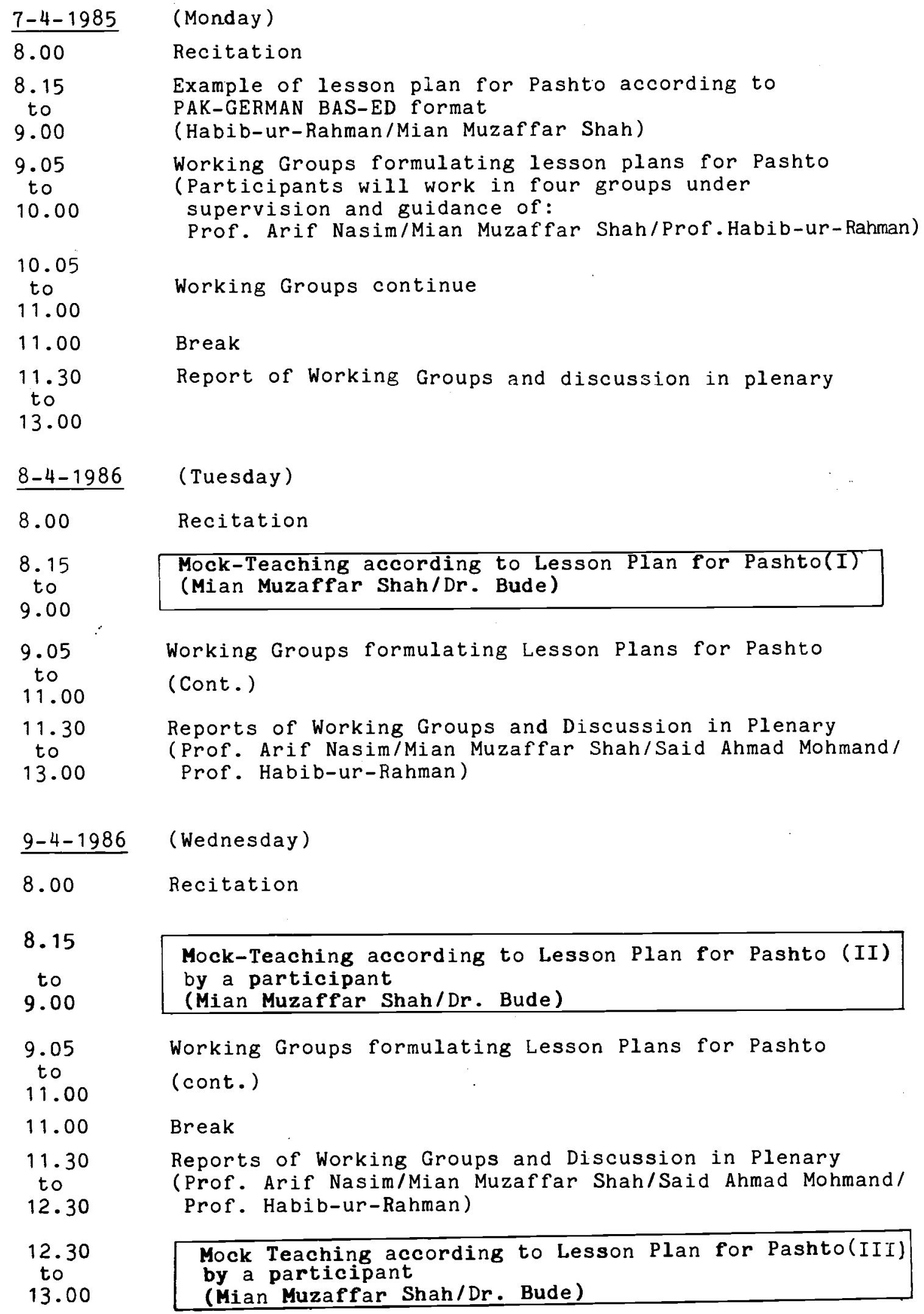




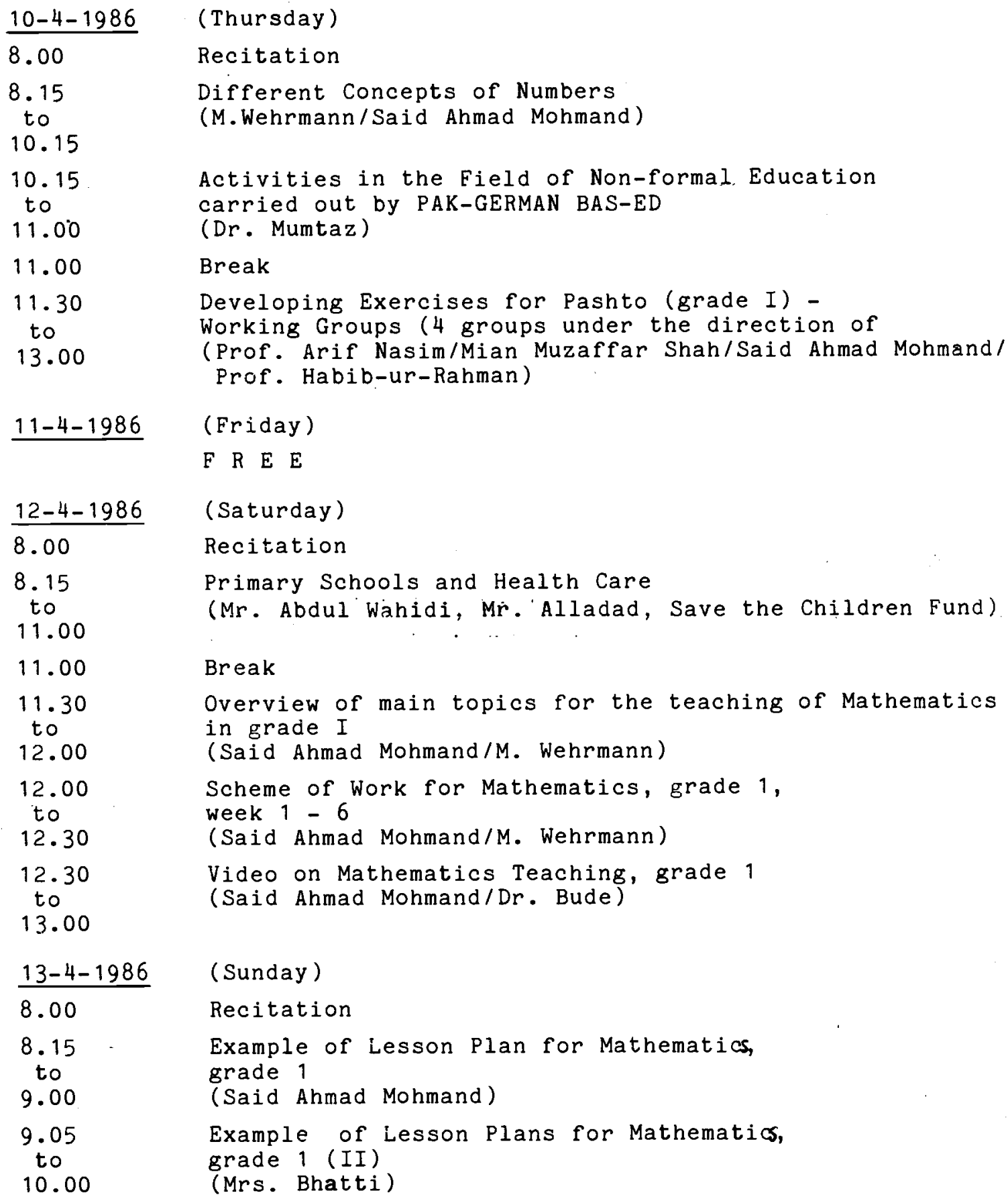

$13-4-1986$ (Sunday)

Activities in the Field of Non-formal. Education carried out by PAK-GERMAN BAS-ED

(Dr. Mumtaz)

\section{Break}

Developing Exercises for Pashto (grade I) Working Groups ( 4 groups under the direction of (Prof. Arif Nasim/Mian Muzaffar Shah/Said Ahmad Mohmand/ Prof. Habib-ur-Rahman)

(Mr. Abdul Wahidi, Mr. Alladad, Save the Children Fund)

Break

Overview of main topics for the teaching of Mathematics in grade $I$

(Said Ahmad Mohmand/M. Wehrmann)

Scheme of Work for Mathematics, grade 1, week 1 - 6

(Said Ahmad Mohmand/M. Wehrmann)

Video on Mathematics Teaching, grade 1

(Said Ahmad Mohmand/Dr. Bude)

Recitation

Example of Lesson Plan for Mathematics, grade 1

(Said Ahmad Mohmand)

Example of Lesson Plans for Mathematics, grade 1 (II)

(Mrs. Bhatti)

Mock-Teaching according to Lesson Plan for Mathematics (II)

(Said Ahmad Mohmand)

Break

Example of Lesson Plan grade 1 (III)

(Mrs. Bhatti)

Mock-Teaching according to Lesson Plan for Mathematics(IID) (Mr. Bhatti) 


\begin{tabular}{|c|c|}
\hline $14-4-1986$ & (Monday) \\
\hline $8: 00$ & Recitation \\
\hline $\begin{array}{l}8.15 \\
\text { to } \\
9.00\end{array}$ & $\begin{array}{l}\text { Examples of Lesson Plans for Mathematics } \\
\text { grade I, (IV \& V) } \\
\text { (Said Ahmad Mohmand) }\end{array}$ \\
\hline $\begin{array}{l}9.05 \\
\text { to } \\
10.00\end{array}$ & $\begin{array}{l}\text { Examples of Lesson Plans for Mathematios, } \\
\text { grade I (VI \& VII) } \\
\text { (Mrs. Bhatti) }\end{array}$ \\
\hline $\begin{array}{l}10.05 \\
\text { to } \\
11.00\end{array}$ & $\begin{array}{l}\text { Mock-Teaching according to Lesson Plan for } \\
\text { Mathematics }(v) \text { by a participant } \\
\text { (Mrs. Bhatti/M. Wehrmann/Dr. Bude) }\end{array}$ \\
\hline 11.00 & Break \\
\hline $\begin{array}{l}11 \cdot 30 \\
\text { to } \\
12.30\end{array}$ & $\begin{array}{l}\text { Examples of Lesson Plans for Mathematics, } \\
\text { grade I (VIII \& IX) } \\
\text { (Said Ahmad Mohmand) }\end{array}$ \\
\hline $\begin{array}{l}12.30 \\
\text { to } \\
13.15\end{array}$ & $\begin{array}{l}\text { Programmes for Non-formal Education } \\
\text { under Preparation } \\
\text { (Dr. Mumtaz/M Wehrmann) }\end{array}$ \\
\hline $15-4-1986$ & (Tuesday) \\
\hline $\begin{array}{l}8.00 \\
8.15 \\
\text { to } \\
10.00\end{array}$ & $\begin{array}{l}\text { Recitation } \\
\text { Examples of Lesson Plans for Mathematics, } \\
\text { grade I (X, XI \& XIII) } \\
\text { (Mrs. Bhatti) }\end{array}$ \\
\hline $\begin{array}{l}10.15 \\
\text { to } \\
11.00\end{array}$ & $\begin{array}{l}\text { Mock-Teaching according to Lesson Plan } \\
\text { for Mathematics (X) by a participant } \\
\text { (Mrs. Bhatti, M. Wehrmann/Dr. Bude) }\end{array}$ \\
\hline 11.00 & Break \\
\hline $\begin{array}{l}11.30 \\
\text { to } \\
13.00\end{array}$ & $\begin{array}{l}\text { Further Exercises for Mathematics, grade I } \\
\text { and Visual Aids for Mathematics Teaching } \\
\text { (M. Wehrmann/Said Ahmad Mohmand) }\end{array}$ \\
\hline 16.4 .1986 & (Wednesday) \\
\hline 8.00 & Recitation \\
\hline $\begin{array}{l}8.15 \\
\text { to } \\
9.00\end{array}$ & $\begin{array}{l}\text { Reference Books for Pilot Schools and their Proper } \\
\text { Usage } \\
\text { (Said Ahmad Mohmand/M. Wehrmann) }\end{array}$ \\
\hline $\begin{array}{l}9.05 \\
\text { to } \\
10.00\end{array}$ & $\begin{array}{l}\text { Preparing Trials in Schools } \\
\text { (Dr. U. Bude/Prof. Habib-ur-Rahman/Mrs. Bhatti/ } \\
\text { Said Ahmad Mohmand) }\end{array}$ \\
\hline 10.30 & $\begin{array}{l}\text { CLOSING SESSION } \\
\text { (CHIEF GUEST MR. BARRY RIGBY, } \\
\text { HEAD OF U H C R, SUB-OFFICE, P E S A W A R) }\end{array}$ \\
\hline
\end{tabular}


5. 2 Lesson Plans

(Examples) 
5.2.1 Lesson Plan Mathematics

1. Grade: I 2. Subject: Mathematics 3. Lesson Plan No.: 1

4. Topic: Matching equal quantities

5. Background Information: Children of 5 +years of age might know the names of numbers, but they have no precise understanding of "number valves, and no concept of "is squal to" or "has as many as", because they don't know' how to compare quantities. Looking at 5 big pebbles and 5 small pebbles they will say that there are more big pebbles.

Finding out if 2 quantities are equal or not, is an important step towards the understanding of numbers. If pupils have the skill of comparing quantities, they will find out that e.g. the quantity 5 always remains the same, if there are 5 elephants or 5 matches or 5 pupils.

6. Type of Lesson: Introduction Lesson

7. Operational Objectives:

- The pupils must be able to match two groups of objects without counting.

- The pupils must be able to recognize, when 2 groups of objects have equal quantities.

- The pupils must use the terms "is equal to" or "as many as" appropriately.

8. Learning/Teaching Material:

Before coming to school, pupils were only used to deal with concrete objects in real situations. Therefore the teacher must start with concrete objects first, before he can use pictures or simplified dravings. Suggested matarials: pupils, slates, pebbles.

9. Blackboard work:

10. Previous knowledge:
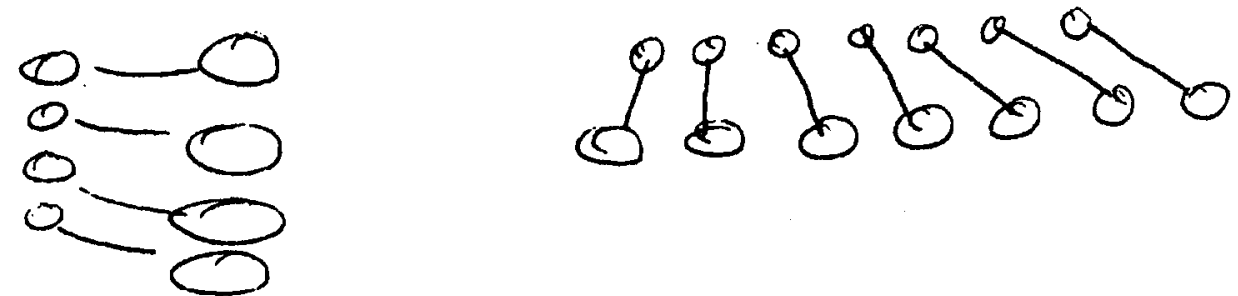

Since this is the first lesson, no particular knowledge related to mathematics is required. Pupils must de able to listen and to speak.

11. Action Plan: See page 2

12. Evaluation: Teacher draw's 5 big and 5 small pebbles on the blackboard and asks pupils to match these quantities, by drawing lines.

13. Follorirup activities: since pupils are neither used to school and classroo:l teaching, nor to do independent works. No independent follow-up activities can be requested. But try (for the better pupils): let them $f$ ind objects, which have even quantities: legs of chairs, tables, wheels of tongas, rickshaws etc.

Note: For the use of the teachers lesson plans were provided in Pashto Language. 


\begin{tabular}{l|} 
Action Plan \\
\hline Teacher
\end{tabular}

Introduction: T. asks P. for objects which all of them have got.

T. asks P. for activities they can perform. (Activities which not everybody can perform).
Lesson Plan No. 1

Pupils
P. say and show: slates, books, caps, noses, heads, feet.

(Some) pupils show: standing on one leg. Jumping on one leg. Sing a song.
Step 1: T. calls 6 pupils to come to the blackboard. T. takes their slates ( 6 slates).

T. puts the slates in front of the pupils. Asks: Are there more children or more slates?

T. says: Every P. has got a slate. There are ás many slates as pupils.

Step 2: T. calls 5 other pupils with slates. Asks: Are there more slates or more P.

Step 3: T. calls 7 pupils with caps.

Step 4: T. puts 5 big pebbles opposite 5 small pebbles.

Asks: Are there more small pebbles or more big pebbles?

Step 5: T. draws 7 big pebbles opposite 7 small pebbles. Connects one big pebble with one small pebble.

T. says: compare the two rows..

Step 6: T. draws two rows with $4 \mathrm{big}$ and 4 small pebbles on the bb.

T. checks pupils individually.
P. stand in one line.

P. stand in one line opposite the line of slates.

P. answer and explain how they found out.

P. put their clates in front of them.

P. state: There are as many slates

as pupils.

P. put their caps in front of them.

P. state: There are as many caps as pupils.

P. form pairs of pebbles, by putting one small pebble on one big pebble. State: There are as many big pebbles as small pebbles (or vice versa).

P. connect other "pairs" of one big and one small pebble, until 7 pairs are formed.

P. state: There are as many small pebbles as big pebbles.

P. copy the 2 rows of pebbles on their slates, connecting one small with one big pebble, forming 4 pairs.

P. correct their slates when necessary.

Conclusion:

T. states: We have compared several times two quantities of objects. In all cases there were as many objects in one quantity as in the other. (As many slates as pupils, as many big pebbles as small pebbles.) 
5.2.1 Lesson Plan Mathematics

1. Grade:

2. Subject: Mathematics

4. Topic: Concept of heavy and light.

3. Lesson Plan: No.6

5. Background Information: Children of this age don't have a defined concept of weight. They mainly assume that larger or bigger things are automatically heavier. If there is a balance at hand it is easy to show the children that the side of the balance going down carries the heavier thing.

Even without a balance we can find some criterias to recognize something as heavy or light:

- Things children can easily lift are light.

Things children can hardly lift or not lift are heavy

- Things, the child (or the wind) can blow are light, things the child cannot blow away, are heavy.

- Things I can throw against the wind are heavy, enough things I cannot throw against the wind, are too light.

For this lesson we should bring some objects to the school with well distinguished weight. Some things should be large and light, others small and heavy, (Definitely needed: feather, pebble, matchboxes, tins; if possible: a balance)

\section{Type of lesson: Introductory lesson}

7. Operational Objectives: At the end of the lesson the children should be able

- to recognize that the weight is not depending on the size.

- to know that only very light things can be blown away.

- state that a balance shows us exactly what is heavier or lighter.

- to know that containers filled with sand, stones or water are heavier than empty ones.

- to apply the words heavy and light correctly.

8. Teaching/Learning Aids:

A balance (if is easy to build),

a sheet of paper, a book, a ball, a balloon, feathers of birds, leaves, pebbles, brick.

\section{Blackbeard work:}
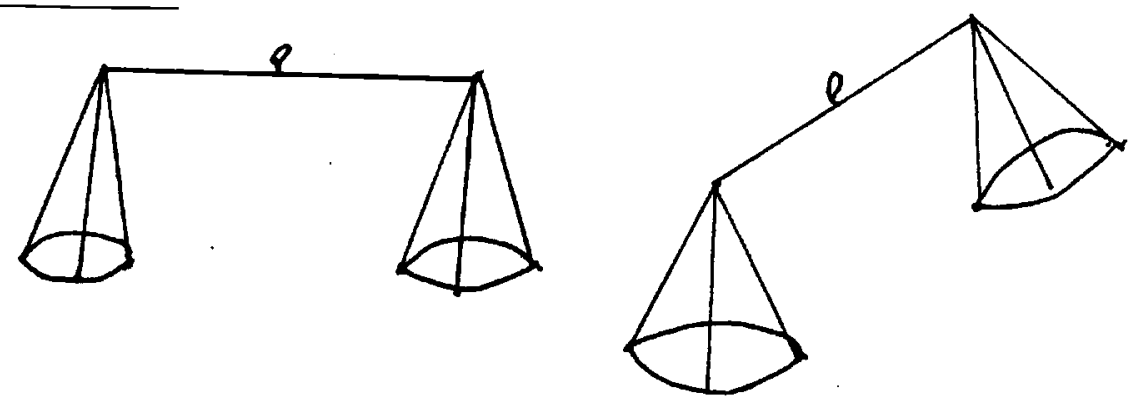

10. Previous Knowledge: The pupils have learnt various pre-number concepts, but none of them is really essential as a préequisite for this lesson. For practicing it is still useful to refer to the pre-number concepts already introduced.

11. Action Plan: See page 2

$12 \frac{1}{2}$ Evaluation: See "conclusion" of Action Plan. Teacher draws two balances, one with pans on the same level, one with pans on different levels. Pupils name objects, which would be correct on the lower pan and on the higher pan. T. and pupils talk about things which have the same weight. Without a real balance this could not be found out precisely.

$\because$ 13. Follow-up Activities: Pupils look at home for heavy and light things. In the next lesson they will talk about these things. 


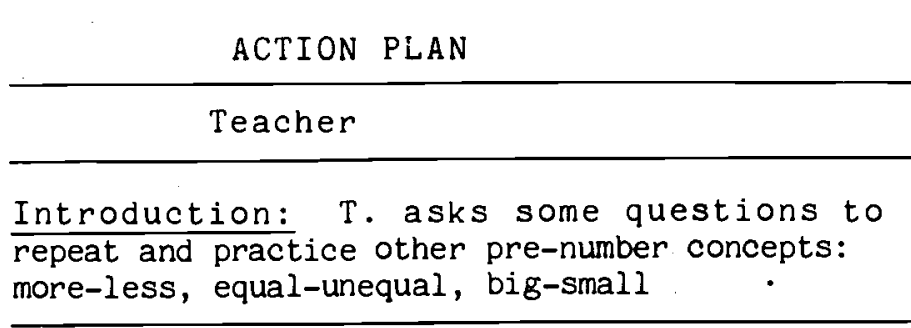

Step 1: T. shows a small book and a larger sheet of paper. "What do you see"?

Do you. see differences between the two ?

Any other difference? Teacher holds book on one flat hand, sheet on the other flat hand, moves both hands

Step 2: T. shows a kite and a book. Which of these two things you can blow away?

Correct: the kite is light, the book is heavy.

Step 3: T. shows a football and a balloon(or any other two things with similar size but different weight ).

Which is bigger, smaller?

Which is heavier, lighter ?

Step 4: T. puts two tins of same size on the table, both covered, but one filled with sand and one empty. Which is heavier?

How do you find out?

Why could one be heavier?

Step 5: T. puts on the table: two matchboxes, two tea packages; one of each empty, one of each filled. How can we find what is heavy and what is light?

$T$. takes a balance and puts the two matchboes on the two pans.

One pan goes down, one up: Why?

(If no scale is available,

Pupils can blow the match boxes, and a balance can be drawn on the blackboard).

Step 6: T. puts different things on the balance: brick-pebble, ball-balloon, state-pencil, bookpaper, ball-pebble of same size.

Conclusion: T. draws two balances, without anv objects one balance with pans on same level $(\rightarrow-)$ one balance with pans on different levels
Lesson Plan No.6

Pupils

P.answer the questions correctly.

P. name book and sheet.

The book is small, the sheet of paper is large.

Some pupils try the same; state: It is difficult to balance the sheet. It is very light.

P. The wind can blow the kite, the book cannot be blown away.

P. repeat: the kite is light, the book is heavy.

P. answer correctly

P. anser: We can blow the balloon but not a football, not a tennis ball. The ball is heavy, the balloon is light.

P. came, lift the tins and say: this tin is heavy, this tin is light.

P. state: one tin is easy, the other one difficult to lift.

P.: There must be something inside. Empty tins are light, filled tins are heavy.

P. We need a scale.

P.: One box is heavy, one is light.

P. state: this pan goes down, because.... is heavy. This pan goes up because..... is light. P. name objects, which could be on the pans

They draw one example, showing one heavy and one light object on the pans. 


\subsubsection{Lesson Plan Mathematics}

1. Grade: 1

2. Subject: Mathematics

3. Lesson Plan: No. 10

4. Topic: "More than", "less than" with numbers 1-5.

(respectively: "larger than" and "smaller than")

5. Background Information:

The pupils know "more than" and "less than" as pre-number concept, applying the method of forming one-to-one relations between two groups of objects.

In the meantime they have learnt the numbers 1-5, but they did not operate with the numbers yet. In this lesson they will start to work, to operate with numbers. The easiest operation is to compare numbers. When comparing quantities we can say "more than" and "less than", when comparing numbers we better say "greater than" and "smaller than".

6. Type of Lesson: Introduction Lesson

7. Eperational Objectives: At the end of the lesson the pupils will be able

- to compare two quantities, finding out which is more and which is less,

- to use numbers when sta ting "more" or "less" (e.g. 3 books are more than 1 book)

- to use the terms "more than", "less than", when comparing quantities, and to use

the terms "greater than" and "smaller than" when comparing numbers.

- to use an arrow to show "is more than". When comparing quantities we can say

"more than" and "less than". When comparing numbers we better say "greater than" and "smaller than".

- to find out and mark, which of two quantities (or numbers) is "more than" (or "greater than").

8. Learning/Teaching Material: Objects, which could be easily brought into the classroom, like pebbles, pencils, matchboxes; blackboard and chalk; number cards, number picture cards.

9. Blackboard Work:
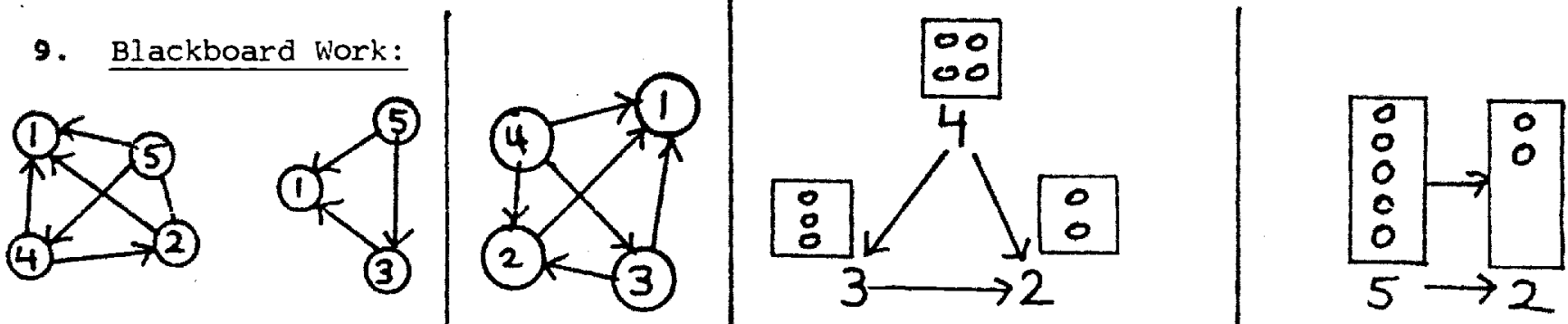

10. Previous knowledge: Pupils know the pre-number concepts, e.g. "equal", "unequal", "more than", "less than". They know the numbers $1-5$ and the numerals $1-5$. They have not yet operated with these figures.

11. Action Plan: See page 2

12. Evaluation: T. shows number cards, pupils state " 3 is greater than 2 " or

" 3 books are more than 1 book".

Several examples.

T. draws circles on the blackboard (3-5 circles). Pupils fill in number and connect the circles with arrows, meaning "is greater than". 
Action Plan

Teacher

Introduction: T.shows four fingers of one hand and two fingers of the other hand. "Which hand shows more fingers"?

Which shows less fingers?

Step 1: T. draws five circles in one box and two circles in another box. Asks: "Where are more circles?"

Step 2: T. draws an arrow from the box with more circles to the box with less circles.

This means "is more than".

T. asks P. to write the correct number under each box.

T. then draws an arrow from the greater number

, the smaller number.

Step 3: T. draw's 3 boxes with 4,3 and 2 circles on the $b b$.

- asks pupils to write the correct numbers under he box.

T. asks pupils to draw arrows from boxes with more circles to boxes with less circles.

Step 4: T. asks four pupils to come to the bb. and put $1,2,3$ and 4 fingers on the $b b$, in different places.

Step 5: T. asks to write the correct numbers into the empty circles (see bb. work).

$r$. draws five circles on the bb.
Lesson Plan No. 10

Pupils
P. point at the hand with four fingers.

P. point at the hand with two fingers, saying "This hand shows less fingers than the other."

P. give the correct answer.

They show that they find the result by forming one-to-one relations (with their fingers, not with ink or chalk).

P. copy the boxes with the arrow on their slates/in their exercise books.

P. do so in their exercise books.

P. copy in their exercise books.

P. copy in their exercise books.

P. do so on the bb. and in their exercise book.

P. do so.

P. draw arrows from hands showing more fingers to hands showing less fingers.

P. draw circles around their hands and take their hands off.

P. do so.

P. fill in numbers from 1-5.

P. draw correct arrows.

\section{Conclusion:}

T. does exercises as described in "12. Evaluation"

$T$. shows two number cards at a time, e.g. 2,5 .

Several examples.

T. draws circles on the bb. (3-5 circles).
P. state "5 is greater than 2" and " 5 books are more than 2 books". $P$. fill in number and connect circles with arrows, meaning "is greater than". 
115

5.2.2 Lesson Plan Pashto: Cat story

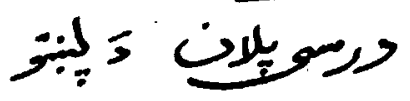

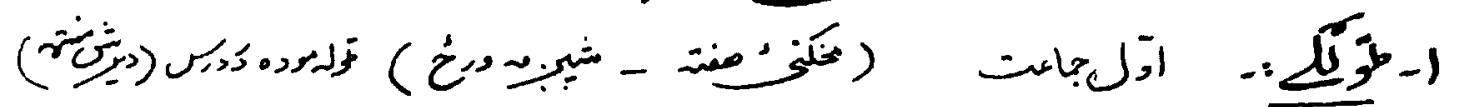

r

-

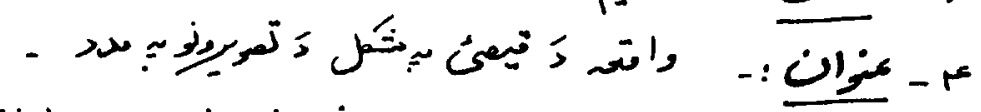

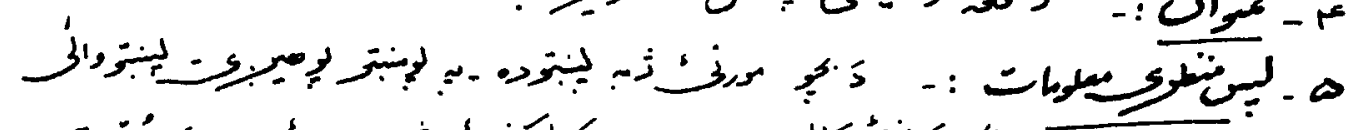

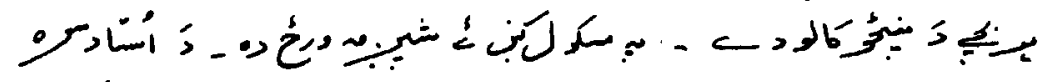

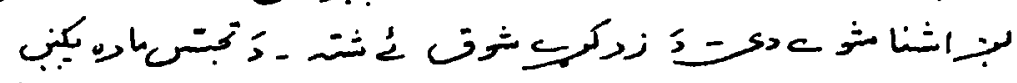

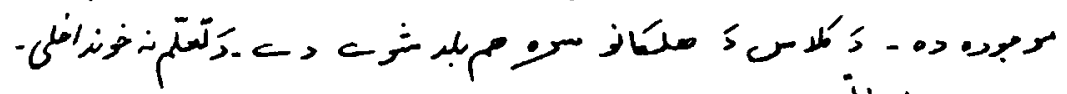
-

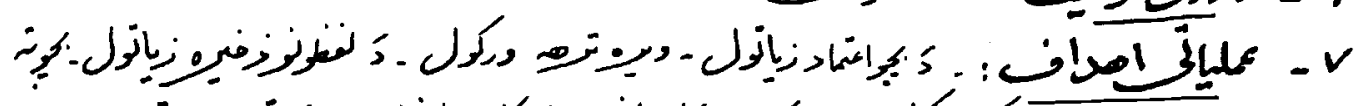

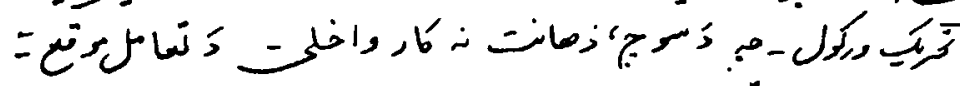

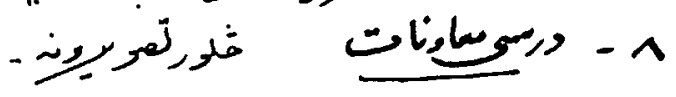

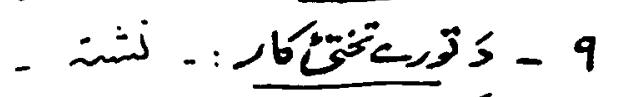

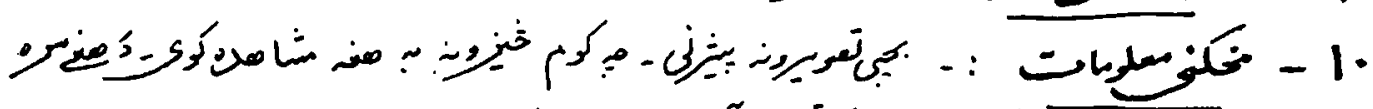

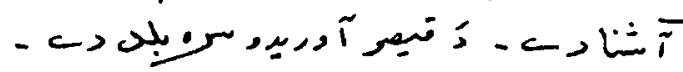

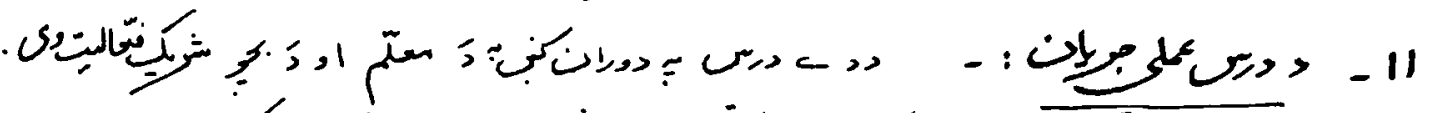

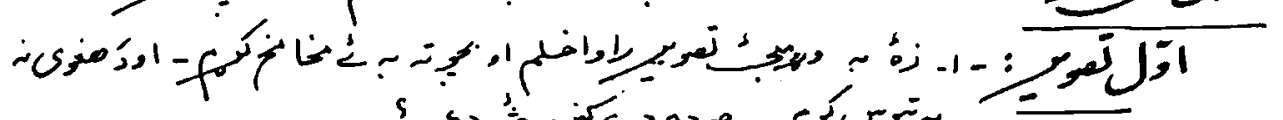

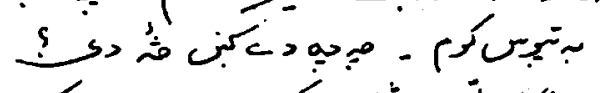

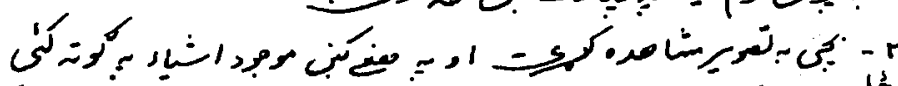

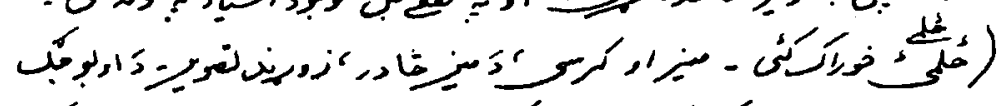

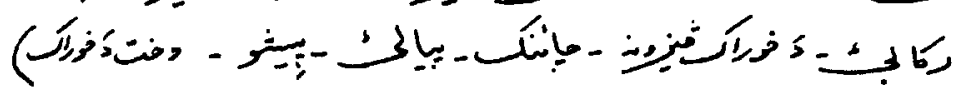

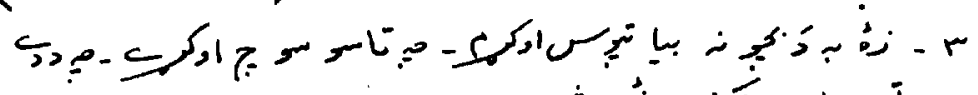

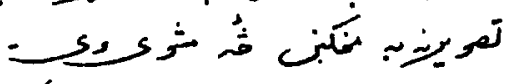

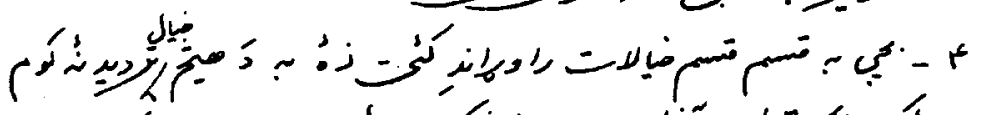

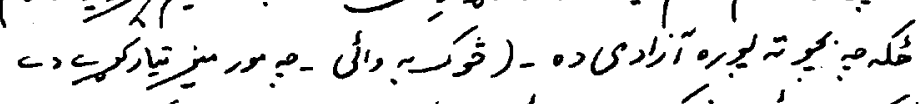

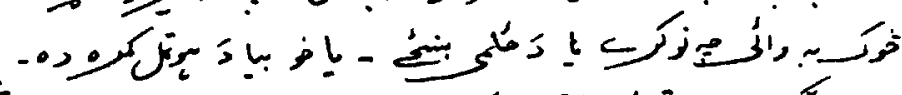

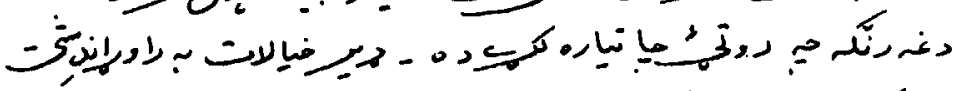

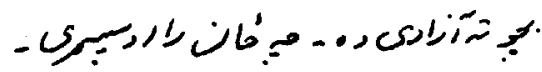

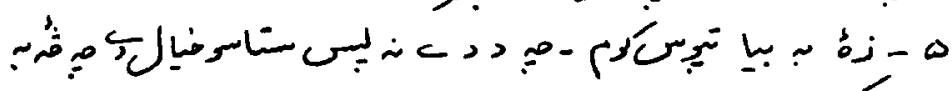

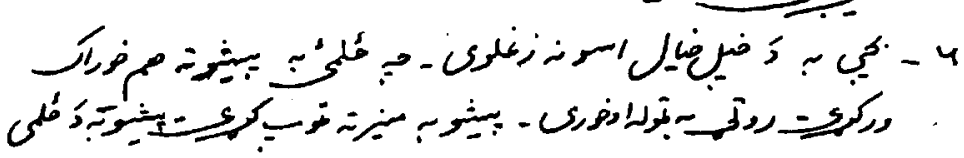


116

(1)

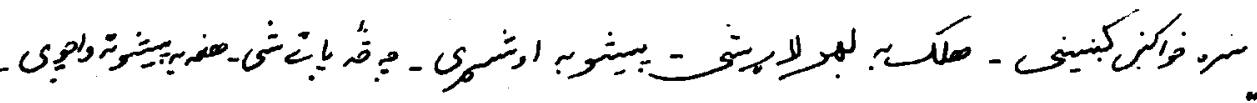

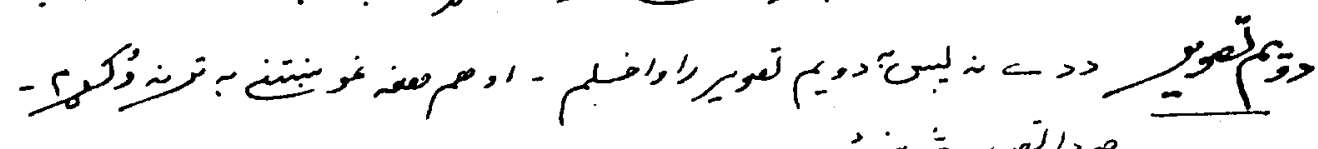

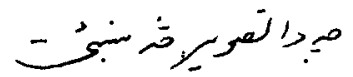

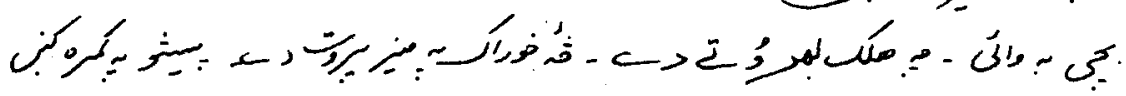

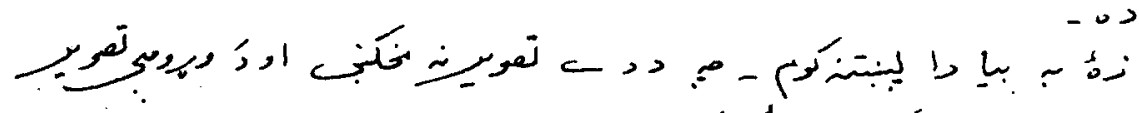

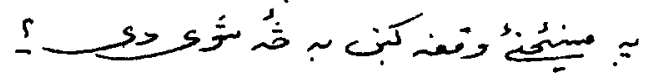

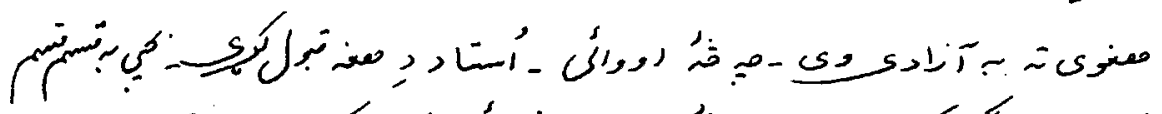

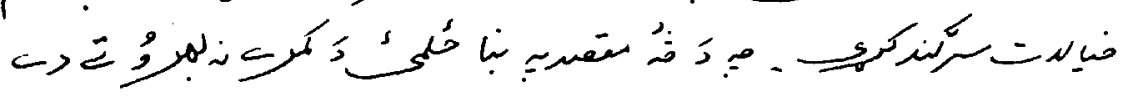

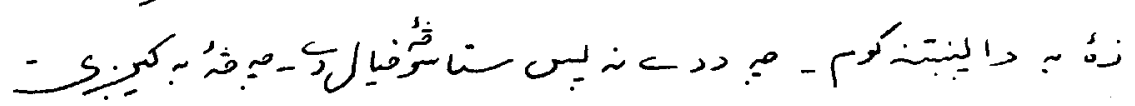

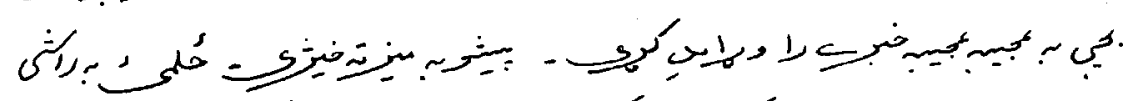

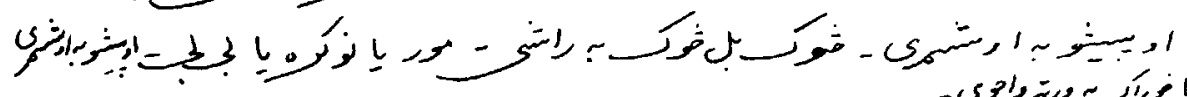

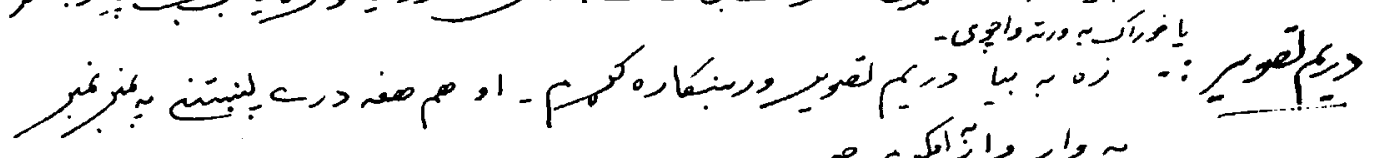

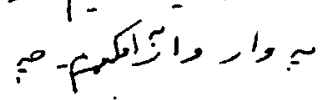

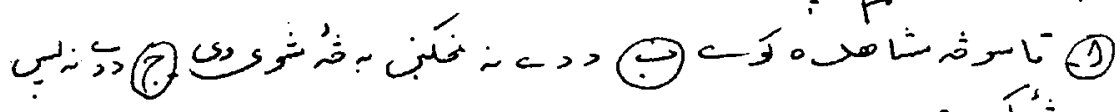

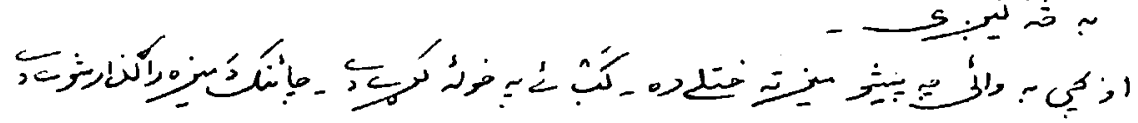

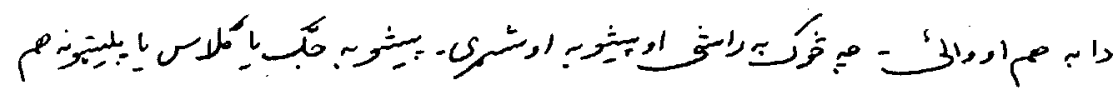

$$
-\mathrm{s}-\mathrm{s}
$$

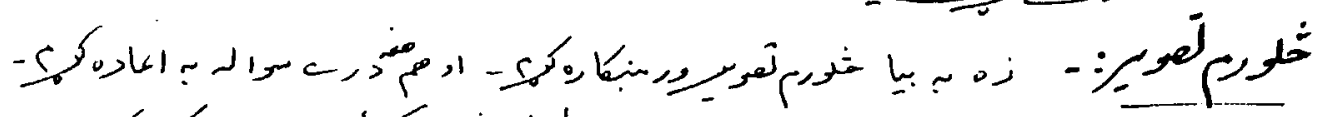

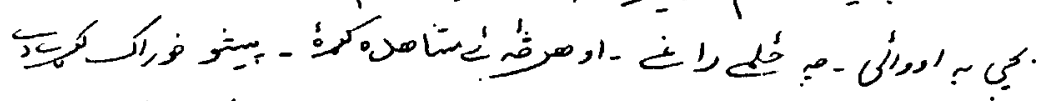

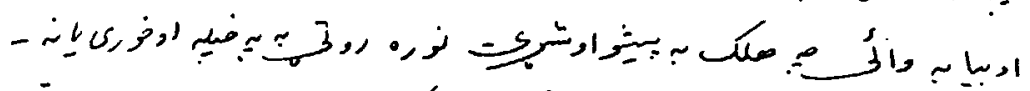

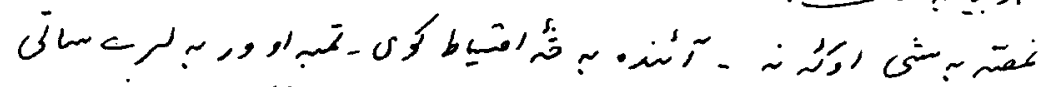

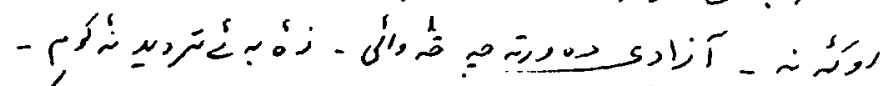

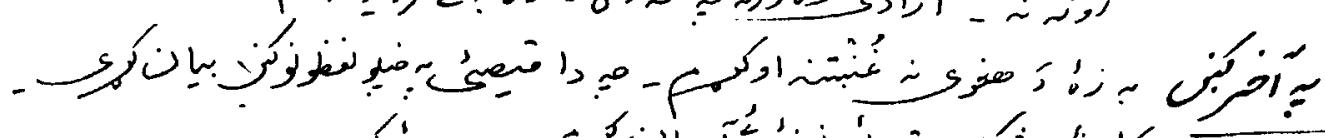
كُ

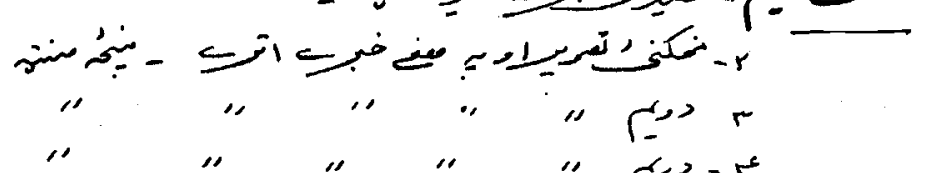

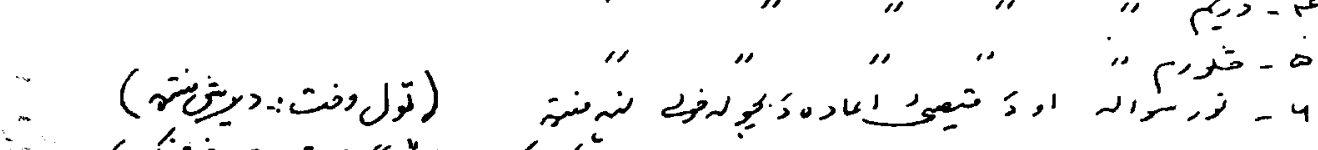

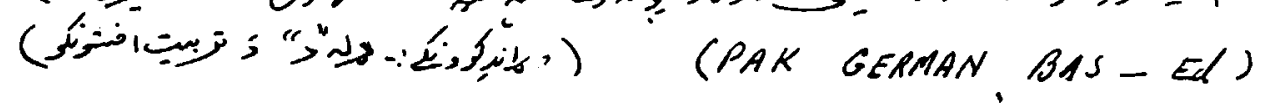




\section{LESSON PLAN}

1. Grade: 1

4. Topic: Introducting the letters
2. Subject: Pashto

I (alef), and
3. Lesson No. :

5. Background Information: In school, reading and writing are the absolutely essential tools for further learning. From primary school to university the student is expected to learn through reading and to express himself by writing. From the beginning the teacher must train the students to read with comprehension. Learning letters or the alphabet is only a preliminary stage in learning to read. As early'as possible the teacher must use meaningful words instead of rote verbalizing.

6. Type of lesson: Introductory lesson

7. Operational objectives: After the lesson the pupils must be able to:

- recognize $\mathcal{N}^{\prime}$ (horse) and $l\left(\right.$ (old man) as keywords for the letters $I$ and $\Psi_{0}$, i.c., the keyword for alef ( $\mid$ ) is the word $\mathcal{H}^{\prime}$ (as), which starts with the letter I (a). We take the word
(Alef).

8. Learning/Teaching Aids: Page 2 of Pashto Primer (for "Introduction").

-The following objects, either originally or in pictures

- for ' I'(alef): Pomme granade (anar), graphes (angur), mango (am), peach (alucha), horse (as)

- for $\leftarrow$ (be) brush (brash), almond (badam), bus (bas), old man (baba), goat (bza).

Flashcards with letters $I$ and

9. Chalkboard Work:
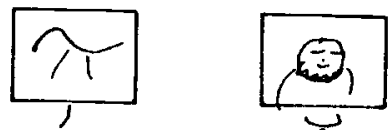

the teacher sticks/draws pictures of a horse and an old man on the blackboard and writes' $/$ ' and
under the pictures. Different pupils practice the letter $\mid$ and $\leftarrow$ on the blackboard.

10. Previous Knowledge: The pupils have worked with textbook page 2, i.e., they can recognize pictures; they know how to talk about pictures.

It would be helpful, if they had some experience in drawing, sketching, filling squares or other patterns.

\section{Action Plan: (see next page)}

12. Evaluation: The teacher asks the pupils to write one line with $\mid$ and one line with $\leftarrow$. He judges the pupils' performance and corrects where necessary. He uses a set of flash cards with the letters $\mid$, pictures of the key words "as" and "baba". He shows them in different order and asks the pupils to name what they see.

He can add pictures of other words with intial letters $\mid$ and $\psi$ (see No. 8: Teaching Aids).

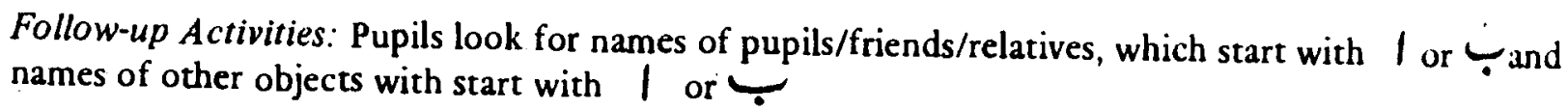




\section{ACTION PLAN}

\begin{tabular}{|c|c|c|}
\hline & Teacher's Activities & Students' Activities \\
\hline Introduction: & $\begin{array}{l}\text { Teacher says: we have talked about many } \\
\text { things in the classroom, at home, in your } \\
\text { village. } \\
\text { T. says: we have seen pictures in the book } \\
\text { and we have talked about them. } \\
\text { loday we are starting to learn to read and } \\
\text { write the name of these objects. }\end{array}$ & $\begin{array}{l}\text { Pupils name some of these objects } \\
\text { Pupils name some of the pictures and } \\
\text { describe, what they show. }\end{array}$ \\
\hline Step 1: & $\begin{array}{l}\text { I. shows objects whose names have " } \mid \text { " } \\
\text { (alef) as initial letter. } \\
\text { I. shows pictures of objects, whose names } \\
\text { have "I "(alef) as initial letter. }\end{array}$ & \\
\hline Step 2: & $\begin{array}{l}\text { T. states that all these words start with } \\
\text { the same letter, with "alef" (" I "). He } \\
\text { sticks or draws a picture of a horse ("as") } \\
\text { on the blackboard and writes " I" under } \\
\text { the picture. } \\
\text { He shows with his arm a long stroke } \\
\text { downward, to demonstrate how to } \\
\text { write " I" (alef). }\end{array}$ & $\begin{array}{l}\text { All pupils copy the long downward } \\
\text { stroke to get a feeling for the direc- } \\
\text { tion of " } " \text { " (alef). }\end{array}$ \\
\hline Stcp 3: & $\begin{array}{l}\text { The teacher writes three nore " } / \text { "on } \\
\text { the black board } \\
\text { T. explains how to write " } f \text { " in the exer- } \\
\text { cise book. } \\
\text { T. controls and corrects pupils. }\end{array}$ & $\begin{array}{l}\text { Some pupils write " } \mid \text { " on the } \\
\text { black board. } \\
\text { All pupils write several " } \mid \text { " in their } \\
\text { exercise books. }\end{array}$ \\
\hline Step 4: & $\begin{array}{l}\text { 1. explains, that "as" (horse) will be } \\
\text { used as a keyword (symbol) for "I" } \\
\text { (alef) }\end{array}$ & \\
\hline Step 5: & $\begin{array}{l}\text { 'I. shows objects and picturcs of objects } \\
\text { whose names have }{ }^{\text {(be) as an intial }} \\
\text { letter.' }\end{array}$ & $\begin{array}{l}\text { Pupils name these objects/pictures } \\
\text { of objects }\end{array}$ \\
\hline Step 6: & $\begin{array}{l}\text { I. states that all these words start with } \\
\text { the letter (be). le sticks/draws a } \\
\text { picture of an old man (baba) on the } \\
\text { blackboard and writes utuder it. } \\
\text { lle writes a big with his arm into the } \\
\text { air. } \\
T \text {. makes aware that the letter consists } \\
\text { of a line and a dot. }\end{array}$ & $\begin{array}{l}\text { All pupils copy this movement and } \\
\text { draw a big } \underbrace{}_{\text {in the air. }}\end{array}$ \\
\hline Step 7: & $\begin{array}{l}\text { T. writes three more " } \\
\text { board He explains how to write it in the } \\
\text { exercise book. } \\
\text { T. controls and corrects students. }\end{array}$ & $\begin{array}{l}\text { All pupils write several times " } \\
\text { in their exercise books. }\end{array}$ \\
\hline Step 8: & $\begin{array}{l}\text { T. states that } \\
\text { word/symbol for the letter " } \\
\text { He refers to other objects/pictures, } \\
\text { whose names also start with "alef" } \\
\text { or "be". }\end{array}$ & $\begin{array}{l}\text { If possible, pupils draw pictures of a } \\
\text { horse and a "baba" in their exer- } \\
\text { cise books, with the respective letters } \\
\text { " J " and "W"" }\end{array}$ \\
\hline Conclusion: & $\begin{array}{l}\text { Teacher recalls that pupils have learned } \\
\text { two letters in this lesson and that they } \\
\text { have done their first writing. He does the } \\
\text { exercises described in } 12 \text {."Evaluation." } \\
\text { He shows flashcards ( }\end{array}$ & $\begin{array}{l}\text { Pupils write one line with " I " and one } \\
\text { line with " } \\
\text { Pupils name the letters and objects. }\end{array}$ \\
\hline
\end{tabular}


119

5.2.2 Lesson Plan Pashto

Topic: Introducing letters 1 and $Y$ ن jus

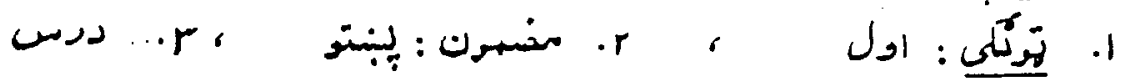

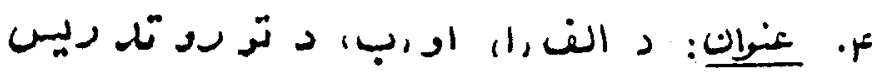

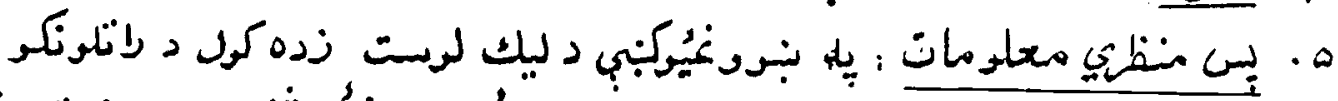

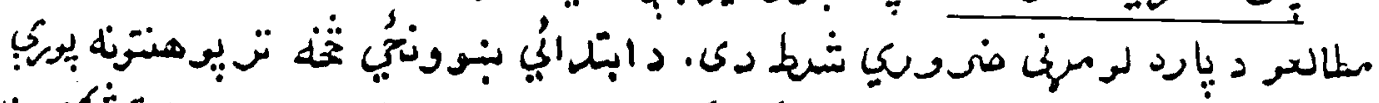

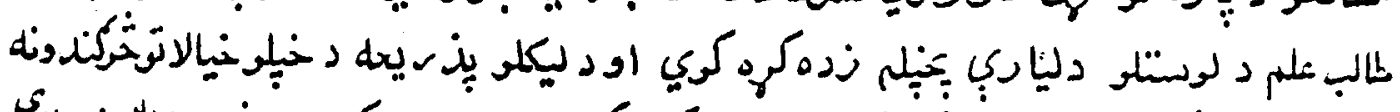

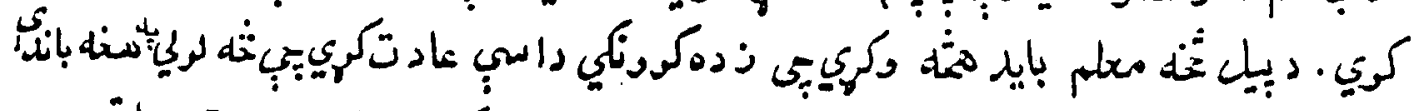

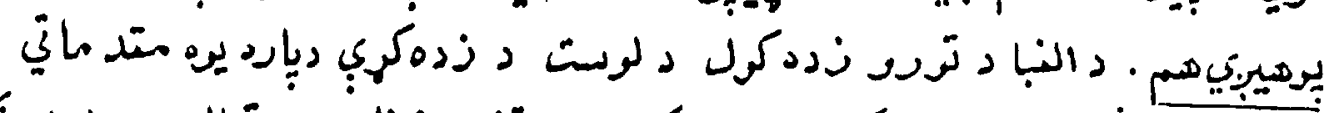

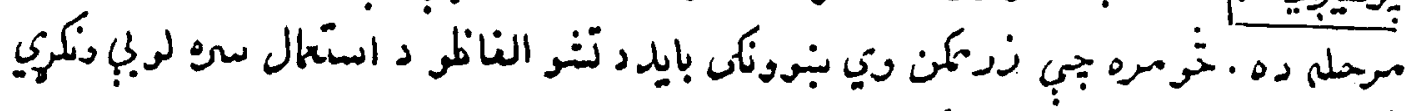

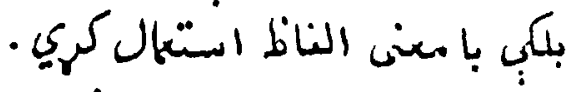

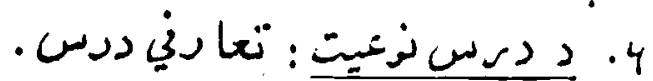

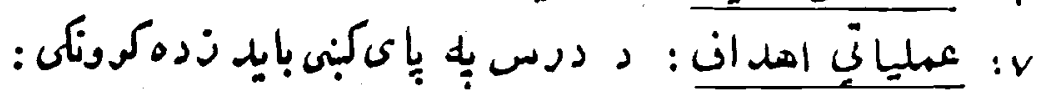

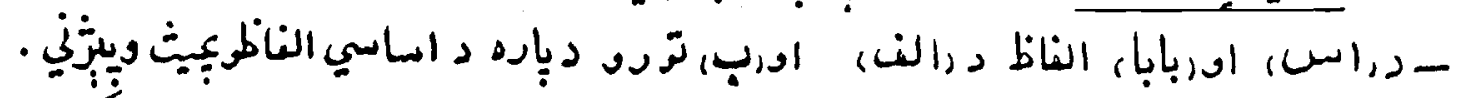

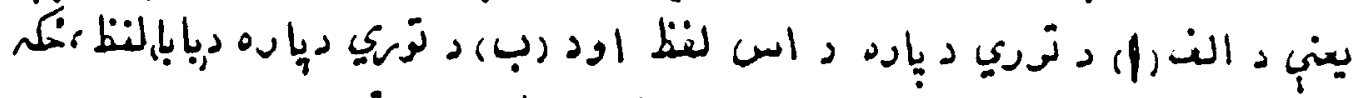

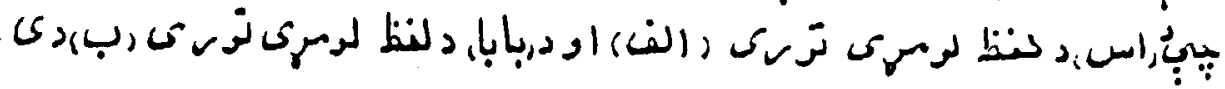

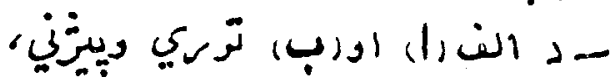

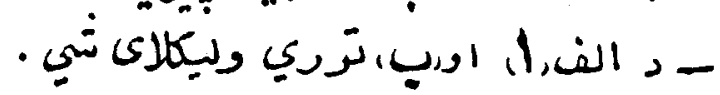

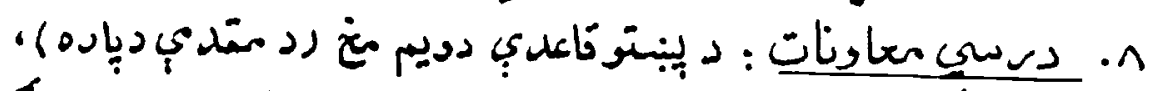

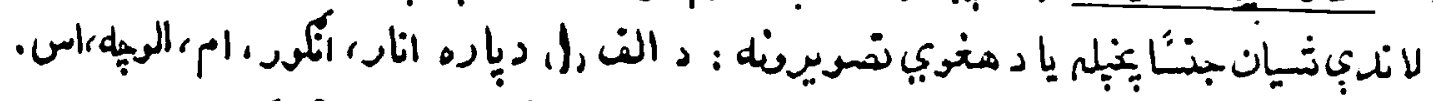

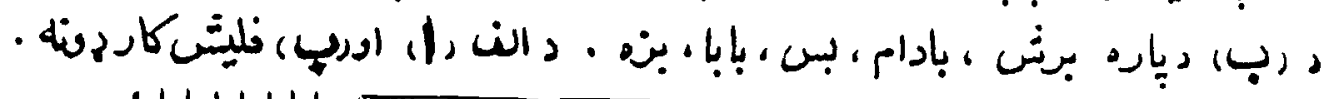

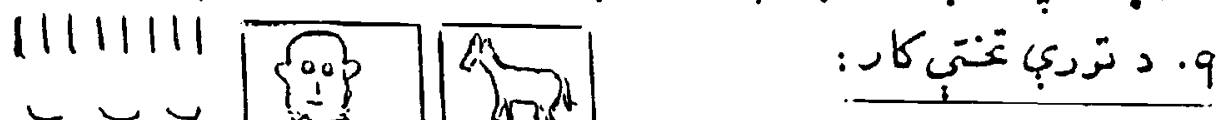

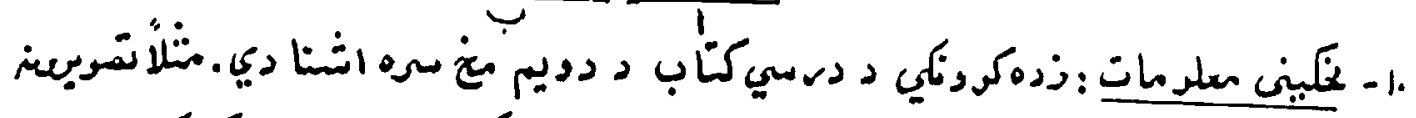

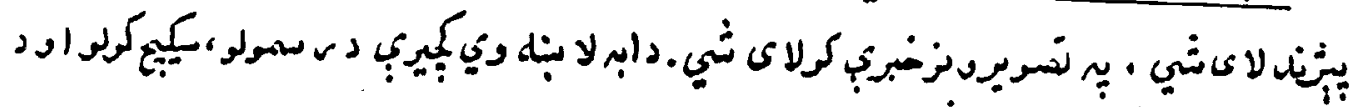

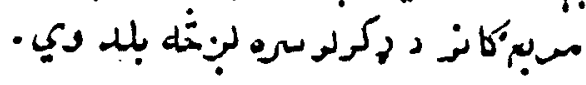

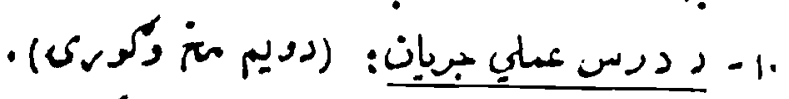

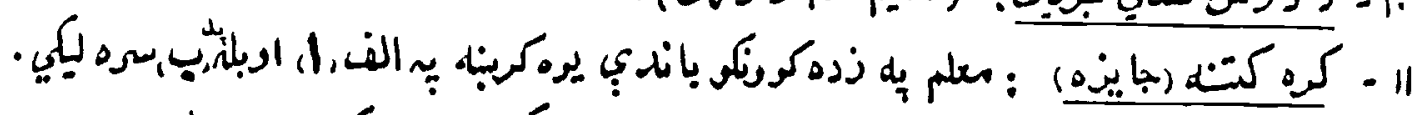

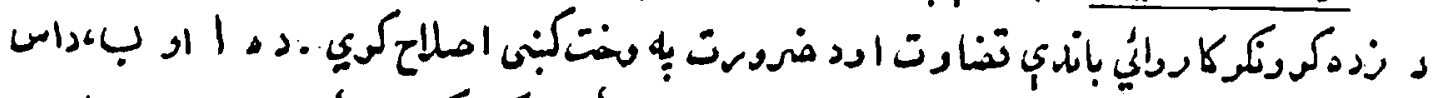

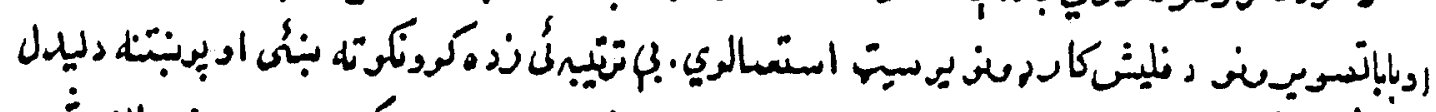

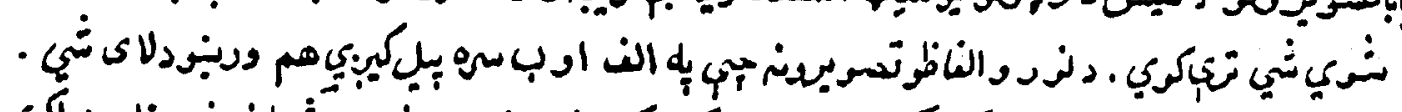

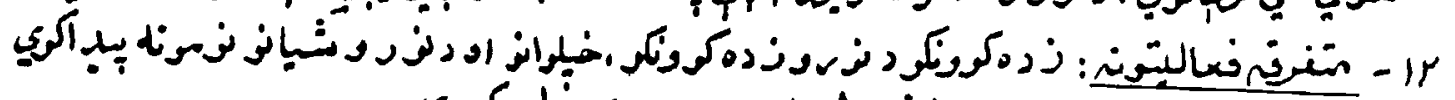

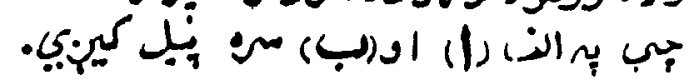




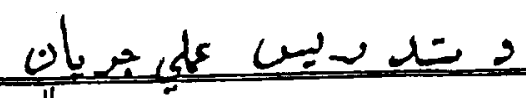

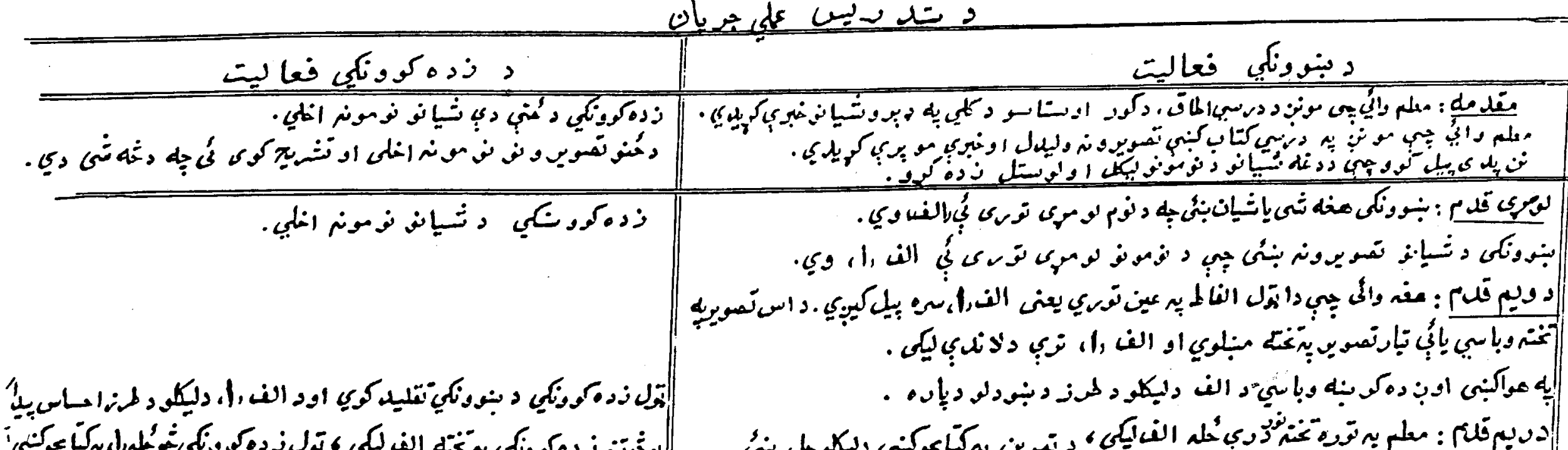

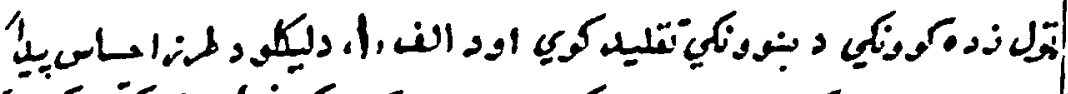

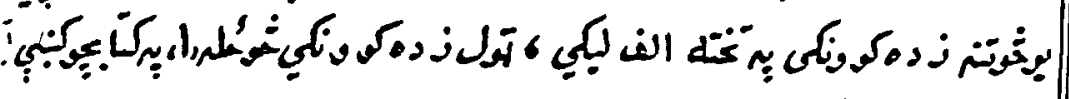

|

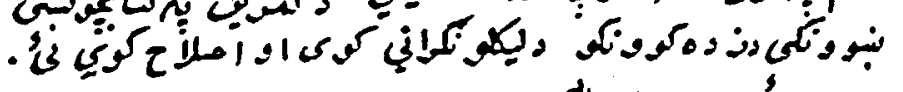

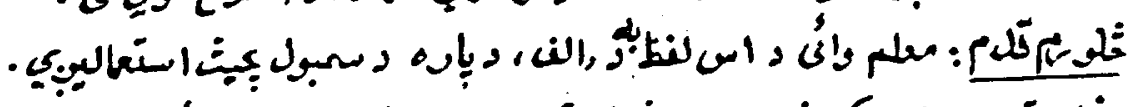

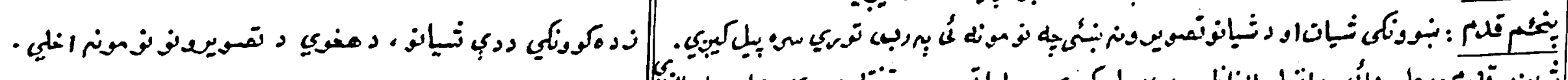

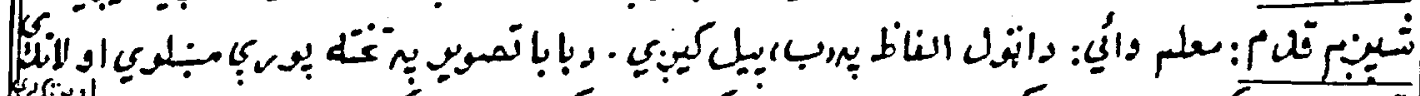

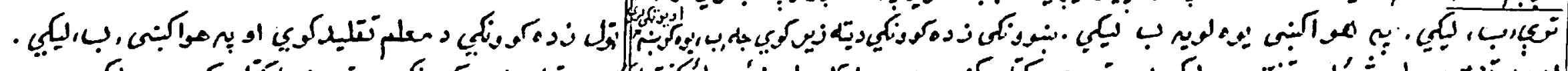

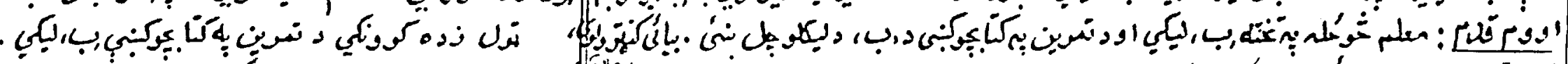

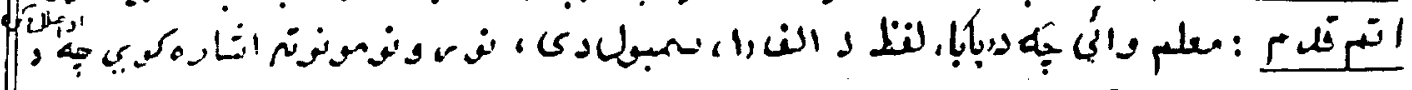

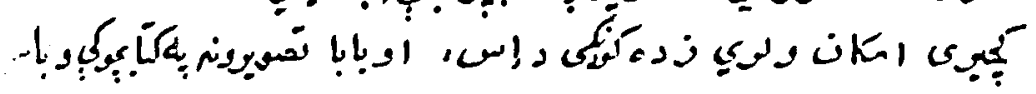

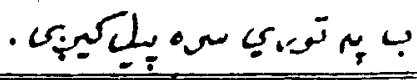

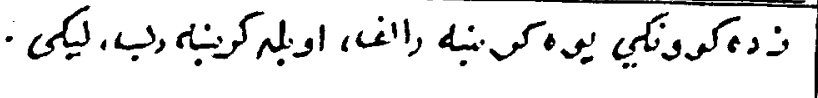

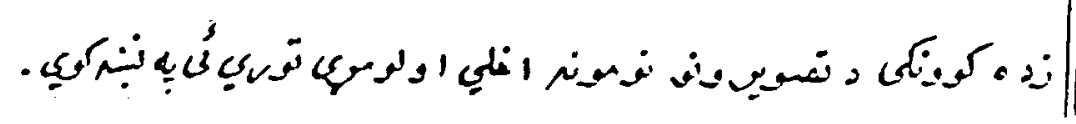

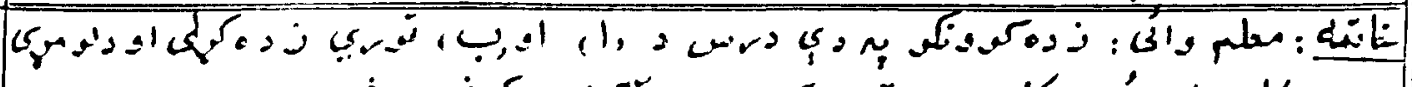

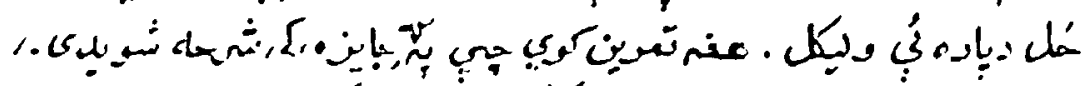
. 
Key word Card for the letter " |"
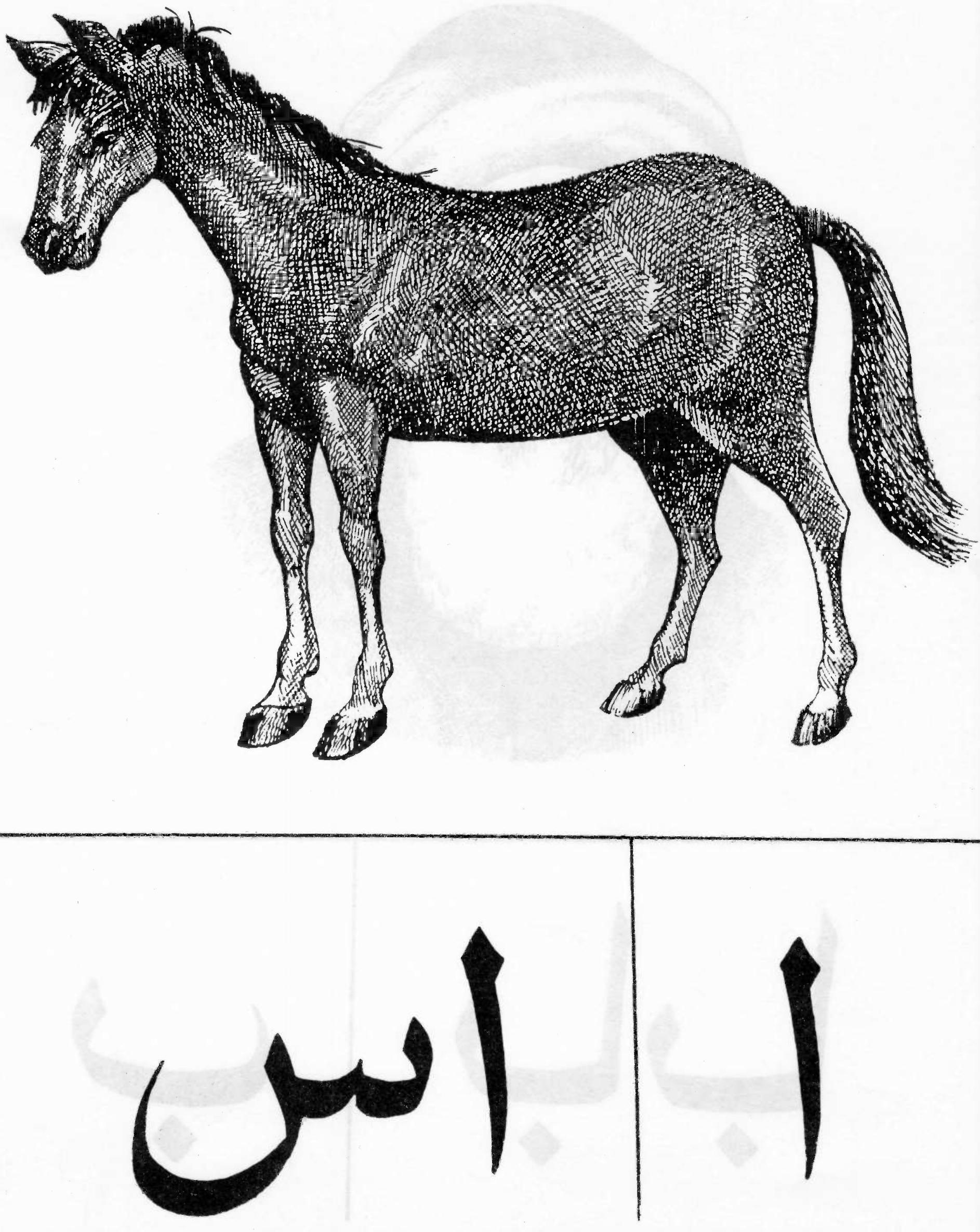
Key word Card for the letter " "
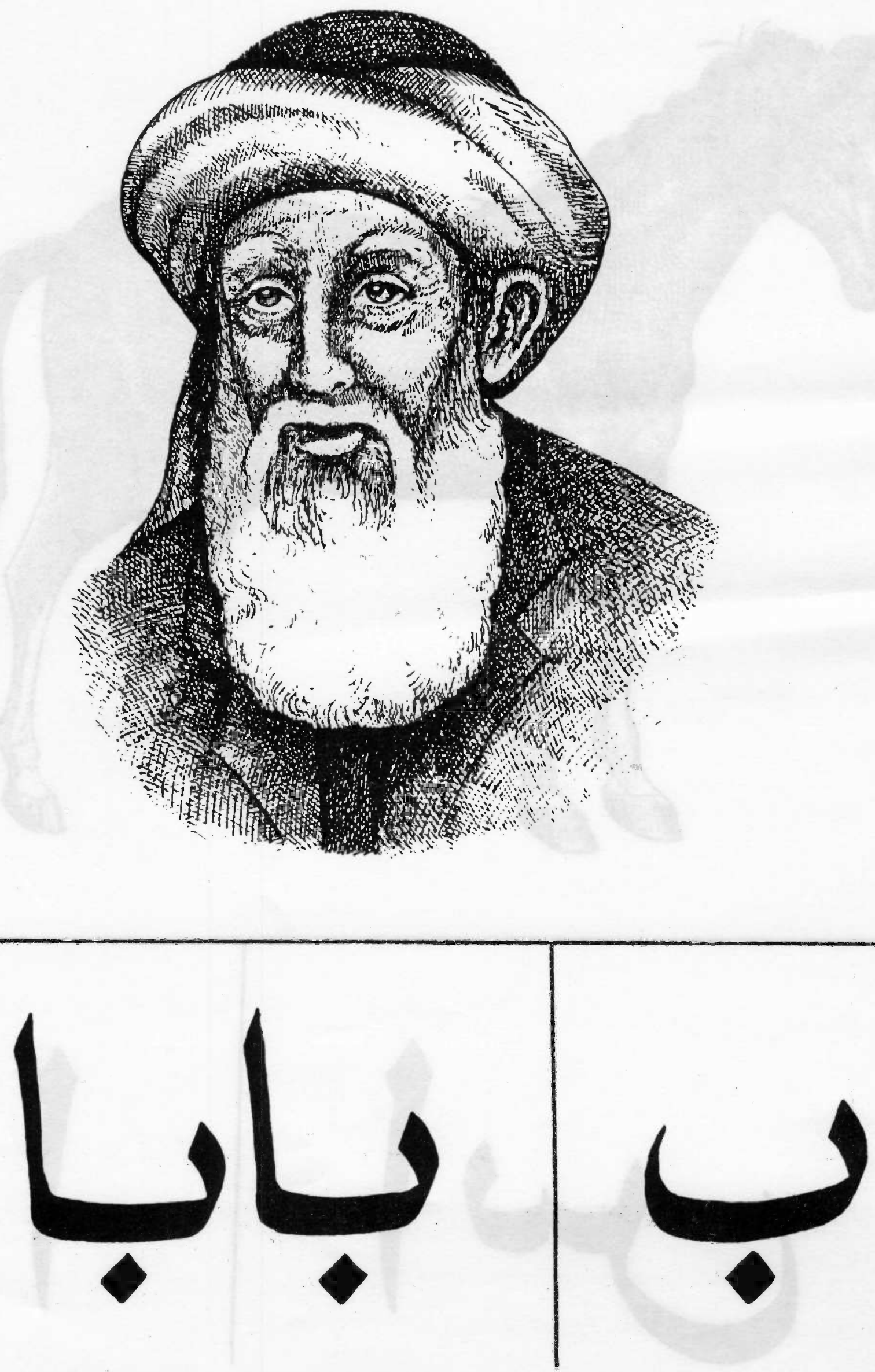
5.2.2 Lesson Plan Pashto

Topic: single action picture EATING بإلك جرمن لومرنه تعلمات

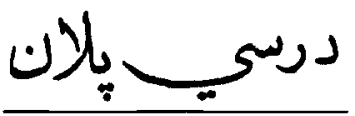

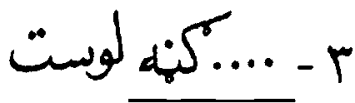

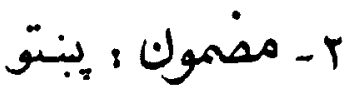

del :

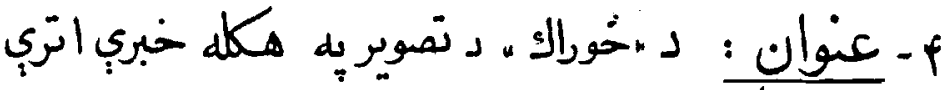

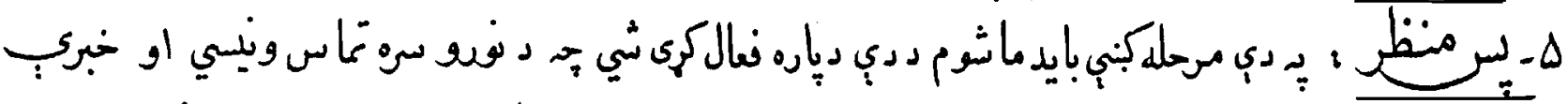

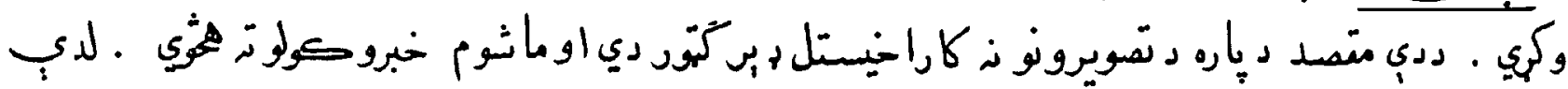

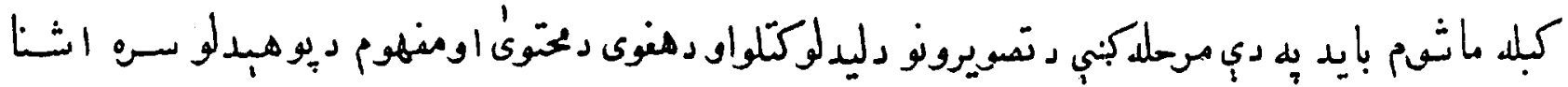

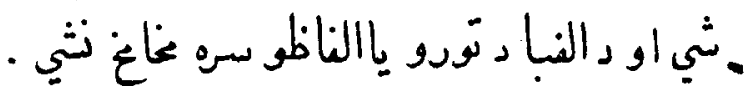

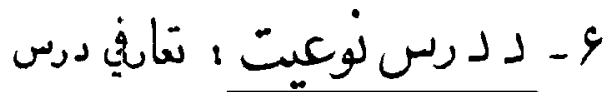

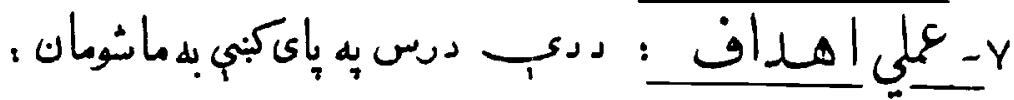

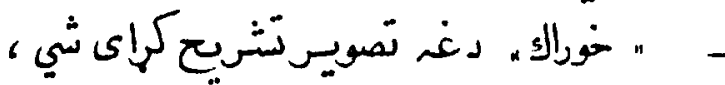

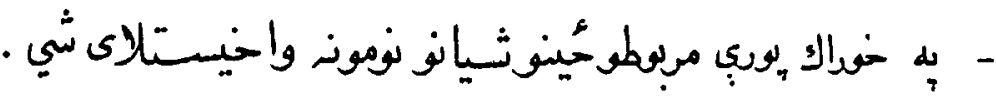

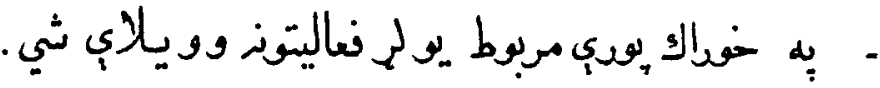

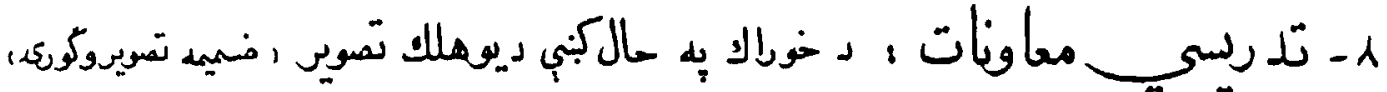

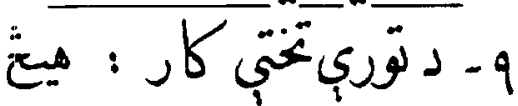

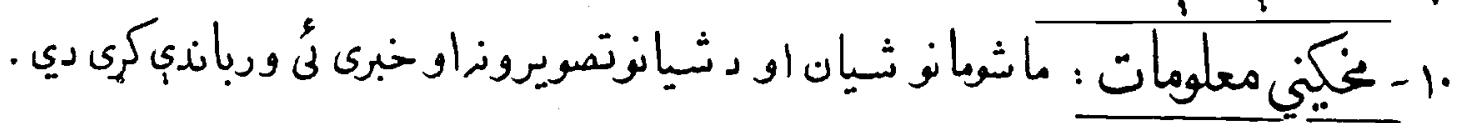

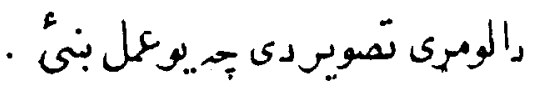

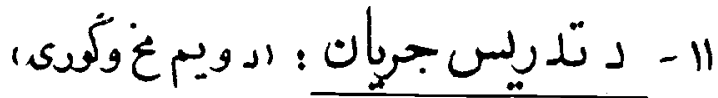

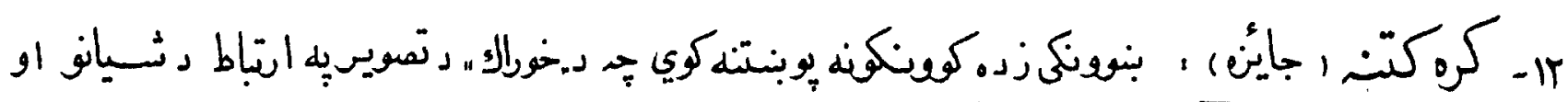
اعمالونومهن واخلي

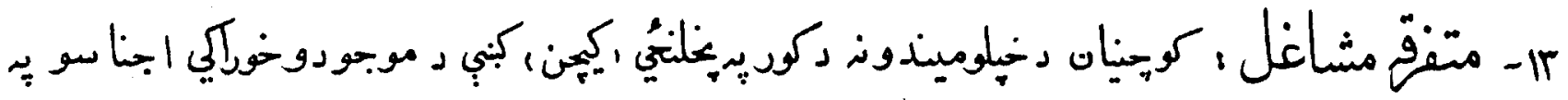
باره كبني يوبنـنـه كِي .

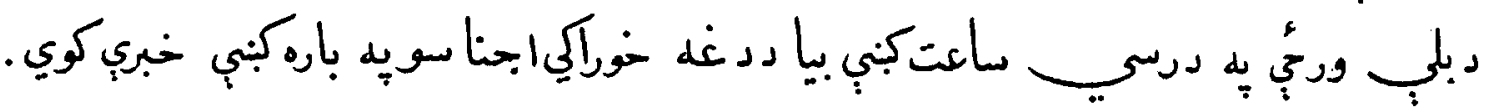




\section{دتدريسنملىجريان}

\section{دزدمكونيكي فعاليت}

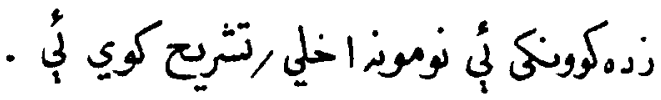

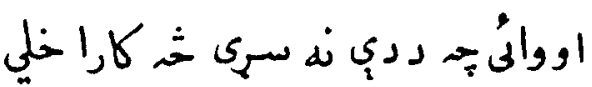

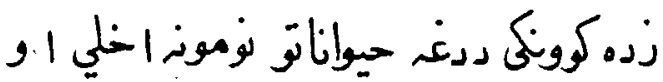

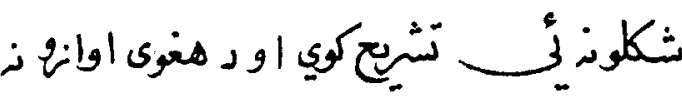
.

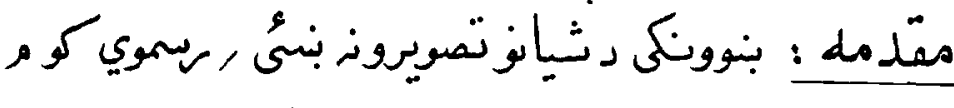

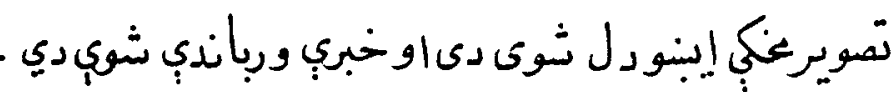

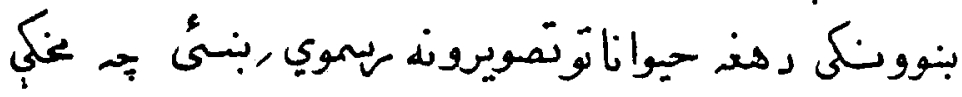

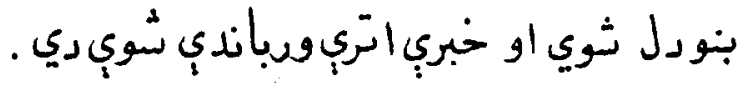

زد مكوونكي خبل مثاهـات او بيا نونت داسي وال راك

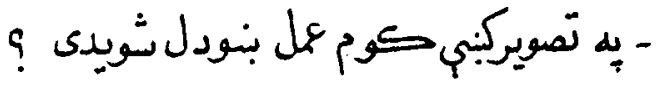

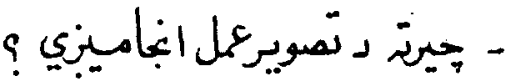

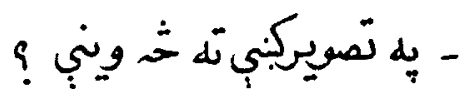

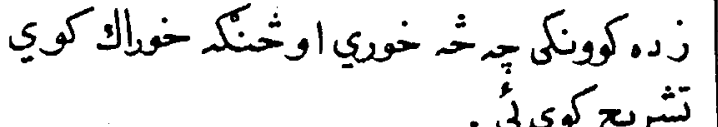

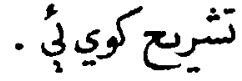

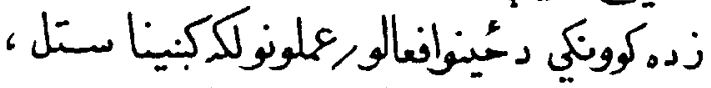
راخيستل ،شيرول رثكول ، زوولـ ـ نو موند

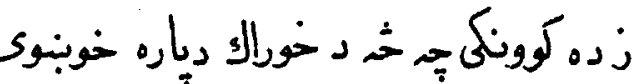

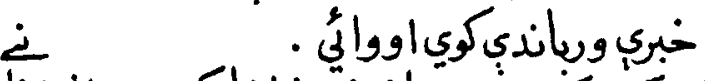

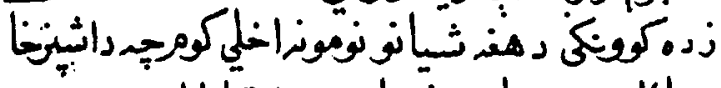

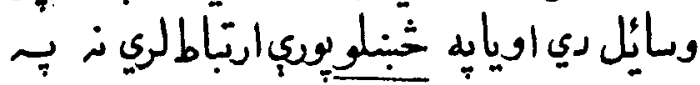
خوريويوري

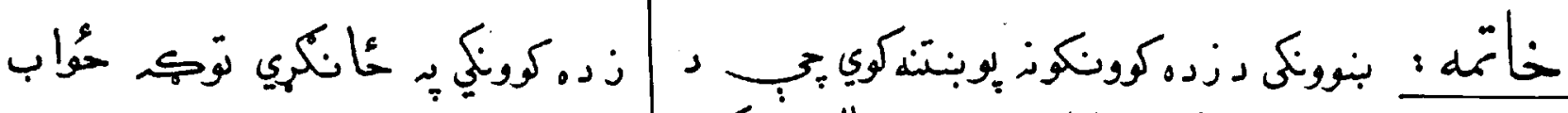

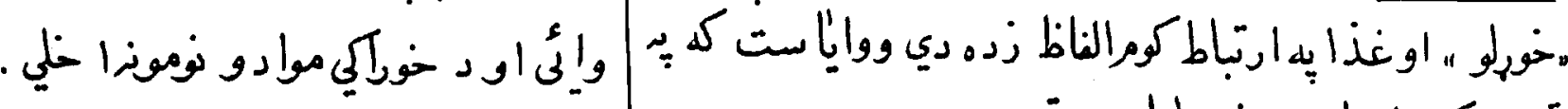

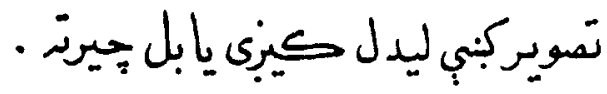

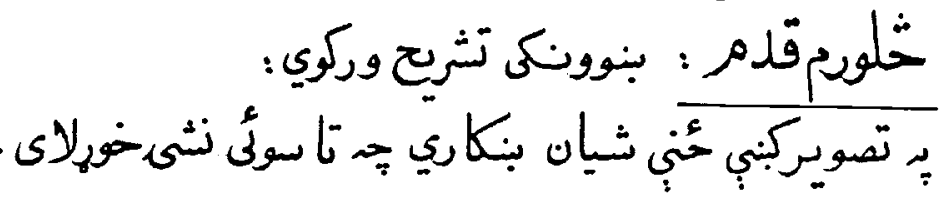

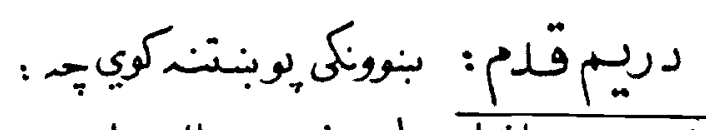

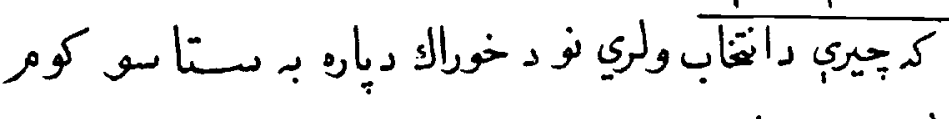

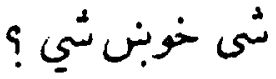

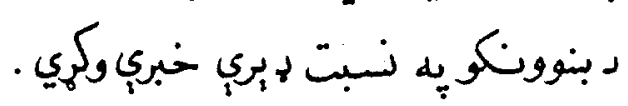

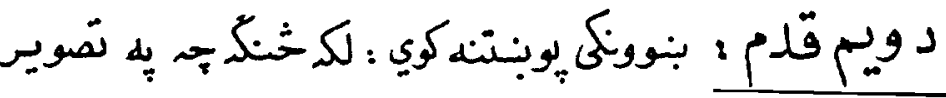

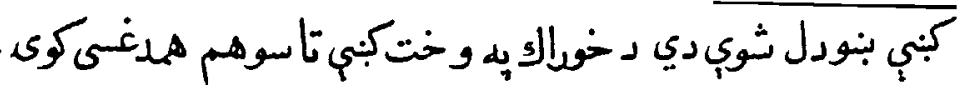


Single Action Picture: EATING

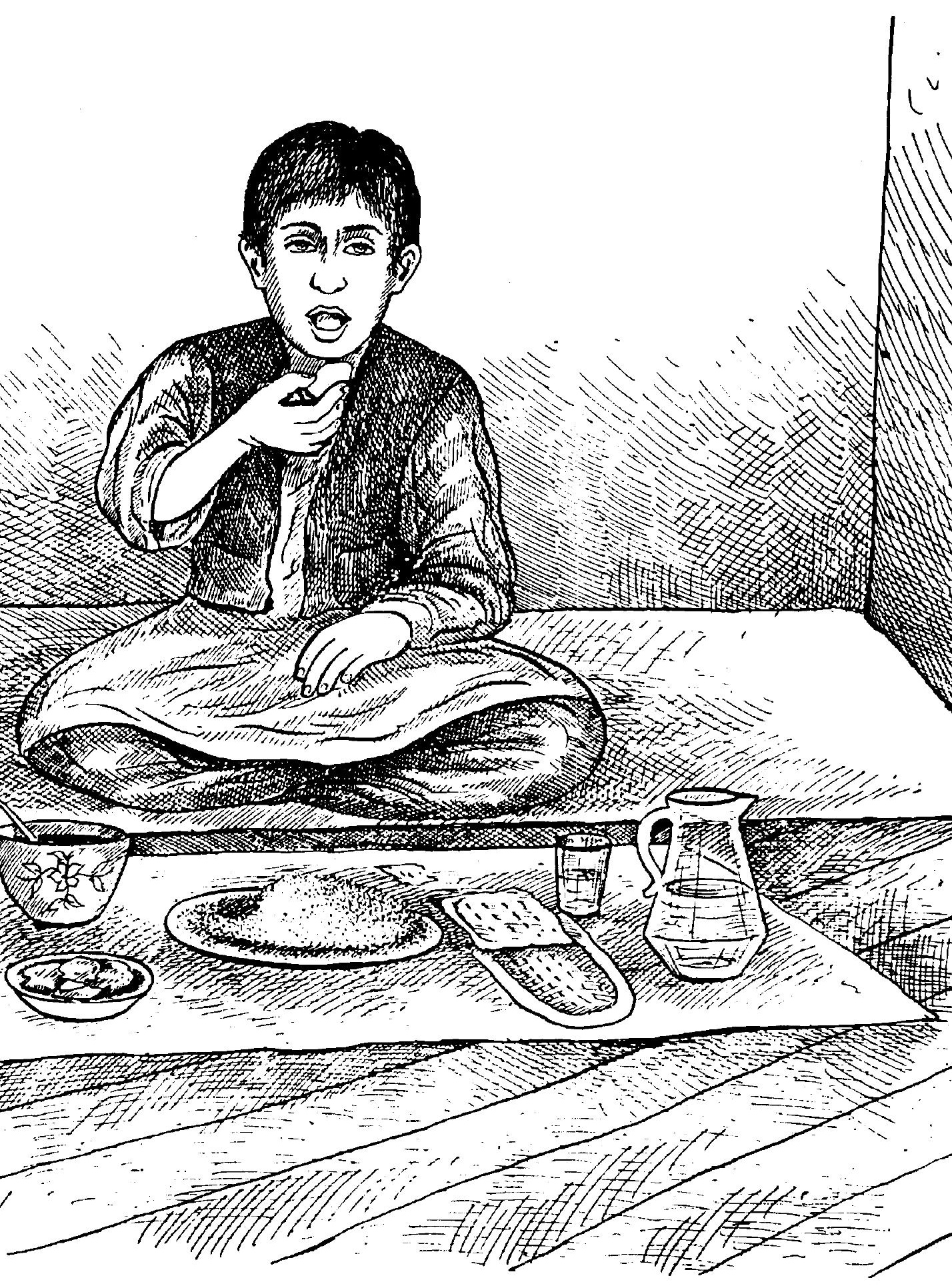


5.3 Teaching-/Learning Materials 
5.3 .1 .

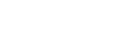

FRONTSIDE :

to be used in an early stage
Key word Cards: Initial Letters

(Initial letter, alone and in combination, printed in red)
BACKSIDE :

to be used in a later stage
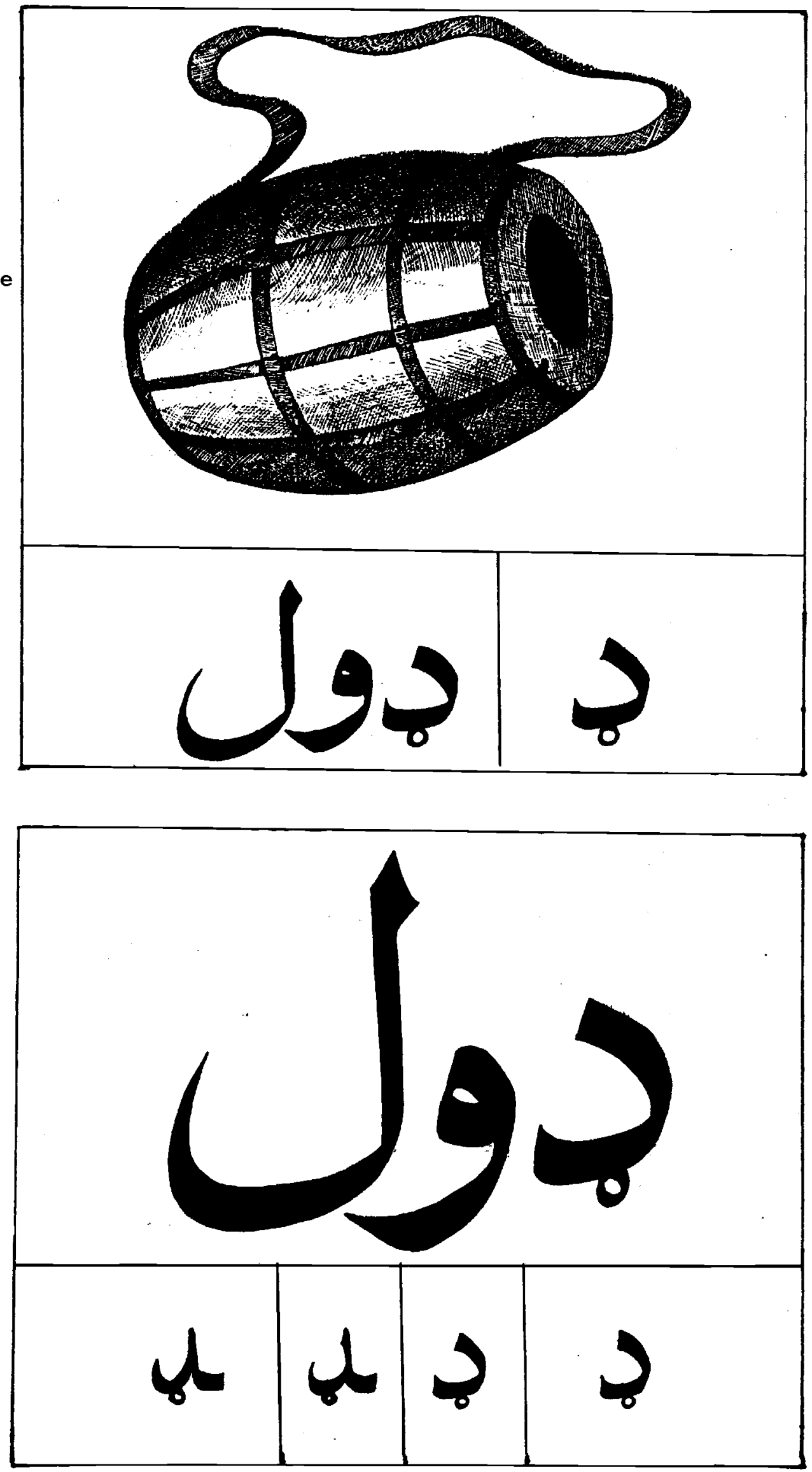
$5 \cdot 3 \cdot 1$.

Key Word Cards:

FRONTSIDE :

to be used in an early stage
Initial Letters

(Initial letter, alone and in combination, printed in red)

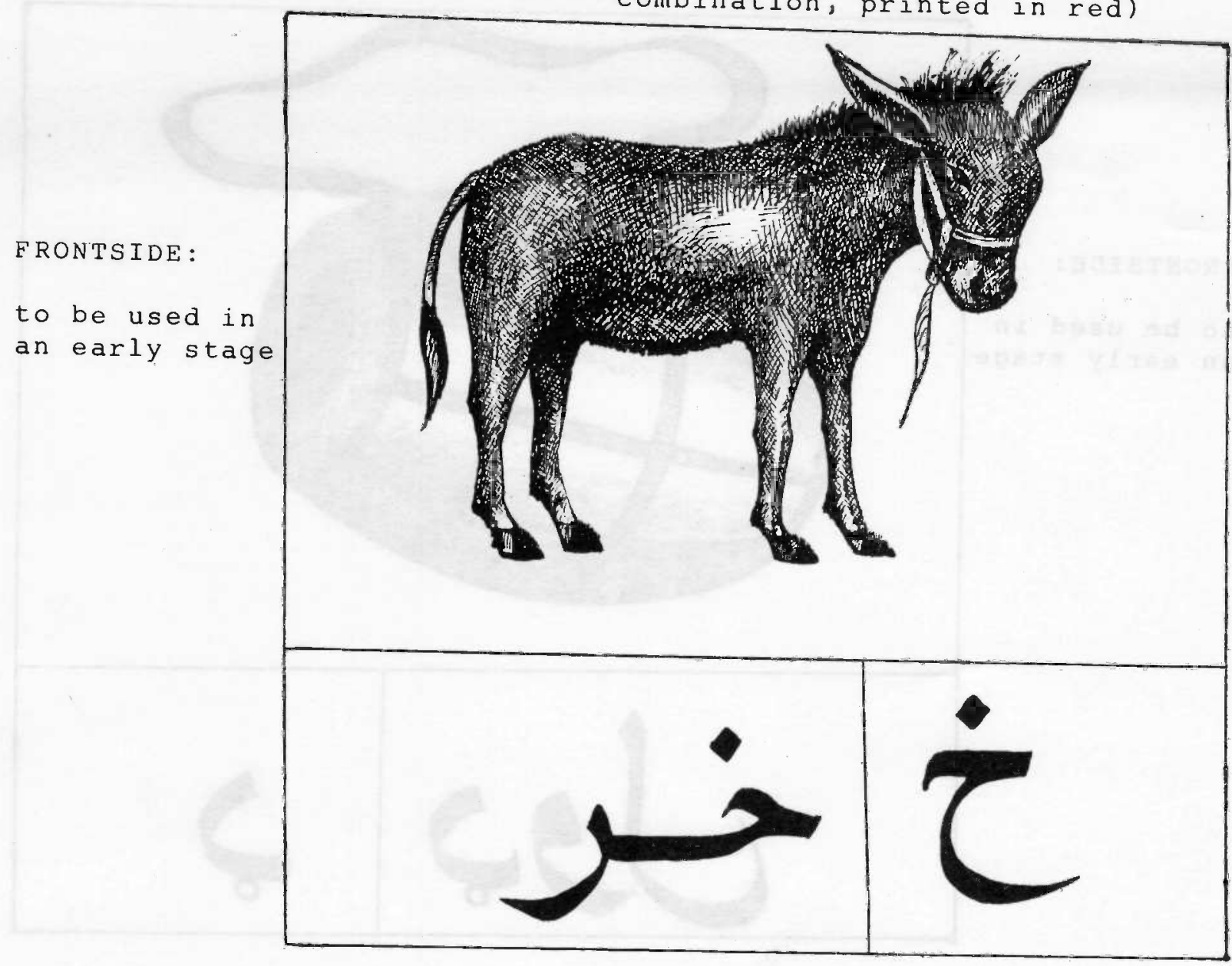

BACKSIDE :

to be used in a later stage

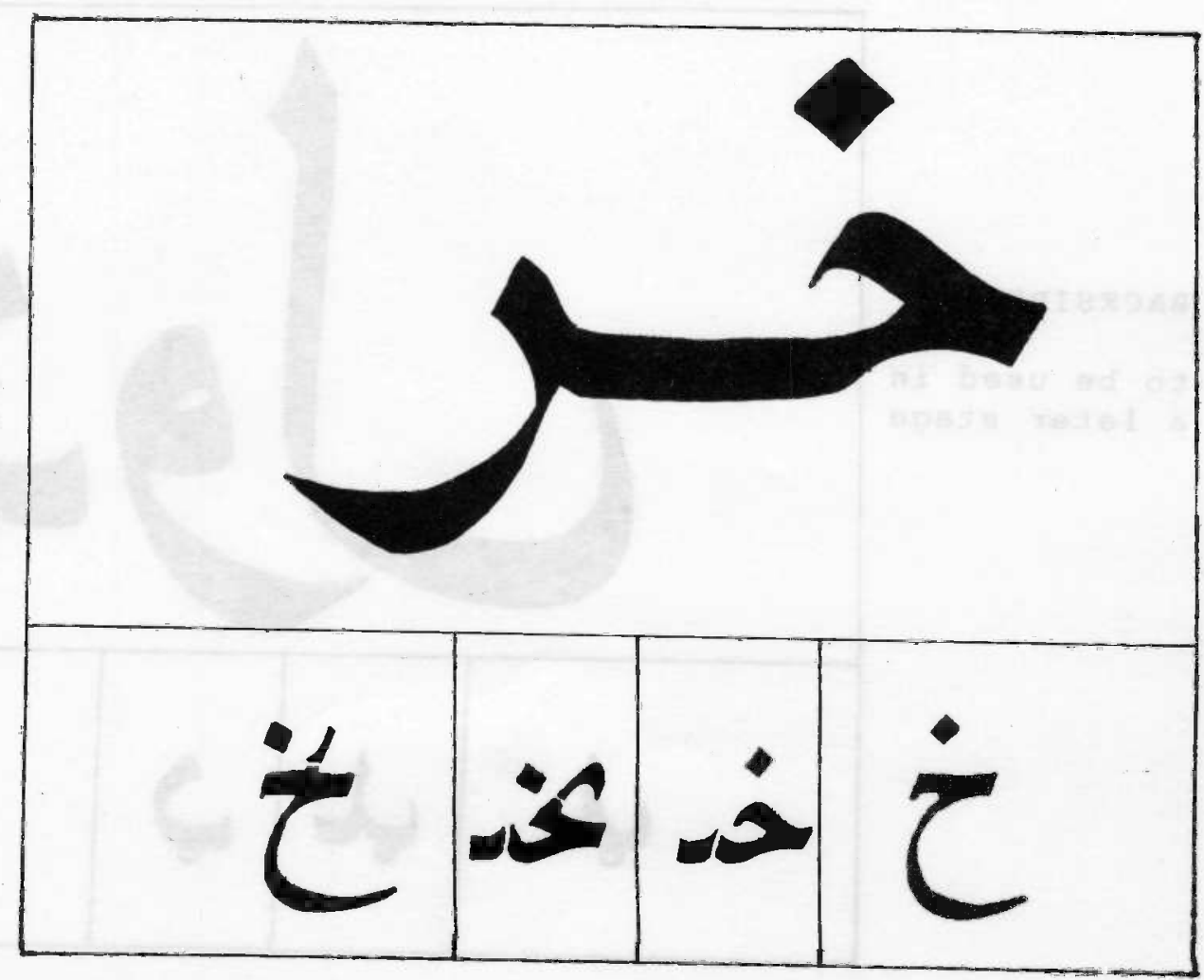


5.3 .1

Key Word Cards:

End Letters

(End letter, alone or in combination, printed in red)

FRONTSIDE :

to be used in an early stage

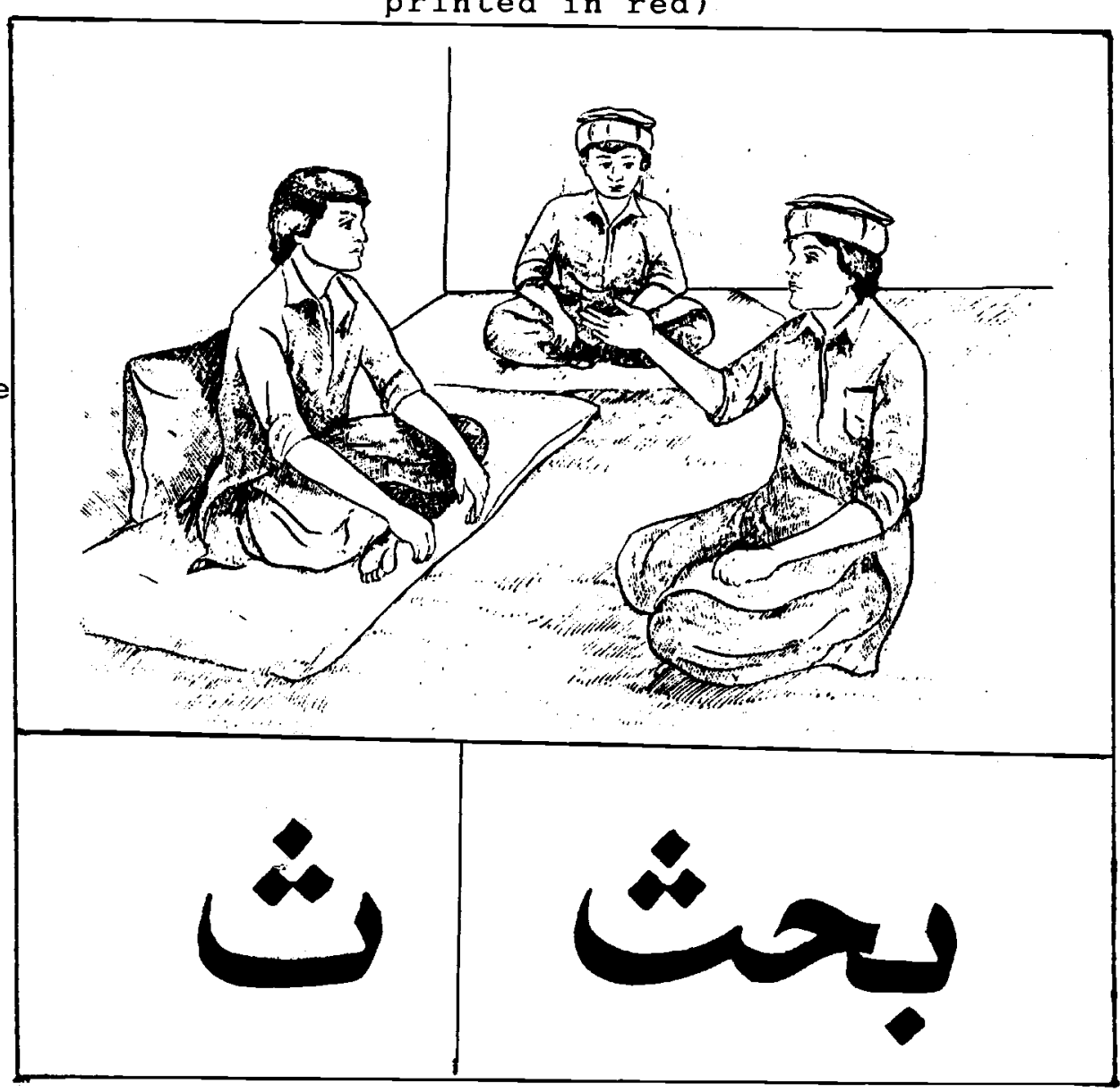

BACKSIDE :

to be used in a later stage

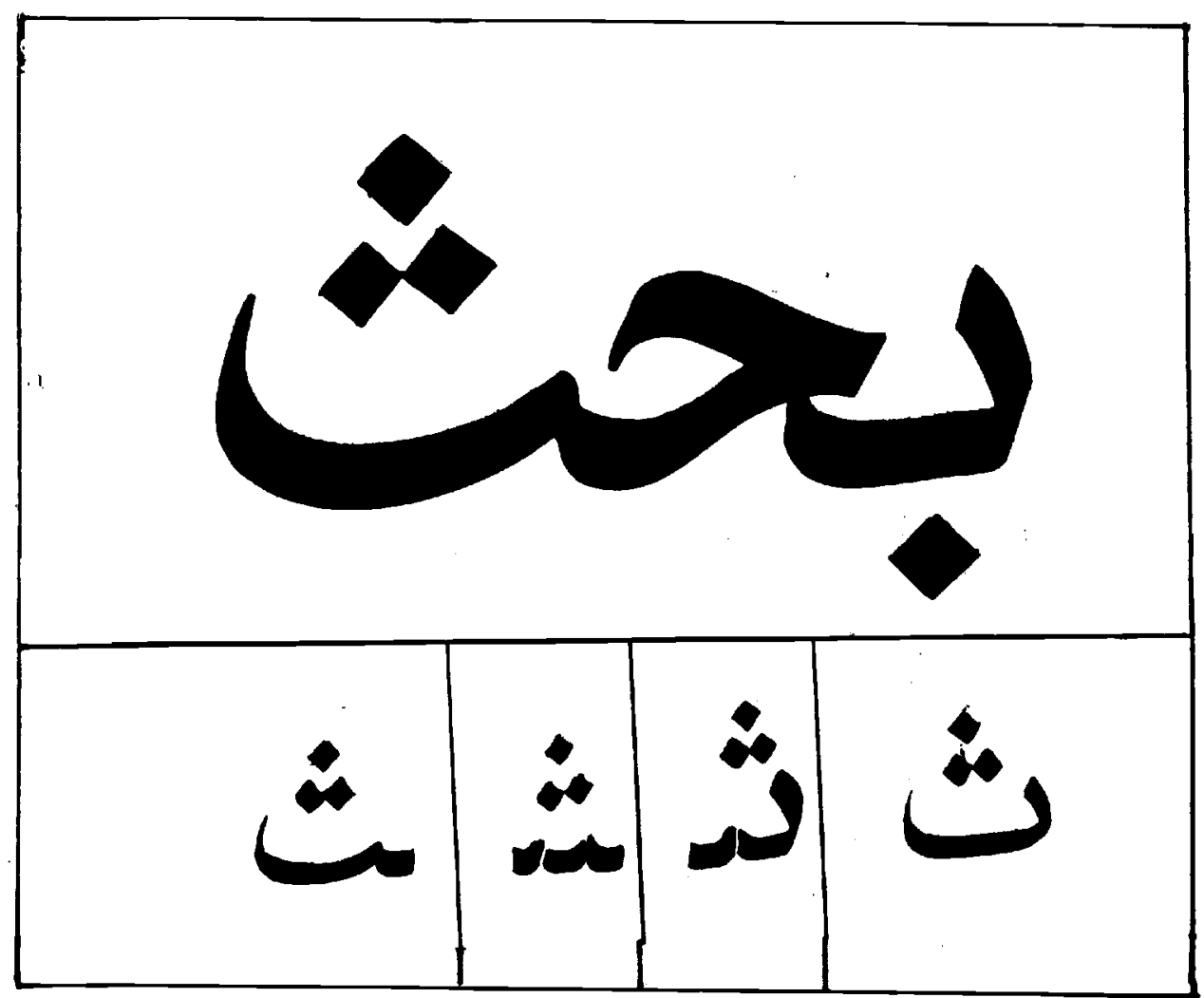


5.3 .1

Key Word Cards: End Letters

(End letter, alone or in combination, printed in red)

FRONTSIDE :

to be used in an early stage
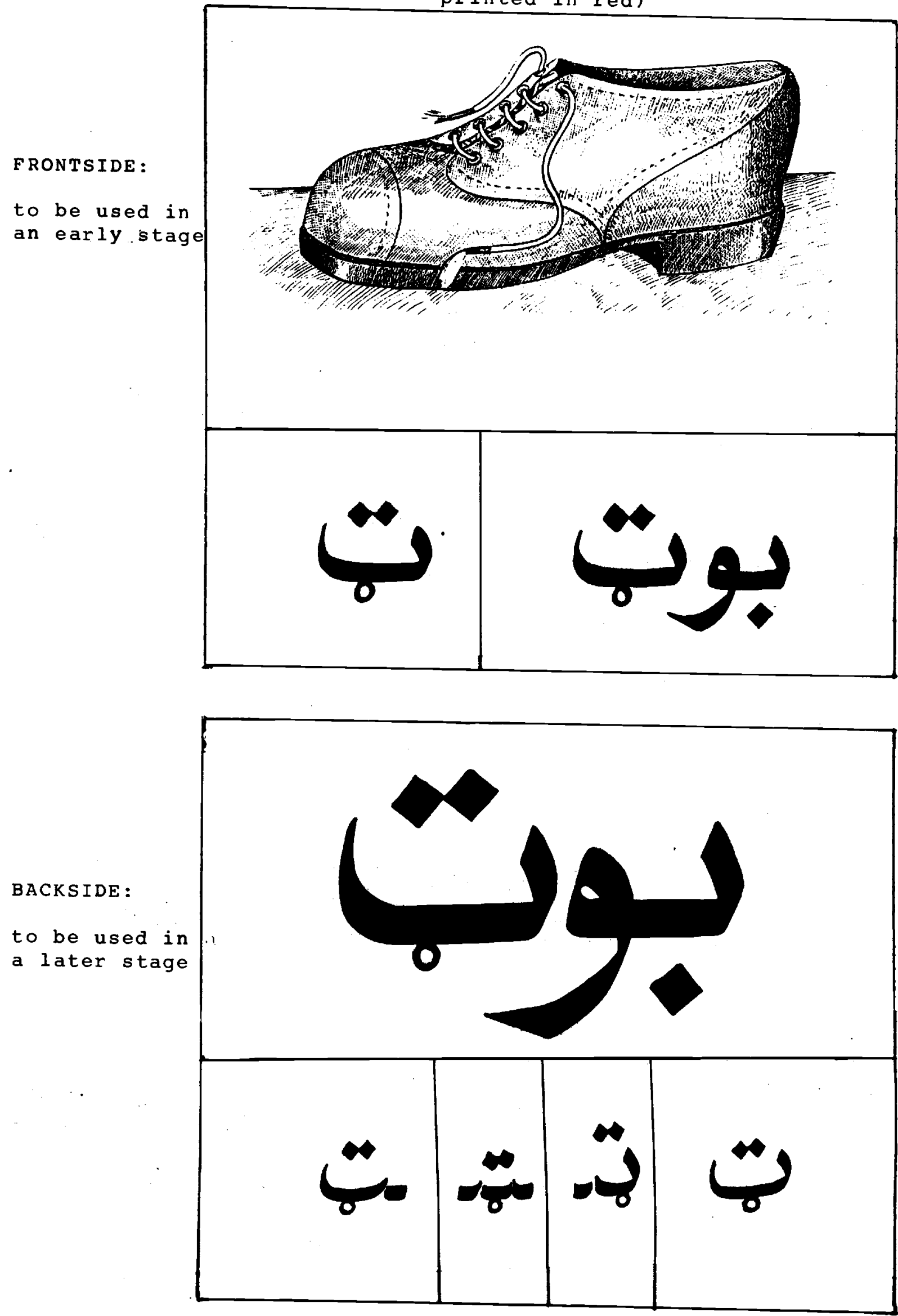


\subsubsection{Cat Story}
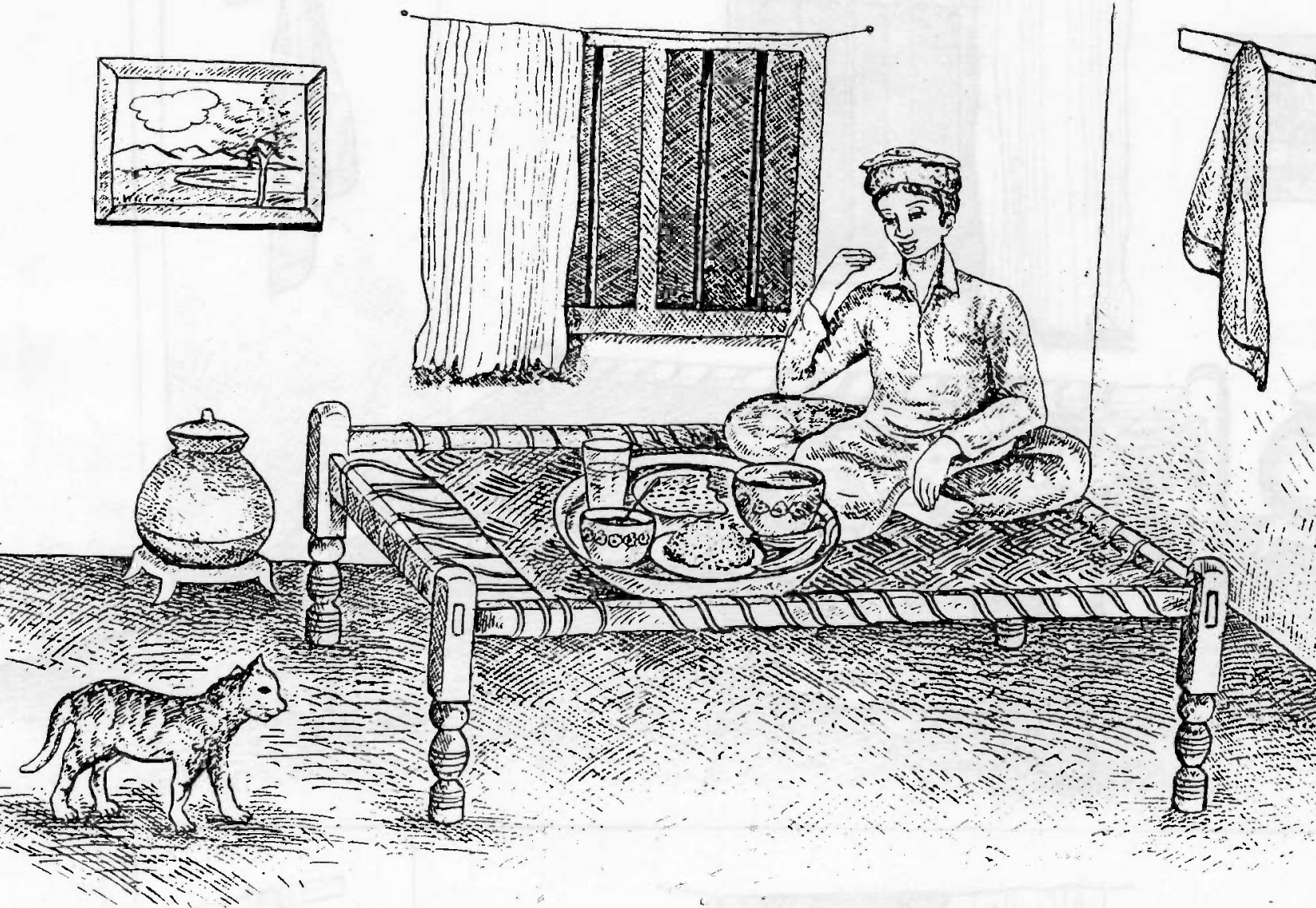

Picture 1
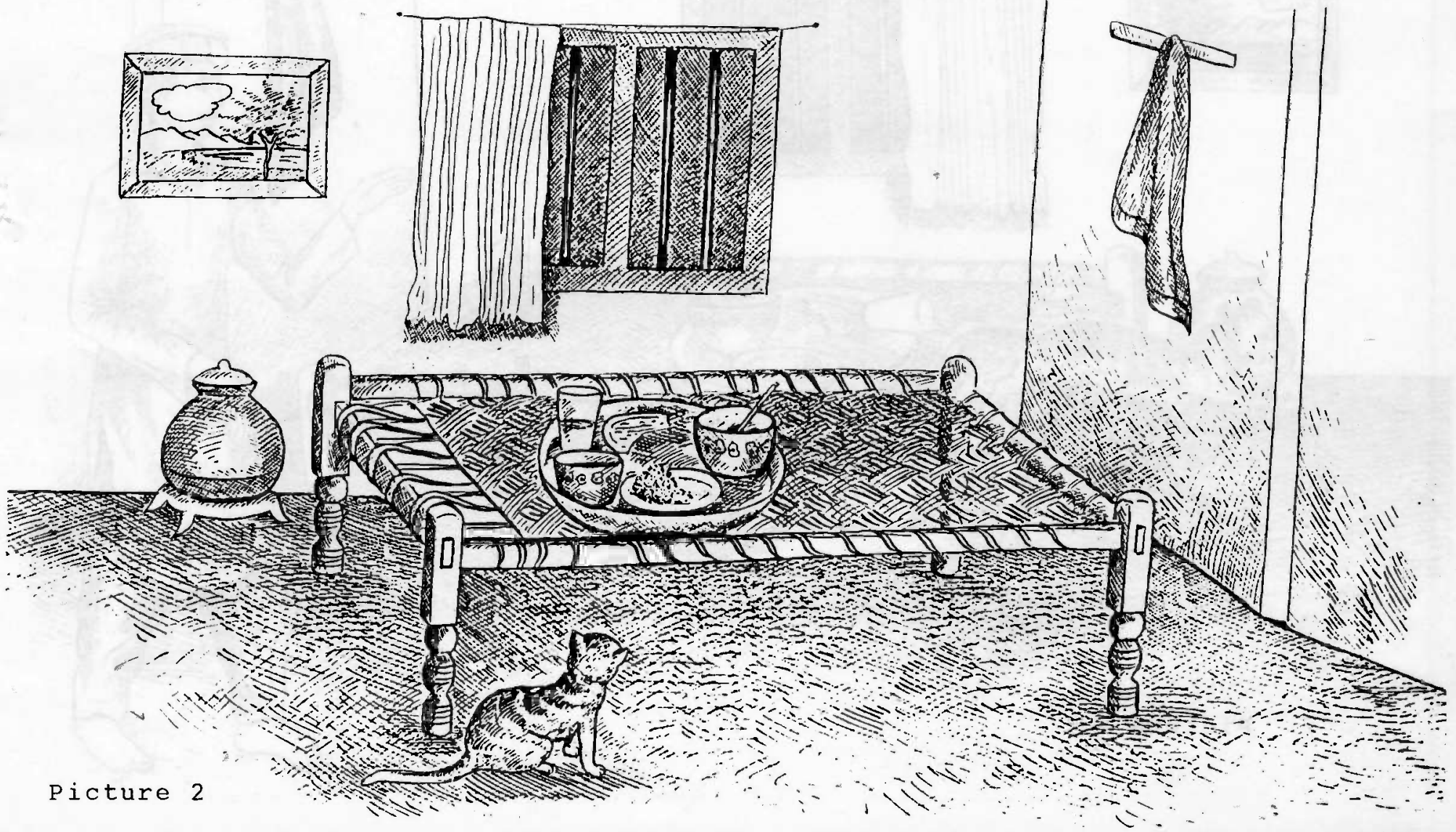
5.3.3 Maths Cards: (so - called). Pashto figures
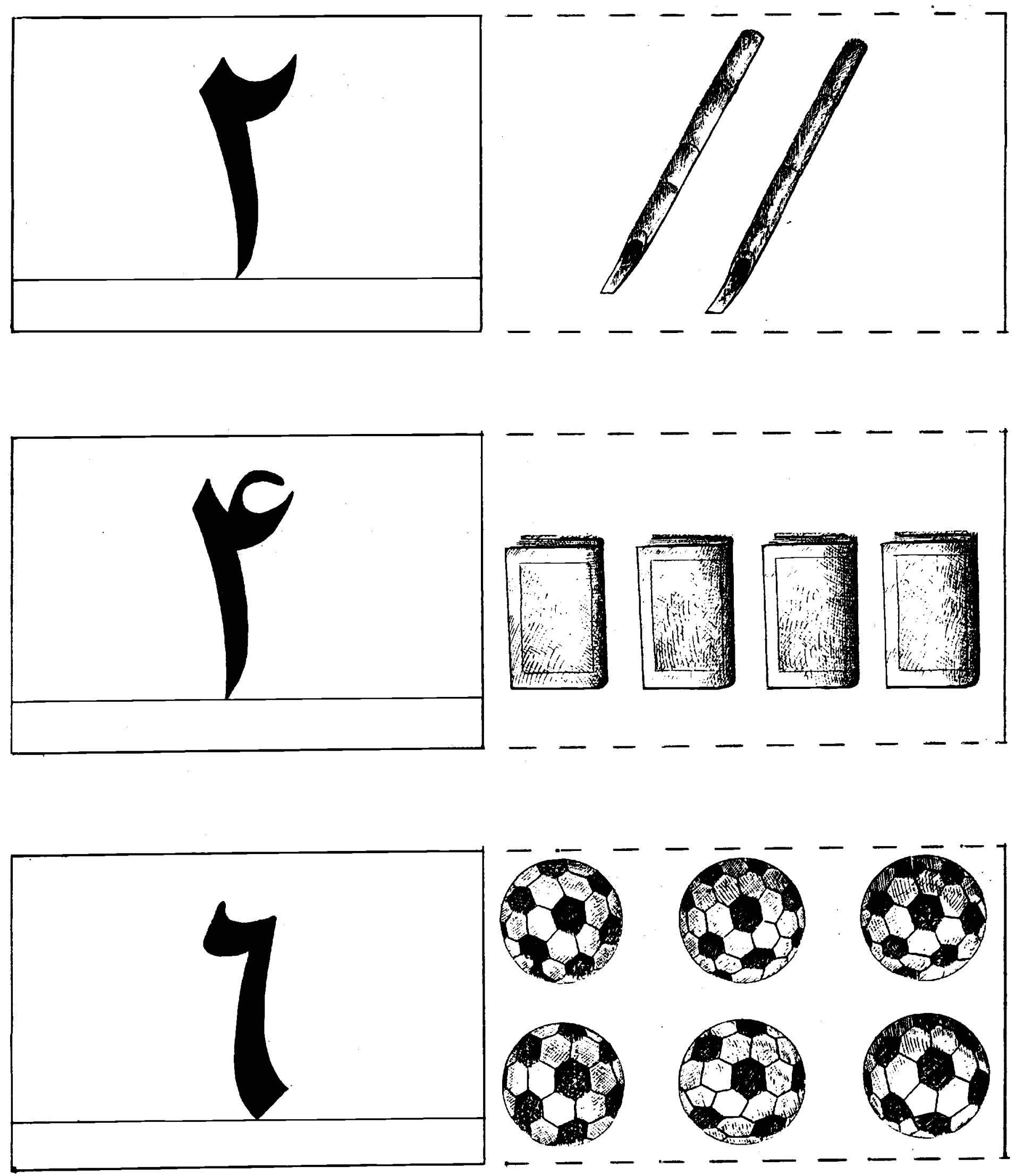

Left: frontside

Right: backside 
5.3.3 Maths Cards: (so - called) English figures
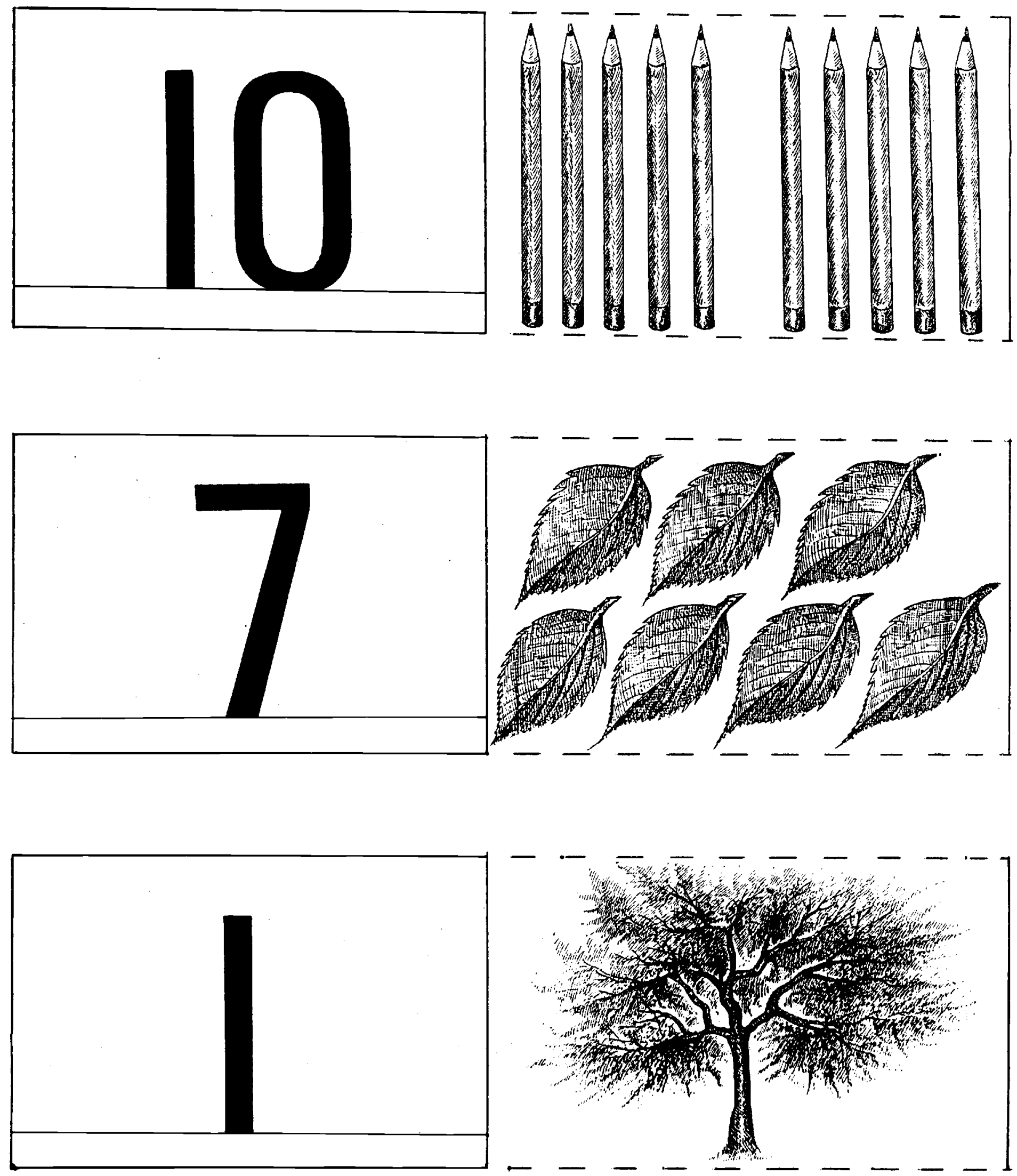

Left: frontside

Right: backside 
5.4 Monitoring Instruments 


\section{DIRECTIONS}

1. Page $I$ of the accompanying Monitoring Instrument is to be filled before the lesson, page II while the lesson is on, and page III immediately after the lesson is over.

2. Please note informations in such a way that whatever is written can be easily read.

3. Please take your observations in such a way that one may easily remember as to what was the specific point that was noted down.

4. Please pass on the filled-in instruments as early as possible to Prof. Habib-ur-Rahman.

5. Please remember that in some cases you might have to add an additional report of what you have observed on a specific visit.

6. The code to be followed in determining the Discrepancy Status shall be as follow:-

Almost no discrepancy (when the agreement between the intended and the actual is $80 \%$ or more).

B - Limited discrepancy (when the agreement between the intended and the actual is of the order of 50 to $80 \%$ ).

C - Substantial discrepancy (when the agreement between the two ranges from $10 \%$ to $50 \%$ ). 


\section{Section I: $\quad$ School Related Information}
a) Date:
b) Name of the School:
c) No. of students present:
d) Name of Head Teacher:
e) Name of Working Teacher:
f) W.T's years of teaching experience:
g) W.T's qualification: General: Professional:
h) Did the W.T. attend April 86 course of PGBEP: Yes: No:
i) Did the H.T. attend April 86 course of PGBEP: Yes: No:

Section II: Guiding questions to the Working Teacher
a) Have you read the scheme of Work so far: Yes: No:

b) Name the lesson plans taught by you so far: 1 .

$$
2 .
$$

c) Did you maintain their record: Yes: No:

d) Difficulties as identified by the working Teacher as a result of his/her experience:

e) In the opinion of the Working Teacher, did the lesson plan work? (give code number):

f) Any modification of the lesson plan as suggested by the teacher: 
Section III:

Particulars of the Monitoring Team Member
a) Name:
b) Arrival Time:
c) Leaving Time:
d) Exact duration for which the lesson was observed:
e) General comments:

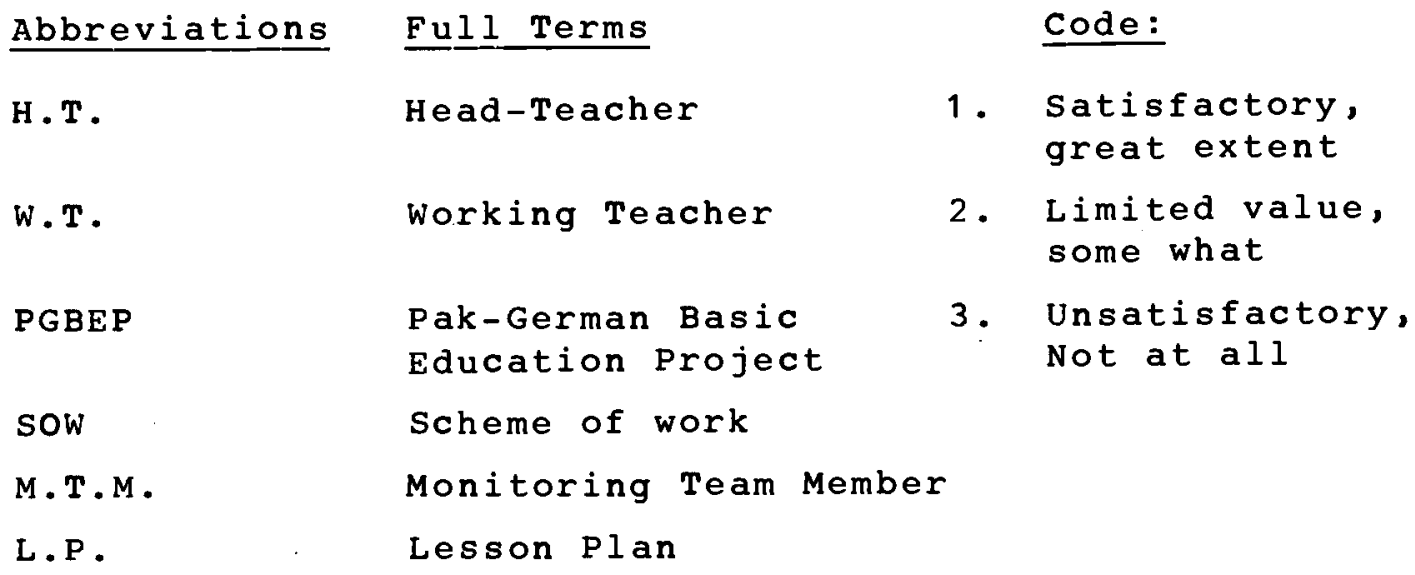


a) Was the relevant L.M. used during lesson?

b) Did pupils enjoy the Learning Materials?

c) Was the L.M. easy to handle?

d) Did the L.M. promote interaction?

Section VI: Pupils Behaviour

a) Did pupils enjoy the lesson?

b) Were pupils involved in group activities?

c) Did pupils show interest in the lesson?

Section VII: Teacher's Behaviour

a) Had the teacher mastered the lesson plan?

b) Did the teacher feel relaxed with pupils?

C) Did the teacher involve pupils?

d) Was teacher good in the use of $\mathrm{bb}$ ?

e) Was teachers voice loud enough?

f) Was teachers voice clear enough?

g) Was teachers level of Pashto appropriate?

h) Was teachers conscious of the use of no cost materials?

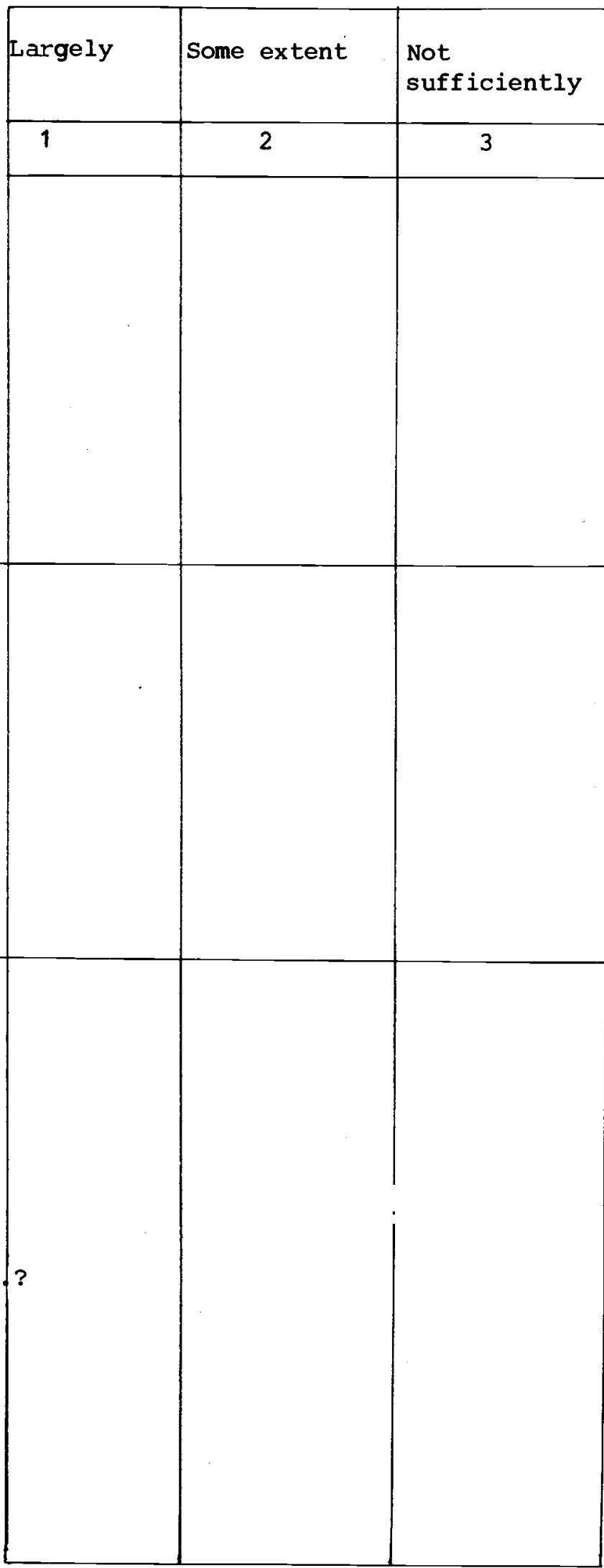


Section VIII:. $\quad$ General Remarks

1. What did you like best in this lesson?

2. What, in your opinion, was worst in this lesson?

3. Any comments: 

A. Lesson Identity: MATHEMATIC 1
B. Topic:
Matching Equal Quantities
C. Classroom Teaching

As intended

As implemented

Discrepancy status

observation

1. Teaching-Learning Process

1.1 Teacher asks pupils to name objects which all of them possess

1.2 Teacher showing 6 pupils and 6 slates ("one pupil and one slate situation")

1.3 Pupils put their caps in front of them and conclude that there are as many caps as pupils

1.4 Teacher puts 5 big pebbles opposite to 5 small pebbles

1.5 Pupils work with pebbles and form pairs of one big and one small pebble

1.6 Teacher checks pupils' work who have been asked to draw on their slates two rows of pebbles

2. Instructional Objectives

2.1 Matching two groups of objects without counting

2.2 Recognising two groups of objects with equal quantities

2.3 Using the term "EQUAL"/"AS MANY" 
A. Lesson Identity: MATHEMATIC 2

B. Topic: Matching Two unequal quantities (More than, less than)

C. Classroom Teaching

As intended

As implemented

Discrepancy

Observation

1. Teaching-Learning Process

1.1 Teacher asks pupils to look at their hands and tell him what they find out

1.2 Teacher asks pupils to compare the $f$ ingers of one hand with those of the other

1.3 Pupils busy comparing toes also

1.4 Teacher draws circles on the chalkboard and calls as many pupils to the board as there are circles drawn

1.5 Pupils draw pairs

1.6 Pupils use terms "more than" "less than."

\section{Instructional Objectives}

2.1 Forming pairs of objects in order to compare quantities

2.2 Stating - after comparison which are more and which are less

2.3 Applying the terms "more than" and "less than"

2.4 Understanding symbols representing $a$. kite, a child or others used during

the lesson status 


\section{SECTION 4}

OBSERVATION SCHEME

A. Lesson Identity:

THEMATIC 3

B. Topic:

Matching of Equal and Unequal Quantities

C. Classroom Teaching

As intended

As implemented

Discrepancy

Observation

\section{Teaching-Learning Process}

1.1 Teacher recalls exercise for "more than" "less than"

1.2 Teacher shows objects such as pebbles, beads etc.

1.3 Pupils state groups which have more or less members (discrimination)

1.4 Teacher shows pictures having groups of objects

1.5 Pupils form pairs and compare which ones have equal or unequal members

1.6 Teacher draws two rows of objects on the chalkboard

\section{Instructional Objectives}

2.1 Naming all objects used in the lesson

2.2 Finding equal/unequal quantities

2.3 Arranging one-to-one relation with the symbols of various objects

2.4 Using terms "is equal to", "the same quantity", "more than", "less than" in the correct way 
A. Lesson Identity: PASHTO I

B. Topic: Simple enquiries about self and environment.

As intended

Simple enquiries about self and environment.

1. Teaching-Learning Process

1.1 Asking 2-3 questions to an individual child about self, parents, brothers etc.

1.2 Asking questions by teacher at a leisured pace. (He is not to hurry)

1.3 Pupils to answer the questions in a loud, clear voice.

1.4 Teacher to encourage the child who has answered a question.

1.5 Pupils to exhibit self-confidence while answering a question.

1.6 Teacher to expand some of the answers as given by students.

2. Instructional objectives

2.1 To enable teacher \& pupils to interact.

2.2 To encourage socialization on the part of pupils.

2.3 To encourage pupils to open up and feel at home.

2.4 To have a feel of the state of language development of pupils.

As implemented 


\section{A- Lesson Identity: PASHTO II B. Topic: A Story Depicted by Illustrations}

C. Classroom Teaching

\section{As intended}

1. Teaching-Learning Process

1.1 Hanging the illustration for children to see from close quarters.

1.2 Teacher to make pupils talk about what they see.

1.3 Pupils talking about his/her observation.

1.4 Teacher to make pupils guess as to what coulá possibly happen.

1.5 Pupils to indulge in fantasy.

1.6 Teacher to narrate the full story.

\section{Instructional objectives}

2.1 To consolidate structures, concepts and vocabulary.

2.2 To provide chance to $c$. to participate at a very initial level.

2.3 To provide a chance to $c$. to indulge in fantasy.

2.4 To provide a chance to $C$. to establish linkages between pictoral elements and words.

As implemented 
A. Lesson Identity: PASHTO III

B. Topic:

Talking about concrete and semi-concrete objects

C. Classroom Teaching

As intended

As implemented

Di screpancy status

\section{Teaching-Learning Process}

1.1 Teacher to establish equation with pupils by reminding them of what was done in the lesson on the previous day.

1.2 Teacher to make pupils talk about the common concrete objects found inside a class.

1.3 Pupils to respond to the questions being posed by teacher.

1.4 Teacher to make punils talk about the semi-concrete objects.

1.5 Pupils to link the semi-concrete with its concrete.

1.6 Teacher to promote pupils talk.

\section{Instructional Objectives}

2.1 To name the common concrete objects.

2.2 To establish linkages between the semi-concrete and its concrete object.

2.3 To observe the details of the concrete or the semi-concrete and to talk about such details.

.


5.5 Monitoring Programme 
MONITORING PROGRAMME

(1st visits)

23-4-86

(Wednesday)

24-4-86

(Thursday)

26-4-86

(saturday)

27-4-86

(sunday)

$28-4-86$
GPS Jalozai

GPS Dagbaisood (Girls

ARPS Jalozai (Boys)

ARPS Dagbaisood (Boys)

GPS Adizai (Boys)

ARPS Matani (Boys)

ARPS Monda Camp (Boys)

GPS Sadargari (Boys)

GPS Badizay (Boys)

ARPS Kacha Ghari (Girls) Ms. Bhatti/Dr.Bude

GPS Hajizai village(Boys) ARPS Hajizai Camp (Girls)

ARPS Barakai (Boys) No.1 ARPS Barakai (Boys) No.3

GPS Moghul Kot (Boys) GPS Haji Sher Ali Khan Koroona (Boys)

GPS Sikanderi (Girls)

ARPS Barakai (Girls)

ARPS Kotki Camp (Girls)

GPS Kotki Payan (Boys)

GPS Jangel Khel (Girls)

ARPS Gamkol Sharif (Boys) Sajid Manzar/Dr.Bude GPS Babri Banda (Boys)

ARPS Ghulam Banda

Habib-ur-Rahman/
Ms. Bhatti/Dr. Bude

Said Ahmad Mohmand/Sajid Manzar

Arif Nasim

Habib-ur-Rahman/

Arif Nasim

Said Ahmad Mohmand/Sajid Manzar

Habib-ur-Rahman/Arif Nasim

Ms. Bhatti/Dr. Bude

Said Ahmad Mohmand/Sajid Manzar

Said Ahmad Mohmand/Sajid Manzar

Ms. Bhatti

Ms. Bhatti/Said Ahmad Mohmand

$$
\text { Habib-ur-Rahman/Arif Nasim }
$$




\section{MONITORING PROGRAMME}

(2nd visits)

\begin{tabular}{|c|c|c|c|c|c|}
\hline $\begin{array}{l}5-5-86 \\
(\text { Monday) }\end{array}$ & $\begin{array}{l}\text { GPS } \\
\text { GPS }\end{array}$ & $\begin{array}{l}\text { H.S.A.K.K. (B } \\
\text { Moghul Kot (B }\end{array}$ & $\begin{array}{l}\text { Boys) } \\
\text { Boys) }\end{array}$ & Manzar/Said Ahmad Mol & mand \\
\hline & $\begin{array}{l}\text { GPS } \\
\text { ARPS } \\
\text { ARPS } \\
\text { ARPS }\end{array}$ & $\begin{array}{c}\text { Sikandari }(G i \\
\text { Barakai No. } 1 \\
\text { Barakai No. } 3 \\
\text { Barakai No. } 4\end{array}$ & $\begin{array}{l}\text { (rls) } \\
(\text { Boys) } \\
(\text { Girls) } \\
\text { (Boys) }\end{array}$ & $\begin{array}{l}\text { Ms. Bhatti } \\
\text { Habib-ur-Rahman/Arif } \\
\text { Ms.Bhatti } \\
\text { Habib-ur-Rahman/Arif }\end{array}$ & $\begin{array}{l}\text { Nasim } \\
\text { Nasim }\end{array}$ \\
\hline $\begin{array}{l}6-5-86 \\
\text { ( Tuesday) }\end{array}$ & $\begin{array}{l}\text { ARPS } \\
\text { GPS } \\
\text { GPS } \\
\text { ARPS } \\
\text { GPS }\end{array}$ & $\begin{array}{l}\text { Kacha Ghari } \\
\text { Badizay } \\
\text { Hajizay } \\
\text { Hajizay } \\
\text { Sadargari }\end{array}$ & $\begin{array}{l}\text { (Girls) } \\
\text { (Boys) } \\
\text { (Boys) } \\
\text { (Girls) } \\
\text { (Boys) }\end{array}$ & $\begin{array}{l}\text { Ms.Bhatti } \\
\text { Habib-ur-Rahman/Arif } \\
\text { Said Ahmad Mohmand } \\
\text { Ms.Bhatti } \\
\text { Manzar Sajid }\end{array}$ & Nasim \\
\hline $\begin{array}{l}7-5-86 \\
(\text { wednesday })\end{array}$ & $\begin{array}{l}\text { ARPS } \\
\text { ARPS } \\
\text { GPS } \\
\text { GPS } \\
\text { ARPS } \\
\text { ARPS }\end{array}$ & $\begin{array}{l}\text { Ghamkol Shar } \\
\text { Ghulam Banda } \\
\text { Babri Banda } \\
\text { Jangal Khel } \\
\text { Kotki } \\
\text { Kotki }\end{array}$ & $\begin{array}{l}\text { if } \\
\text { (Boys) } \\
\text { (Girls) } \\
\text { (Girls) } \\
\text { (Boys) }\end{array}$ & $\begin{array}{l}\text { Manzar Sajid } \\
\text { Said Ahmad Mohmand } \\
\text { Said Ahmad Mohmand } \\
\text { Ms.Bhatti } \\
\text { Habib-ur-Rahman/Arif } \\
\text { Dr.Bude }\end{array}$ & Nasim/. \\
\hline $\begin{array}{l}8-5-86 \\
(\text { Thursday) }\end{array}$ & $\begin{array}{l}\text { GPS } \\
\text { GPS } \\
\text { ARPS } \\
\text { ARPS }\end{array}$ & $\begin{array}{l}\text { Jalozai } \\
\text { Dag Baisood } \\
\text { Jalozai } \\
\text { Dag Baisood }\end{array}$ & $\begin{array}{l}(\text { Girls) } \\
(\text { Girls) } \\
\text { (Boys) } \\
\text { (Boys) }\end{array}$ & $\begin{array}{l}\text { Ms. Bhatti/ } \\
\text { Habib-ur-Rahman } \\
\text { Said Ahmad Mohmand }\end{array}$ & \\
\hline $\begin{array}{l}0-5-86 \\
\text { saturday) }\end{array}$ & $\begin{array}{l}\text { ARPS } \\
\text { ARPS } \\
\text { GPS }\end{array}$ & $\begin{array}{l}\text { Monda } \\
\text { Matani } \\
\text { Adizay }\end{array}$ & $\begin{array}{l}\text { (Boys) } \\
\text { (Boys) } \\
\text { (Boys) }\end{array}$ & $\begin{array}{l}\text { Manzar Sajid//Dr. Bude } \\
\text { Said Ahmad Mohmand } \\
\text { Habib-ur-Rahman/Arif }\end{array}$ & Nasim \\
\hline
\end{tabular}


MONITORING PROGRAMME

( $3 r d v i s i t s)$

\begin{tabular}{|c|c|c|c|c|}
\hline $\begin{array}{l}18-5-86 \\
\text { ( Sunday) }\end{array}$ & $\begin{array}{l}\text { ARPS } \\
\text { GPS }\end{array}$ & $\begin{array}{l}\text { Hajizay Camp } \\
\text { Hajizay }\end{array}$ & $\begin{array}{l}\text { (Girls) } \\
\text { (Boys) }\end{array}$ & $\begin{array}{l}\text { Ms. Bhatti/Dr. Bude } \\
\text { Habib-ur-Rahman/Said Ahmad } \\
\text { Mohmand }\end{array}$ \\
\hline $\begin{array}{l}19-5-86 \\
(\text { Monday) }\end{array}$ & $\begin{array}{l}\text { GPS } \\
\text { GPS } \\
\text { GPS }\end{array}$ & $\begin{array}{l}\text { H.S.A.K.K. } \\
\text { Mughul Kot } \\
\text { Sikandari }\end{array}$ & $\begin{array}{l}\text { (Boys) } \\
(\text { Boys) } \\
(\text { Girls) }\end{array}$ & $\begin{array}{l}\text { Said Ahmad Mohmand } \\
\text { Habib-ur-Rahman/Manzar Sajid } \\
\text { Ms. Bhatti }\end{array}$ \\
\hline $\begin{array}{l}20-5-86 \\
(\text { Tuesday ) }\end{array}$ & $\begin{array}{l}\text { ARPS } \\
\text { ARPS } \\
\text { ARPS }\end{array}$ & $\begin{array}{ll}\text { Barakai } & \text { No.1 } \\
\text { Barakai } & \text { No.3 } \\
\text { Barakai } & \text { No.4 }\end{array}$ & $\begin{array}{l}\text { (Boys) } \\
(\text { Girls) } \\
(\text { Boys) }\end{array}$ & $\begin{array}{l}\text { Habib-ur-Rahman } \\
\text { Ms. Bhatti } \\
\text { Said Ahmad Mohmand/Dr.Bude }\end{array}$ \\
\hline $\begin{array}{l}21-5-86 \\
(\text { wednesday })\end{array}$ & $\begin{array}{l}\text { ARPS } \\
\text { ARPS } \\
\text { GPS }\end{array}$ & $\begin{array}{l}\text { Kacha Ghari } \\
\text { Monda } \\
\text { Sadargari }\end{array}$ & $\begin{array}{l}(\text { Girls) } \\
(\text { Boys) } \\
(\text { Boys) }\end{array}$ & $\begin{array}{l}\text { Ms. Bhatti } \\
\text { Manzar Sajid } \\
\text { Habib-ur-Rahman/Arif Nasim }\end{array}$ \\
\hline $\begin{array}{l}22-5-86 \\
(\text { Thursday })\end{array}$ & $\begin{array}{l}\text { GPS } \\
\text { ARPS } \\
\text { GPS }\end{array}$ & $\begin{array}{l}\text { Jalozai } \\
\text { Jalozai } \\
\text { Badizay }\end{array}$ & $\begin{array}{l}\text { (Girls) } \\
(\text { Boys) } \\
\text { (Boys) }\end{array}$ & $\begin{array}{l}\text { Ms. Bhatti } \\
\text { Habib-ur-Rahman/Manzar Sajid } \\
\text { Said Ahmad Mohmand/Dr. Bude }\end{array}$ \\
\hline $\begin{array}{l}24-5-86 \\
(\text { saturday })\end{array}$ & $\begin{array}{l}\text { GPS } \\
\text { ARPS }\end{array}$ & $\begin{array}{l}\text { Dag Baisood } \\
\text { Dag Baisood }\end{array}$ & $\begin{array}{l}\text { (Girls) } \\
\text { (Boys) }\end{array}$ & $\begin{array}{l}\text { Ms. Bhatti } \\
\text { Habib-ur-Rahman/Said Ahmad } \\
\text { Mohmand }\end{array}$ \\
\hline $\begin{array}{l}25-5-86 \\
(\text { Sunday })\end{array}$ & $\begin{array}{l}\text { ARPS } \\
\text { ARPS }\end{array}$ & $\begin{array}{l}\text { Kotki } \\
\text { Ghamkol sharif }\end{array}$ & $\begin{array}{l}(\text { Girls) } \\
(\text { Boys) }\end{array}$ & $\begin{array}{l}\text { Ms.Bhatti } \\
\text { Habib-ur-Rahman/Manzar sajid }\end{array}$ \\
\hline $\begin{array}{l}26-5-86 \\
(\text { Monday) }\end{array}$ & $\begin{array}{l}\text { GPS } \\
\text { ARPS } \\
\text { GPS }\end{array}$ & $\begin{array}{l}\text { Jangel Khel } \\
\text { Ghulam Banda } \\
\text { Babri Banda }\end{array}$ & $\begin{array}{l}\text { (Girls) } \\
\text { (Boys) } \\
\text { (Boys) }\end{array}$ & $\begin{array}{l}\text { Habib-ur-Rahman/Arif Nasim } \\
\text { Said Ahmad Mohmand } \\
\text { Manzar Sajid }\end{array}$ \\
\hline $\begin{array}{l}27-5-86 \\
\text { (Tuesday) }\end{array}$ & $\begin{array}{l}\text { GPS } \\
\text { ARPS }\end{array}$ & $\begin{array}{l}\text { Adizay } \\
\text { Matani }\end{array}$ & $\begin{array}{l}\text { (Boys) } \\
\text { (Boys) }\end{array}$ & $\begin{array}{l}\text { Manzar Sajid } \\
\text { Habib-ur-Rahman/Arif Nasim }\end{array}$ \\
\hline
\end{tabular}

